\title{
Different Strokes for Different Folks: Experimental Evidence on the Effectiveness of Input and Output Incentive Contracts for Health Care Providers with Different Levels of Skills
}

\section{Manoj Mohanan, Grant Miller, Katherine Donato, Yulya Truskinovsky, and Marcos Vera-Hernández}

\begin{abstract}
A central issue in designing performance incentive contracts is whether to reward the production of outputs versus use of inputs: the former rewards efficiency and innovation in production, while the latter imposes less risk on agents. Agents with varying levels of skill may perform better under different contractual bases as well-more skilled workers may be better able to innovate, for example. We study these issues empirically through an experiment enabling us to observe and verify outputs (health outcomes) and inputs (guideline adherence) in Indian maternity care. We find that both output and input incentive contracts achieved comparable reductions in post-partum hemorrhage $(\mathrm{PPH})$ rates, the dimension of maternity care most sensitive to provider behavior and the largest cause of maternal mortality. Interestingly, and in line with the theory, providers with advanced qualifications performed better and used new health delivery strategies under output incentives, while providers with and without advanced qualifications performed equally under input incentives.
\end{abstract}

JEL Codes: D86, J41, O15

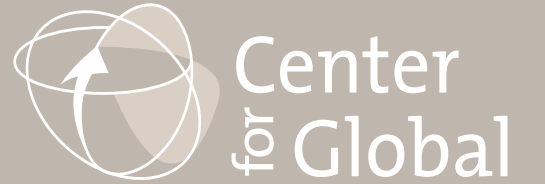

$$
\begin{array}{ll}
\text { Center } & \text { Working Paper } 464 \\
\text { Development } & \text { October } 2017
\end{array}
$$




\title{
Different Strokes for Different Folks: Experimental Evidence on the Effectiveness of Input and Output Incentive Contracts for Health Care Providers with Different Levels of Skills
}

\author{
Manoj Mohanan \\ Duke University \\ Grant Miller \\ Stanford University \& NBER \\ Katherine Donato \\ Harvard University \\ Yulya Truskinovsky \\ Harvard T.H.Chan School of Public Health \\ Marcos Vera-Hernández \\ University College London \& IFS
}

Mohanan is the lead author. Donato, Miller, Truskinovsky, and VeraHernandez contributed equally to the manuscript. This research was made possible by funding and support from 3ie and DFID-India (Grant number OW2: 205 co-PIs: Mohanan and Miller), World Bank HRITF (Grant number TF099435: PI Mohanan) and Government of Karnataka. We are grateful, for comments and suggestions, to Alessandra Voena, Alessandro Tarozzi, Amar Hamoudi, Duncan Thomas, Erica Field, Jerry La Forgia, Jishnu Das, Imran Rasul, Meredith Rosenthal, Michael Callen, Nava Ashraf, Neeraj Sood, Oriana Bandiera, Paul Gertler, Rohini Pande, Rob Garlick, Victoria Baranov, Xiao Yu Wang, and to audiences at AEA/ASSA 2017, ASHEcon 2016, Barcelona GSE 2016, BREAD/CEPR 2016, Duke, Erasmus, Harvard, iHEA Congress Milan, Tilburg University, University of Heidelberg, and University of Southern California. Manveen Kohli provided excellent project management. We are thankful to Kultar Singh, Swapnil Shekhar, and Anil Lobo from Sambodhi, as well as the field team for project implementation and data collection. We gratefully acknowledge the support we received from World Bank (Paolo Belli, Patrick Mullen, and Vikram Rajan) and the Government of Karnataka (Vandita Sharma, Selva Kumar, Suresh Mohammed, Raghavendra Jannu, Atul Tiwari, Dr. Nagaraj, Dr. Sridhar, Dr. Prakash Kumar, Dr. Amruteshwari, and several others). We are especially grateful to the many doctors and clinical experts who provided valuable guidance and feedback, including Matthews Mathai, Dinesh Agarwal, Ayaba Worjolah, Vinod Paul, Sharad Iyengar, Kirti Iyengar, Amarjit Singh, Suneeta Mittal, Lalit Baveja, and Sunesh Kumar. 
The Center for Global Development is grateful for contributions from the Bill \& Melinda Gates Foundation in support of this work.

Manoj Mohanan, Grant Miller, Katherine Donato, Yulya Truskinovsky, and Marcos VeraHernández. 2017. "Different Strokes for Different Folks: Experimental Evidence on the Effectiveness of Input and Output Incentive Contracts for Health Care Providers with Different Levels of Skills.” CGD Working Paper 464. Washington, DC: Center for Global Development. https://www.cgdev.org/publication/different-strokes-different-folksexperimental-evidence-effectiveness-input-and-output

Center for Global Development 2055 L Street NW Washington, DC 20036

202.416.4000

(f) 202.416 .4050

www.cgdev.org
The Center for Global Development is an independent, nonprofit policy research organization dedicated to reducing global poverty and inequality and to making globalization work for the poor. Use and dissemination of this Working Paper is encouraged; however, reproduced copies may not be used for commercial purposes. Further usage is permitted under the terms of the Creative Commons License.

The views expressed in CGD Working Papers are those of the authors and should not be attributed to the board of directors, funders of the Center for Global Development, or the authors' respective organizations. 


\section{Contents}

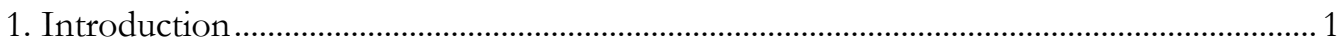

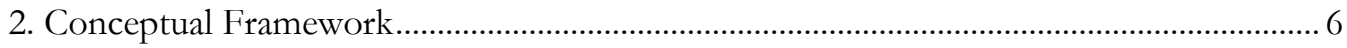

3. Study Design, Incentive Contract Structure, Data Collection, and Estimation.................. 9

3.1 Design and Implementation of the Experiment ...................................................... 9

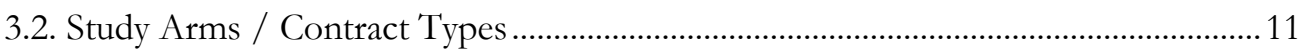

3.3. Data Collection, Household Sampling, and Measurement........................................... 15

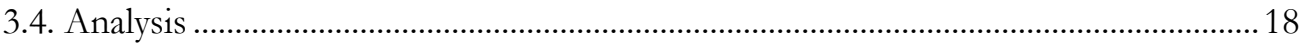

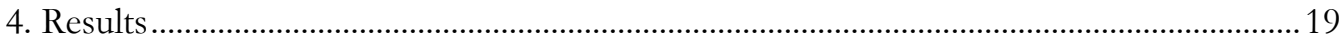

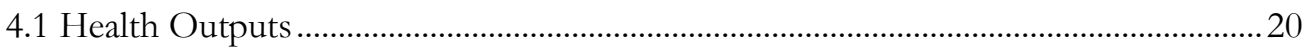

4.2 Health Input Use and Underlying Mechanisms ....................................................2.

4.3 Relative Costs of Input and Output Contracts ………………………………...........2 23

4.4 The Role of Skills in in Provider Responses to Output and Input Incentive

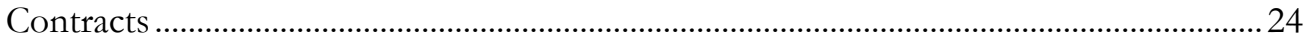

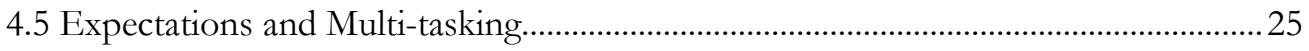

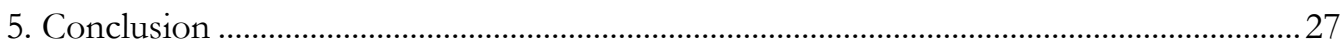

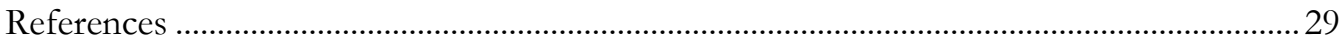

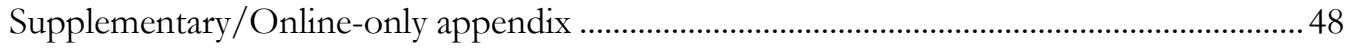

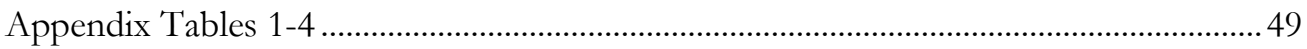

Appendix 1: Contracts .................................................................................................. 53

Appendix 2: Calculation and Measurement of Inputs and Outputs .................................77 


\section{INTRODUCTION}

Performance incentives have long been used to correct a range of principal-agent problems (Hall and Liebman 1998, Jensen and Murphy 1990, Lazear 2000, Roland 2004, Rosenthal et al. 2004). A central issue in the design of performance incentives is whether to reward an agent's use of inputs or instead to reward outputs directly (Khalil and Lawarree 1995, Prendergast 2002, 2011, Raith 2008). ${ }^{1}$ A key underlying assumption in models of output incentive contracts is that workers know the production function, and if correctly incentivized, can find the optimal combination of inputs to produce a given level of output. However, if workers have low levels of human capital or skills, this assumption might be untenable, leading to suboptimal input choices. Alternatively, agents' knowledge of the production function is less relevant for them to be rewarded according to input use (following explicit guidelines given by better-informed principals). But an important drawback of input incentive contracts is that highly skilled agents are unable to take advantage of local contextual information that might be relevant when choosing optimal input combinations to achieve desired outputs.

In this paper, we study input- and output incentive contracts for maternal health care in India - and the ways in which health providers with varying levels of skill respond to them through a field experiment. The production of good maternal and neonatal health is complex, and in India, there is considerable scope for improvement in performance and substantial variation in health providers' human capital. We randomly assign maternal health care providers to two treatment arms and a control arm. Providers in treatment arms were given incentive contracts rewarding performance either for input use (adherence to guidelines for best practices)

\footnotetext{
${ }^{1}$ The decision depends on a variety of considerations, including the costs of monitoring inputs relative to outputs; the degree of risk aversion of agents relative to principals; the riskiness of the output measure; the degree to which productivity is heterogeneous across agents; the extent of distortions due to multi-tasking; and the feasibility of principals dictating inputs to agents (Lazear 1986, Baker 2002, Prendergast 2002)
} 
or production of outputs (good maternal and neonatal health - low levels of post-partum hemorrhage, sepsis, pre-eclampsia, or neonatal death). We also study how responses to performance contracts vary by levels of skills by comparing performance of providers with advanced medical training to those with basic medical training. We focus on providers' implementation of new strategies in the two contracts and how the effect of these innovations varies by providers' skill level.

We conducted our study in rural areas of Karnataka, an Indian state with poor levels of maternal and neonatal health. In 2013, Karnataka's maternal mortality rate (MMR) was 144 deaths per 100,000 live births, and its neonatal and infant mortality rates were 25 and 31 per 1,000 live births, respectively (Mony et al. 2015, NHM 2013). The top three causes of maternal mortality are post-partum hemorrhage, pre-eclampsia, and sepsis, and the major risk factors for neonatal mortality are infections (sepsis and tetanus, for example), pre-term births, and birth asphyxia. Policy efforts to improve maternal and neonatal health outcomes have long focused on promoting childbirth in medical facilities (rather than in private homes), where many of these causes can - in principle - be prevented or managed. However, despite rapidly rising institutional delivery rates (reaching $94.3 \%$ in 2015-16) (Government of India 2016), poor maternal and neonatal health outcomes persist because of low quality maternal health care in medical facilities (NRHM 2015).

The quality of public services such as health and education in developing countries is generally low (Chaudhury et al. 2006, Das and Hammer 2014, Das et al. 2012, Das et al. 2016, Mohanan et al. 2015), and the use of performance incentives is increasingly widespread (see Finan, Olken, and Pande (2015) and Miller and Babiarz (2014) for reviews). Output incentives are more common in the education sector (Behrman et al. 2015, Glewwe, Ilias and Kremer 2010, 
Lavy 2002, Muralidharan and Sundararaman 2011), while incentives based on service delivery indicators such as institutional deliveries, delivery of prenatal care, vaccinations, and healthcare utilization are typically used in the health sector (Ashraf, Bandiera and Jack 2014, Basinga et al. 2011, Celhay et al. 2015, Dupas and Miguel 2016, Gertler, Giovagnoli and Martinez 2014, Gertler and Vermeersch 2013, Miller and Babiarz 2014, Miller et al. 2012, Olken, Onishi and Wong 2014, Sherry, Bauhoff and Mohanan 2017, Soeters et al. 2011). ${ }^{2,3}$ The predominance of input incentive contracts in the health sector - an environment in which there is often considerable scope for innovation using local/contextual information ${ }^{4}$ - underscores the importance of empirical research comparing contractual bases in health.

On average, we find that providers in both the input and output contract arms achieved similar improvements in maternal health, reducing rates of post-partum hemorrhage ( $\mathrm{PPH}$ - the leading cause of maternal mortality both in India and globally) by approximately 21 percent. Performance on other dimensions of maternal and neonatal care (pre-eclampsia, sepsis, and neonatal survival) did not change in either contract group relative to the control group. In achieving PPH reductions, providers in both groups used similar strategies (and similar input combinations), focusing on stocking medicines that reduce bleeding after delivery, for example. Despite the flexibility to do so, we also find little evidence that output contract providers

\footnotetext{
${ }^{2}$ There have been few efforts to directly reward health outcomes in developing countries. Two recent exceptions in China and India study interventions outside the medical care system, focusing on childhood malnutrition. Primary school principals in China, who were offered performance incentives for reducing anemia, were able to reduce anemia prevalence by $25 \%$ by the end of the academic year (Luo et al. 2015, Miller et al. 2012). In India, Singh (2015) found that frontline workers in India's Integrated Child Development Services (ICDS) program who were offered high levels of incentives were able to reduce severe malnutrition by 6.3 percentage points. The Plan Nacer program in Argentina introduced performance incentives based on 10 indicators, of which two were outcomes (birth weight and APGAR scores) and the remaining 8 were self reported / administrative service delivery indicators (Gertler, Giovagnoli and Martinez 2014).

${ }^{3}$ Fritsche, Soeters, and Meessen (2014) report that the World Bank's health results trust fund, which supports performance based financing programs in health, had over 60 projects at various stages of development. Other examples of performance incentives in developing countries include: (Basinga et al. 2011, Peabody et al. 2011, Soeters et al. 2011, Van de Poel et al. 2016)

${ }^{4}$ See http://www.innovationsinhealthcare.org/ for examples of efforts that adopt novel approaches to improving access to care and improving quality of health care.
} 
developed or implemented novel strategies on average to improve outcomes. Moreover, despite equivalent PPH reductions in both contract groups, input contract payments were substantially smaller than output ones: average payments for input and output contracts were INR 13,850 and 56,812 respectively (about US \$252 and \$1033 in 2010). ${ }^{5}$

Health providers with varying levels of skills responded very differently to input- and output incentive contracts, however. High skill providers with advanced medical training in obstetrics and gynecology in output contracts stated that they had implemented new health delivery strategies and produced better health outcomes, reducing PPH rates by 9 percentage points relative to lower skilled providers who have basic medical training but no advanced qualifications. In contrast, there were no significant differences in implementation of new strategies or health outcomes between high and low skilled providers in the input contracts group.

We also investigate two potential concerns with our study. First, because we reward providers according to contracted outcomes among their patients, providers could potentially manipulate the composition of their patients rather than improving their performance (selecting patients more likely to experience good health outcomes, for example). To address this concern, incentive contracts were explicitly structured to be nullified if providers diverted risky patients, and we collected population surveillance data to test for patient selection; we do not find evidence of providers in treatment arms referring high risk patients away to other hospitals.

Second, a natural concern with performance incentives is the possibility of "multitasking," or the diversion of effort from unrewarded outcomes to rewarded ones (Holmstrom and Milgrom 1991,

\footnotetext{
5 Our incentive contracts were not specifically designed to achieve identical levels of outcomes, since the underlying production function was unknown. The identical levels of performance in the two treatment arms is only a convenient accident that now enables us to directly compare the cost to the principal of these two types of contracts. However, since we do not observe providers' responses across a full range of rates for rewards, we are unable to draw inferences about efficiency of the two contract structures.
} 
Mullen, Frank and Rosenthal 2010, Prendergast 1999). To minimize the possibility of multitasking, our incentive contracts covered all major inputs and outputs involved in maternity care including neonatal health, and maternity care was deliberately chosen as a relatively narrow area of medical practice. ${ }^{6}$

Our paper makes two contributions to existing literature. First, because we purposefully designed our study to observe and verify both input use (beyond what is ordinarily possible in real-world settings) and outputs, we are able to test the effectiveness of input and output incentive contracts. ${ }^{7}$ While there is a wide theoretical literature on this topic (Hall and Liebman 1998, Holmstrom and Milgrom 1991, Jensen and Murphy 1990, Khalil and Lawarree 1995, Laffont and Martimort 2009, Lazear 2000, Prendergast 1999, 2002, 2011), the empirical literature that explores the relative effectiveness of contracting on inputs vs. outputs remains thin. To the best of our knowledge, this paper is the first to empirically compare the performance of agents under input and output contracts in a health care setting. Second, we study the important role of provider training and skill in differential behavioral responses to each type of contract. By focusing on how agents' performance varies by level of human capital, we extend the growing literatures on the impact of performance incentives and optimal contracts (Callen et al. 2015).

The rest of the paper proceeds as follows: Section 2 provides a simple conceptual framework of input and output contracts, followed by details of the study design, data collection,

\footnotetext{
${ }^{6}$ The restricted scope of pregnancy and maternity care was also a rationale for selecting obstetric providers for our study. Although obstetric care providers typically refer neonatal care to pediatricians, many of the providers in our sample are the only healthcare providers in their area. Hence we include neonatal health outcomes in the contracts to minimize concerns of multitasking.

${ }^{7}$ We collect detailed information on inputs, using 48 indicators for five key domains of medical care delivered to mothers and their infants throughout pregnancy, delivery, and post-natal care.
} 
and analysis in Section 3. Section 4 presents results, including mechanisms that might explain our findings, and Section 5 concludes.

\section{CONCEPTUAL FRAMEWORK}

In this section we outline a basic principal-agent framework to elucidate the trade-offs between input and output contracts and the role played by agent skill. In our set-up, a principal (health authority) hires an agent (health care provider) to maximize health, $y$, net of monetary costs paid to the agent, $w$. A health care provider produces health according to: $y=$ $h\left(\theta_{1} e_{1}, \theta_{2} e_{2}, \varepsilon\right)$, where $e_{1}$ and $e_{2}$ are inputs chosen by the provider; $\theta_{1}$ and $\theta_{2}$ are productivity shifters that vary across providers; and $\varepsilon$ is a random component with cumulative distribution function $G_{\varepsilon}$, which is strictly positive for all values of $\varepsilon$. The health production function $h(\cdot)$ is increasing in all of its arguments and strictly concave. The provider's objective is to maximize utility from payments, $U(w)$, net of input costs, $v_{1}\left(e_{1}\right)+v_{2}\left(e_{2}\right)$, where $U^{\prime}(\cdot)>0, U^{\prime \prime}(\cdot)<$ $0, v_{1}^{\prime}(\cdot)>0, v_{2}^{\prime}(\cdot)>0, v_{1}^{\prime \prime}(\cdot)>0, v_{2}^{\prime \prime}(\cdot)>0$

We assume that there are two type of providers, $H$ and $L$, with high and low levels of medical training (qualifications) corresponding to high and low levels of (clinical) skills. The proportion of low skill providers among all providers is $\pi$. Low skilled providers believe that the health production function is $y_{i}=h\left(\theta_{1}^{L} e_{1}, \theta_{2}^{L} e_{2}, \varepsilon\right)$, with $\theta_{1}^{L} \neq \theta_{1}$ and $\theta_{2}^{L} \neq \theta_{2}$. In other words, low skill providers have incorrect beliefs about the productivity shifters. Alternatively, high skill providers hold correct beliefs - that is, $\theta_{1}^{H}=\theta_{1}$ and $\theta_{2}^{H}=\theta_{2}$. We also assume that the distribution of $\varepsilon$ as well as those of $\theta_{1}$ and $\theta_{2}$ are independent of provider skill. ${ }^{8}$

\footnotetext{
${ }^{8}$ By way of example, our set-up assumes that the effect of a certain medicine is the same independently of being prescribed by a high or low skill provider, but the two types of providers might differ in how effective they perceive the medicine to be.
} 
We assume that both input choices $\left(e_{1}, e_{2}\right)$ and output $(y)$ are verifiable. Principals know the distribution of productivity shifters, $F_{\theta_{1}, \theta_{2}}$, but they cannot make contracts with agents contingent on the values of these productivity shifters. In other words, principals cannot take advantage of local/contextual information, reflected in $\theta_{1}$ and $\theta_{2}$, when writing contracts. Unlike the standard setting in which a contract can be made fully contingent on agents' production functions, this restriction implies that input incentive contracts will not necessarily be optimal (even if inputs are verifiable) and output incentive contracts can be more efficient (Khalil and Lawarree 1995, Prendergast 2002, 2011).

An input incentive contract is a function $w\left(e_{1}, e_{2}\right)$ that remunerates providers according to input levels. The principal will choose $w\left(e_{1}, e_{2}\right)$ such that

$$
\begin{gathered}
\operatorname{Max} \iint h\left(\theta_{1} e_{1}, \theta_{2} e_{2}, \varepsilon\right) \partial F_{\theta_{1}, \theta_{2}} \partial G_{\varepsilon}-w\left(e_{1}, e_{2}\right) \\
s t: \operatorname{Max}_{\left\{e_{1}, e_{2}\right\}}\left[U\left(w\left(e_{1}, e_{2}\right)-v_{1}\left(e_{1}\right)-v_{2}\left(e_{2}\right)\right] \geq \bar{U},\right.
\end{gathered}
$$

where $\bar{U}$ is the provider's reservation utility. Implicitly, an input incentive contract is only feasible if the principal can observe input levels $\left(e_{1}, e_{2}\right)$. Note that the provider does not bear any financial risk because payment is only contingent on input levels, which are completely under his/her control. Also, both high and low skill providers will choose the same input levels because both maximize the same function, $U\left(w\left(e_{1}, e_{2}\right)\right)-v_{1}\left(e_{1}\right)-v_{2}\left(e_{2}\right)$, which is independent of health outcomes produced - and hence their beliefs about the health production function. ${ }^{9}$ Consequently, input-based payments allow the principal to circumvent low skill providers' incorrect beliefs about the productivity shifters. Under input incentive contracts, average health outcomes, $y=\iint h\left(\theta_{1} e_{1}, \theta_{2} e_{2}, \varepsilon\right) \partial F_{\theta_{1} \theta_{2}} \partial G_{\varepsilon}$, are therefore also the same for high and low skill providers.

\footnotetext{
${ }^{9}$ This is true because we are assuming that providers are not altruistic. In other words, they will not provide additional, unrewarded inputs that they know to be beneficial if not compensated for doing so.
} 
An output incentive contract is a function $w(y)$ that remunerates providers according to health outcomes produced. In this case, a provider of type $j \in\{H, L\}$ who wants to achieve average health outcome $y$ and believe him/herself to have productivity shifters $\left(\theta_{1}^{j}, \theta_{2}^{j}\right)$ will choose inputs $\left(e_{1}, e_{2}\right)$ to:

$$
\begin{gathered}
\operatorname{Max} \int U\left(w\left(h\left(\theta_{1}^{j} e_{1}, \theta_{2}^{j} e_{2}, \varepsilon\right)\right)\right)-v_{1}\left(e_{1}\right)-v_{2}\left(e_{2}\right) \partial G_{\varepsilon} \\
\text { st: } y=\int h\left(\theta_{1}^{j} e_{1}, \theta_{2}^{j} e_{2}, \varepsilon\right) \partial G_{\varepsilon}
\end{gathered}
$$

implying that provider input choices $\left(e_{1}, e_{2}\right)$ depend on their beliefs about their productivity shifters $\left(\theta_{1}, \theta_{2}\right)$.

The model above assumes that both input choices and outputs are verifiable and allows us to consider trade-offs between input- and output incentive contracts. On one hand, provider remuneration under the output incentive contract, $w(y)$, is partly random and not completely under the control of the agent. This risk introduces a distortion in the output incentive contract, requiring principals to compensate agents for this risk. On the other hand, because principals (health authorities) cannot take advantage of local/contextual information (reflected in $\theta_{1}$ and $\theta_{2}$ ) when establishing contracts, an input incentive contract could lead some providers to choose inefficient combinations of inputs $\left(e_{1}, e_{2}\right)$. Output incentive contracts can circumvent this by allowing providers to choose $\left(e_{1}, e_{2}\right)$ according to their own productivity shifters $\left(\theta_{1}, \theta_{2}\right)$.

In the output contract case, high skill providers, who hold correct beliefs about the productive shifters $\left(\theta_{1}, \theta_{2}\right)$ can make more efficient input choices than with input incentive contracts. The amount of inefficiency for low skill providers in our model depends on how 
incorrect their beliefs about $\theta_{1}^{L}$, and $\theta_{2}^{L}$ are. It therefore remains possible that input incentive contracts deliver more efficient input choices among low skill providers. ${ }^{10}$

A testable implication of our conceptual framework is that health outcomes will depend on provider skills under output incentive contracts (with better health outcomes for more skilled providers), but that health outcomes will be independent of provider skill with input incentive contracts. More generally, we expect higher skilled providers under output contracts to tailor their input choices to their local/contextual information.

\section{Study Design, Incentive Contract Structure, Data Collection, and Estimation}

\subsection{Design and Implementation of the Experiment}

Our experiment and data collection activities spanned two years, from late 2012 to late 2014. ${ }^{11}$ The timeline of the project is shown in Figure 1, with details about when data were collected indicated at the bottom, and timing of the intervention visits indicated at the top.

\section{1.a. Eligibility of providers}

Using multiple data sources, we identified the potential universe of private obstetric care providers for inclusion in our study. The first source was data collected by the Karnataka state government on all private sector doctors who provided obstetric care (i.e., those who cared for pregnant mothers and conducted deliveries) in rural areas - at least $10 \mathrm{~km}$ away from district headquarters. Second, during field visits by our enumerators to verify these providers, our field teams located additional providers who were inadvertently missed in the government survey and conducted interviews with them to confirm eligibility. Further eligibility for providers' inclusion

\footnotetext{
${ }^{10}$ Ultimately, the relative efficiency of input- or output incentive contracts depends on a variety of parameters including the amount of risk, providers' degree of risk aversion, the variability in productivity shifters, the proportion of low skill providers, and how misinformed low skill providers are.

11 This study was approved by Duke University Office of Human Subjects Research (Pro00031046).
} 
in our study was based on conducting at least two deliveries per month, practicing primarily in OBGYN clinics ${ }^{12}$, willingness to participate in the study (including responding to surveys and signing the incentive contracts), and continuing to practice in the same location over the study period.

\section{1.b. Randomization}

The set of providers that we randomize come from the two different sources mentioned above. Of the 120 eligible providers in the data from the state government, using simple randomization, 38 providers were assigned the input group, 40 to the output group, and 42 to the control group. Other eligible providers, who were inadvertently left out in the governmentfunded survey and identified by our field team during fieldwork, were randomized as follows: once the provider was confirmed to meet all eligibility criteria, the field team would call our project office to assign the provider to a study arm. This allocation was done according to a list of sequential unique identifiers, which were randomized prior to fieldwork (this list was unknown to field enumerators). Using this procedure, 2 providers were allocated to the input group, 13 to the output group, and 5 to the control. ${ }^{13}$

In all, 140 providers met all eligibility criteria and signed the incentive contracts in our study (note that the control group also signed a contract). Of these, 5 providers declined to participate over the course of the study, and were classified as attritors from the study (2 from the input incentive group and 3 from the control group). Our final analytical sample thus includes 135 providers: 53 providers in outputs arm, 38 providers in inputs arm, and 44 providers in

\footnotetext{
${ }^{12}$ Providers working in large multi-specialty hospitals were not included in our sample. We targeted smaller facilities in order to ensure that providers would have sufficient agency over their facilities' health provision. ${ }^{13}$ Note that we could not ensure an equal number of providers across arms because we did not know how many providers the field team would find, and we did not want to have a predictable sequence so that our field enumerators could anticipate the treatment allocation of a potential provider.
} 
control arm. ${ }^{14}$ Table 1 shows the number of providers who were identified in sampling and the attrition.

Table 2 reports summary statistics for our final sample of providers used for analysis. Just over half of providers were female. Nearly 60 percent had advanced qualifications in obstetrics or a related field - we refer to this group as "MBBS plus". Of the remaining, over half had either basic training in allopathic medicine, equivalent to an MD in USA or comparable training in Ayurvedic medicine - corresponding to MBBS and BAMS degrees respectively (Mahal and Mohanan 2006). The average provider had been practicing for nearly two decades. Joint tests of orthogonality show there are no significant differences in provider demographics between the three study arms (Appendix Table A1). The attrition of five providers across the three study groups was not statistically different at the 5\% level (Appendix Table A2).

\subsection{Study Arms / Contract Types}

The three contracts (control, input incentive contract, and output incentive contract) were designed to be as comparable as possible other than the basis of payment. Providers were first introduced to the contracts during visits between February and April 2013 (Figure 1 shows our study timeline). During these initial visits, all providers (including those in the control group) were given copies of letters of support from the state government and a full set of reference materials including guidelines for maternity care from the World Health Organization (WHO) and Government of India (GoI). ${ }^{15}$ These letters also provided a broad overview of what participation in the study would entail, including future meetings and payments to compensate participating providers for their time to compile patient lists and complete surveys.

\footnotetext{
${ }^{14}$ Further details on enrollment of providers and sample sizes at each stage are included in the pre-analysis plan (https://www.socialscienceregistry.org/trials/179).

${ }^{15}$ A complete set of guidelines was also provided to the providers on a CD. If a provider was unable to access the materials on the $\mathrm{CD}$, she was offered the option of having the hard copy versions sent to her at no charge.
} 
Each provider was also given a copy of his/her randomly assigned contract. Each treatment group contract explained the specific basis by which the provider would be rewarded at the end of the study period, including details of reward calculations and payments (Appendix 1 shows each type of contract and accompanying WHO guidelines). The contracts specified that the final payment will be made only at the end, and there were no interim incentive payments. Input and output incentive contracts were designed to have equal maximum level of payments. Payment levels were also set to ensure that the project could meet payment obligations in the event that all providers achieved the maximum performance level. The resulting contracts offered providers the potential to earn up to approximately INR 150,000 (about US $\$ 2,700$ at the time of the contract - slightly more than 15 percent of a specialist doctor's salary in Karnataka).

The control arm contract was designed to inform providers about our study of maternal and child health, to provide the same $\mathrm{WHO}$ and GoI guidelines, and to require control providers to sign an 'agreement' confirming their willingness to participate in a study of maternal and neonatal health. The control contract did not mention reward payments made to other providers in the study.

Enumerators were trained to ensure that the providers fully understood their contracts, including incentive payment basis and structure, the potential reward payments possible for strong performance, and the fact that providers would not lose money by participating in the study, regardless of their performance. Contracts also specified that providers' performance on rewarded outcomes would be evaluated using data collected from household surveys with their 
patient population. ${ }^{16}$ Finally, providers in all three arms were offered INR 2,500 (about US \$45) at each visit as compensation for the time required to participate in the study. This small payment also aimed to develop credibility for future reward payments.

\section{2.a. Output Contract Structure}

Output incentive payments were offered for achieving low rates of four adverse health outcomes (post-partum hemorrhage (PPH), pre-eclampsia, sepsis, and neonatal mortality) during the study period among a provider's patients. Ideally, we would have set the reward levels for each health outcome optimally: the rewards that maximize the principal's utility subject to the participation constraint of the provider. However, this requires detailed knowledge of the production, utility, and cost functions, which are unknown to us. Our approach, which we describe below, resembles one of a cautious policy maker, ensuring that total incentive payments do not exceed a fixed budget constraint.

For neonatal mortality, a provider would receive INR 15,000 unless one of their newborn patients died. For each of the other three maternal health outcomes (PPH, Pre-eclampsia, and Sepsis, ), the reward payment for output $i, P\left(x_{i}\right)$, was a decreasing linear function of incidence rate $x_{i}$, with payment increment $\alpha_{i}$ for incidence rates below a pre-established incidence rate ceiling $\overline{x_{l}}$ :

$$
P\left(x_{i}\right)=\left\{\begin{array}{cl}
\alpha_{i}\left(\bar{x}_{i}-x_{i}\right), & x_{i} \leq \bar{x}_{i} \\
0, & x_{i}>\bar{x}_{i}
\end{array}\right.
$$

We set $\bar{x}_{i}$ equal to the pre-intervention average rates, which we estimated using existing data from government surveys. To set levels of $\alpha_{i}$, we first allocated the remaining available budget for output contracts (after deducting payment for neonatal mortality) to each of the 3 outputs

\footnotetext{
${ }^{16}$ To avoid possible collusion or gaming, information about specific survey questions used to calculate rewards was not shared with anyone outside of the study team, including the enumerators when they first met providers to implement the contracts.
} 
equally. $\alpha_{i}$ for each output was then determined by dividing the available budget for that output by the potential improvement for that output (i.e., the difference between the pre-intervention average level of $\bar{x}_{i}$ and 0.05 , which assumes providers would, on average, not be able to eliminate negative health outcomes completely): ${ }^{17}$

$$
\alpha_{i=\text { OUTPUT }}=\frac{(\text { Budget for output contracts }-N M R \text { payment }) / 3}{\left(\overline{x_{i}}-0.05\right)}
$$

The final reward payment for providers in the output group was then the sum of rewards for each of the four outputs.

\section{2.b. Input Contract Structure}

Providers assigned to the input treatment arm were offered incentive payments for health inputs provided to patients according to 2009 World Health Organization (WHO) guidelines. ${ }^{18}$ These inputs are categorized into five domains: pregnancy care, childbirth care, counseling for postnatal maternal care, newborn care, and counseling for postnatal newborn care. ${ }^{19}$ Analogous to the structure of output incentives, for each domain $i$, the input reward payment $P\left(x_{i}\right)$ was structured as an increasing linear function of the input level $x_{i}$ - the share of measurable inputs for appropriate care for domain $i$, averaged over the provider's patients - with incremental payment $\alpha_{i}$ above a pre-established performance floor $\underline{x}_{i} \%$ :

$$
P\left(x_{i}\right)=\left\{\begin{array}{cl}
\alpha_{i}\left(x_{i}-\underline{x}_{i}\right), & x_{i} \geq \underline{x}_{i} \\
0, & x_{i}<\underline{x}_{i}
\end{array}\right.
$$

\footnotetext{
${ }^{17}$ For example, pre-intervention rates of post-partum hemorrhage $(\mathrm{PPH})$ were estimated at 35 percent $\left(\bar{x}_{P P H}=35\right)$ in the study area. Providers could earn $\alpha_{P P H}=$ Rs. 850 (equivalent to about $\$ 17$ at the time of the contract) for every percentage point below 35 percent incidence of $\mathrm{PPH}$ in their patient population. If the rate of PPH measured in their patient population over the study period was 25 percent, they would earn $\$ 170$; if they were able to completely eliminate PPH in their patient population, they would earn $\$ 595$.

18 These were the most up-to-date guidelines at the time of the intervention.

${ }^{19}$ Details of the measurement of these health inputs are below and in Appendix 2: Calculation of Inputs and Outputs.
} 
As in the output contract case, $\alpha_{i}$ for inputs was calculated by dividing the available budget by the projected range of improvements from the pre-intervention average rates to an average of $90 \% .^{20}$ The final reward payment for each provider was the sum of rewards earned for performance in each of the five domains of care.

\section{2.c. Control Arm Contracts}

Providers assigned to the control arm received contract agreements that provided the same information, guidelines, and participation payments as in the two incentive contract arms but had no payments related to performance. Control providers were also told that the project team would collect survey data from their patients and received the same follow-up visits as intervention arm providers.

\subsection{Data Collection, Household Sampling, and Measurement}

We collected data from providers through multiple interviews over the study period and from households at end of study period (Figure 1 shows details of timing of data collection and intervention visits to providers). Through our provider surveys, we collected information about providers' medical practices, staffing, and infrastructure, as well as intended strategies for improving quality of care and health outcomes.

Additionally, we collected patient lists from providers to create our primary patient sampling frame. A natural concern with this approach is that providers would have incentives to selectively report only patients with relatively good performance indicators. To minimize this concern, we also collected data from approximately 75 households (not used in this analysis) in

\footnotetext{
${ }^{20}$ For example, pre-intervention coverage of the inputs in the Childbirth Care domain was estimated at about 65 percent $\left(\underline{x}_{\text {Childbirth Care }}=65\right)$ in the study area: patients receive $65 \%$ of appropriate childbirth care according to WHO guidelines. Providers earn $\alpha_{\text {Childbirth Care }}=$ Rs. 750 (equivalent to about $\$ 15$ at the time of the contract) for every percentage point in coverage of these inputs above 65 percent. If 75 percent of a provider's patients had received appropriate level of inputs for the Childbirth Care domain, she would earn $\$ 150$, and if she were able to provide this level of care for $100 \%$ of her patients, she would earn $\$ 525$.
} 
areas surrounding the clinic to ensure there were no cases with negative outcomes at the providers' facilities but were not reported by providers, or that were inappropriately referred away. The incentive contracts also clearly explained that any instances of patient list manipulation, either through selective referrals or reporting, would nullify the contracts. ${ }^{21}$

Using patient lists, we then sampled up to 25 women who had recently given birth at the provider's facility. ${ }^{22}$ Enumerators collected the list of patients and a study team member managing the field project conducted random sampling of 25 patients. In instances where there were fewer than 25 deliveries over the timespan of data collection, all listed patients were surveyed. These surveys measured the four major health outcomes ${ }^{23}$, input use in the five domains of maternity care, and basic socio-demographic information. We aimed to interview every mother within approximately 2 weeks after she gave birth to minimize recall inaccuracy (Das, Hammer and Sánchez-Paramo 2012). In practice, we conducted surveys with new mothers between 7-20 days after delivery, and also did a very brief follow up with these mothers after 28 days after birth to assess the infant's status. In total, we interviewed 2,895 new mothers. ${ }^{24}$

\footnotetext{
${ }^{21}$ See page 5 of sample contracts in Appendix 1 for exact language on selective referrals that would nullify contracts. Using data collected from communities around the provider, we verified that there were no unusual patterns of referral suggesting providers did not respond by selecting patients with better outcomes or selectively reporting by providers.

${ }^{22}$ Power calculations were conducted prior to the data collection. Estimated pre-intervention performance rates and feasible improvement levels (i.e., target levels) were determined using existing data from government surveys and calibrated through piloting with doctors in Karnataka and Delhi to ensure that they were locally appropriate. We assumed 25 mothers per provider and an intra-class correlation coefficient of 0.05 . At the individual level, all five categories for quality of care have at least 85 percent power to detect improvements that reach the target levels, with the "Childbirth Care", "Postnatal Maternal Care", and "Postnatal Newborn Care" categories having at least 95 percent power. Two of the four outputs, post-partum hemorrhage and pre-eclampsia, have at least 85 percent power to detect improvements to the target levels. Note that these calculations do not take into account additional precision gained by including covariates.

${ }_{23} \mathrm{We}$ collected data from household surveys about signs and symptoms for the health outcomes and used algorithms described in the appendix to establish whether a woman had each adverse health outcome or not.

${ }^{24}$ Some providers conducted fewer than 25 deliveries over the data collection period, resulting in fewer than the targeted 3,375 mothers ( 135 providers x 25 mothers). On average, we have data from 21.4 mothers per provider, with an interquartile range of 17 to 26 mothers per provider.
} 
Measurement of health input use and outputs poses important challenges, especially in developing country contexts where reliable administrative data on input use are not available. Using providers' reports of outcomes leads to concerns of gaming when incentives are tied to performance. Furthermore, providers may not always be able to accurately identify some health outcomes. For example, in the case of maternal health, evidence from studies comparing actual blood loss to providers' visual estimates show that providers tend to underestimate the amount of blood loss by one third (Patel et al. 2006).

Given that we chose to measure health outcomes and health input use through household surveys, we relied on two general criteria for selecting our specific measures (which we use both for calculating incentive payments as well as for our empirical analysis). First, we chose questions previously validated through past research published in the clinical literature (Filippi et al. 2000, Stanton et al. 2013, Stewart and Festin 1995). Second, prior to our study, we conducted our own validation exercise. Specifically, we trained nurse enumerators to observe and code health input use in real-time during labor and delivery for 150 deliveries in rural Karnataka. Within two weeks after delivery, we then visited these new mothers and administered a set of survey questions intended to measure the same health input use, as reported by the mother. We then chose measures that performed well in our validation exercise as additional survey questions for the project. ${ }^{25}$

Mothers in our sample were classified as having an adverse health outcome based on a combination of her responses to relevant questions, following previous studies of the sensitivity and specificity of responses to these questions for clinical evaluation of the incidence of these outcomes (Filippi et al. 2000, Stanton et al. 2013, Stewart and Festin 1995). We evaluate inputs provided by each provider by measuring each provider's adherence to WHO guidelines. Given

${ }^{25}$ Results from this validation study to be published in a separate manuscript, and available upon request. 
the criteria described above, we generated household survey questions that women could plausibly answer and that related to the guidelines. The responses to these questions were assigned a score of 1 if they adhered to the guidelines, and 0 otherwise. ${ }^{26}$ A provider's performance in a particular domain was then the mean of these scores for all mothers who received care from the provider, where higher scores reflect greater adherence to the guidelines and better performance. For analysis of inputs within each domain, we aggregate the multiple measures into a summary index following Anderson (2008). ${ }^{27}$

\subsection{Analysis}

We use the estimation strategy that we specified in our pre-analysis plan published in the AEA RCT registry in December 2013 (prior to collecting any household-level data). To estimate the effect of each type of incentive contract on health outputs and health input use, we regress outcomes on dummy variables indicating treatment status with the following estimating equation:

$$
y_{i p}=\alpha+\beta T_{p}+\theta X_{p}+\gamma Z_{i}+s_{d}+\lambda_{e}+u_{i p}
$$

where $y_{i p}$ is an outcome of interest (i.e. level of care - inputs - received or health outcomes) for woman $i$ who received care from provider $p, T_{p}$ is a vector of provider-level treatment indicators, $X_{p}$ is a vector of baseline (pre-contract) provider characteristics, $Z_{i}$ is a vector of time-invariant household characteristics (such as mother's age, education status, religion, and birth history), and $s_{d}$ and $\lambda_{e}$ represent district and enumerator fixed effects (respectively). We also show estimates

\footnotetext{
${ }^{26}$ For example, if a woman answered affirmatively to the question, "Was your blood pressure checked during labor?", the question was assigned a "1". Details about the specific questions used for each domain and how responses were coded are included in the Appendix on Calculation of Inputs and Outputs, also available at https://www.socialscienceregistry.org/trials/179.

27 The Anderson index is calculated as a weighted mean of the standardized values of all inputs within each domain (with variables re-defined so that higher values imply a better/more desirable outcome). The weights are calculated to maximize the amount of information captured in the index, with highly correlated variables receiving less weight (Anderson 2008).
} 
that do not condition on household or provider characteristics, but only include enumerator and district fixed effects, as specified in our pre-analysis plan. In all cases, we cluster standard errors at the provider level.

Given that we test multiple hypotheses across two treatment arms, we report p-values adjusted for multiple comparisons within each pre-specified family of hypotheses to control for the Familywise Error Rate (using the free step-down re-sampling method described in Westfall and Young (1993)) and across the two types of contracts. Following our pre-analysis plan, we consider PPH, sepsis, and neonatal death as one family of health outcomes influenced by medical care provided around the time of delivery (as opposed to care throughout pregnancy for preeclampsia, which we test across two types of contracts). Similarly, for input use, we consider three domains (childbirth care, postnatal maternal care, and newborn care) to be a family of outcomes because these are all inputs provided at the time of delivery.

As section 2 indicated, we expect health outcomes to vary according to a provider's skills under output incentive contracts, but to be independent of them under an input incentive contract. To test this hypothesis, we augment regression (1) with an indicator for higher provider qualification multiplied by each provider contract arm.

\section{RESULTS}

In this section, we first report how our incentive contracts influenced the production of health outputs and the provision of health inputs, investigate the mechanisms underlying these results, and examine the relative costs of the two types of contracts. We then study how providers with varying levels of qualifications and skills responded differently to each type of contract. 


\section{$\underline{4.1 \text { Health Outputs }}$}

Table 3 reports estimates of how each incentive contract influences maternal and child health outcomes. Our preferred (pre-specified) estimates from Equation 1, shown in evennumbered columns, condition on provider and patient characteristics as well as district and enumerator fixed effects (odd-numbered columns report estimates that condition only on district and enumerator fixed effects). The levels of statistical significance indicated reflect $\mathrm{p}$-values adjusted for multiple comparisons within each family of hypotheses to control for the Familywise Error Rate. Appendix Table A3 shows the unadjusted as well as adjusted p-values for the main results.

In both incentive contract groups, post-partum hemorrhage $(\mathrm{PPH})$ rates declined by nearly identical (and statistically indistinguishable) amounts relative to the control group. ${ }^{28}$ Column 2 shows that input contract providers reduced PPH incidence among their patients by 8.4 percentage points, while output contract providers reduced $\mathrm{PPH}$ incidence by 7.4 percentage points. Compared to the control group mean (0.365), these reductions correspond to a $23 \%$ and $20 \%$ decline, respectively. Both are also statistically significant after correcting for multiple comparisons: adjusted p-values using the Westfall and Young (1993) step-down resampling method are 0.01 for the input group and 0.031 for the output group (p-values with and without multiple comparison corrections are reported in Appendix Table A3).

We do not find statistically significant changes for other health outcomes after adjusting for multiple comparisons. ${ }^{29}$ This pattern of results is reasonable - in rural India, PPH is most amenable to improvement through changes in provider behavior at the time of delivery (with the use of drugs to control post-partum bleeding, for example, for which we find evidence in Section

\footnotetext{
${ }^{28}$ Testing $\beta_{\text {output }}=\beta_{\text {input }}$, we fail to reject the null hypothesis $(\mathrm{p}=0.897)$.

${ }^{29}$ Among the results for pre-eclampsia and sepsis for input and output contracts, only the pre-eclampsia result is marginally significant $(\mathrm{p}=0.07)$ when not adjusting for multiple comparisons.
} 
4.2). Alternatively, among the four domains of health outcome, providers have the least control over pre-eclampsia because it is a hypertensive disorder developed earlier during pregnancy and women generally seek antenatal care from other providers. Furthermore, the biological causes of pre-eclampsia remain scientifically unclear, essentially making it impossible for providers to predict and prevent this condition, but it can be better managed if detected earlier in the pregnancy (Mol et al. 2016, Phipps et al. 2016, Steegers et al. 2010). For sepsis, a key preventive strategy (wearing gloves during delivery) was already practiced among 99\% of control group providers, and prophylactic antibiotics are commonly used at high (and inappropriate) rates in rural India, including Karnataka. ${ }^{30}$

\subsection{Health Input Use and Underlying Mechanisms}

Table 4 then reports estimates from Equation 1 for provision of health inputs. Because we only find significant health improvements for PPH, we do not expect substantial improvements in input use across all five domains of maternal and neonatal care. Column 6 shows that in the output contract group, the postnatal maternity care index (which primarily reflects postnatal health counseling to mothers shortly after delivery) rose by 0.0773 index points relative to the control group; this estimate is statistically significant (unadjusted $p$-value $=0.033$ ), but not at conventional levels after correcting for multiple hypotheses testing $(\mathrm{p}=0.156)$ - see Appendix Table A4 for full adjusted and unadjusted p-values. ${ }^{31}$ There were no improvements in the five composite domains of maternal and neonatal care in the input incentive contract group. (In Section 4.5, we discuss the 0.14 point decline in the postnatal newborn care counseling index shown for the output contract group in Column 10, which we believe reflects a reduction in

\footnotetext{
${ }^{30}$ The other clinical action listed in the guidelines given to providers is handwashing, but provider handwashing behavior is not reliably observed by mothers or accompanying caregivers. Antibiotics are routinely overused in clinical settings in India (Ganguly et al. 2011).

${ }^{31}$ The magnitude of the increase (0.0773) is not directly interpretable because the weights used to compute the index change the scale (Anderson 2008).
} 
effort devoted to newborn care (i.e., 'multi-tasking' (Holmstrom and Milgrom 1991, Prendergast 2011)).

However, other than in postnatal maternity care, we do not observe significant improvements for indices in other domains of care. This is probably because the indices aggregate many inputs, only a subset of which directly influence PPH (those included in Active Management of Third Stage of Labor (AMTSL), for example). ${ }^{32}$ Although not pre-specified, we therefore directly examine changes in two inputs most closely related to PPH: parenteral oxytocic drugs (whose administration is recommended universally for all mothers) and manual removal of placenta (which reflects complications that could potentially be avoided with better care). ${ }^{33}$

The first two columns of Table 5 report estimates for providers' stocking of parenteral oxytocic drugs at their clinics. Consistent with our PPH results in Section 4.1, we find that providers in both output and input contract groups were approximately 7 percentage points more likely to maintain stocks of parenteral oxytocic drugs in their clinics (an increase of 25 percent relative to the control group mean of 0.29). Consistent with this finding, Columns 3 and 4 also show estimates of patients' reported use of medicines to prevent bleeding, which are 6 percentage points higher in both incentive contract groups relative to the control group (estimates

\footnotetext{
32 Active Management of Third Stage of Labor (AMTSL) recommended by WHO guidelines also includes early cord clamping, controlled traction of the umbilical cord, and trans-abdominal manual massage of the uterus (Urner, Zimmermann and Krafft 2014). Abdominal massage was included in the 2009 guidelines from Government of India (MOHFW 2009) and was also recommended by Am. Coll. of Obs. and Gyn. at the time (ACOG 2011). The 2012 revised guidelines from WHO no longer recommend cord traction or abdominal massage as standard practice (Tunçalp, Souza and Gülmezoglu 2013).

${ }^{33}$ Within the WHO guidelines that our input contracts reward, a clinical action closely related to the prevention of $\mathrm{PPH}$ - and recommended universally for all mothers - is the administration of medicines (parenteral oxytocic drugs), which are effective in stopping post-delivery bleeding. Clinical actions not universally recommended - ones that are clinically appropriate conditional on presence of a risk factor or manifestation of an adverse outcome, for example - are more difficult to interpret if the conditions requiring them are preventable.
} 
are statistically indistinguishable from each other with and without conditioning on various control variables, but only statistically different from zero in Column 3). ${ }^{34}$

Additionally, a key corrective clinical action to prevent PPH when the placenta is not delivered normally is manual placenta removal (Urner, Zimmermann and Krafft 2014). ATMSL, which is recommended by WHO guidelines, minimizes the time required for normal delivery of an intact placenta, so reductions in manual placenta removal can be interpreted as improvements in maternity care related to PPH (Begley et al. 2011). Column 8 of Table 5 shows a statistically significant 7 percentage point decline in manual placenta removal in the output contract arm (26 percent reduction), suggesting fewer instances in which corrective action was needed. ${ }^{35}$ The corresponding estimate in the input arm is less precise, but comparable in magnitude.

\subsection{Relative Costs of Input and Output Contracts}

Given that our input and output incentive contracts produced statistically indistinguishable improvements in maternal health, we next briefly compare the costs required to produce these health benefits. Figures 2 and 3 show the distributions of incentive payments made to providers in treatment arm. Ex post, the average payment was much higher in the output contract group (INR56,812, or USD 1033) than in the input contract group (INR13,850, or USD 252). ${ }^{36}$ In each figure, we also construct counterfactual distributions that reflect hypothetical input contract payments to output contract group providers (and vice versa). In general, for the specific contracts that we study, payments for outputs are nearly four times as expensive as payments for inputs. Importantly, this potentially reflects a substantial risk premium required by

\footnotetext{
34 This particular input is possibly measured with greater error than others because mothers and those accompanying them during childbirth are unable to observe the specific types of drugs administered.

35 Although abdominal massaging is no longer a recommended best practice as per revised WHO guidelines, we also see in Table 5 that providers in input contract arm were 7 percentage points (18 percent) more likely to massage the mother's abdomen relative to control arm, while providers in output contracts arm had no significant change.

${ }^{36}$ Exchange rate 1 USD $=55$ INR in 2013.
} 
providers accepting output payment contracts to compensate them for the risk that they are not rewarded for additional effort exerted (because outputs are not fully under their control).

In the setting of our study, the input contract was more efficient than the output incentive contract because it delivered the same health outcomes at much lower cost for the principal. However, it is important to note that this only applies to the input and output incentive contracts studied here, and it is not generalizable to comparing other input and output contracts. For instance, if the elasticity of an output with respect to the reward in the output contract is very low, a much less generous output contract could have delivered similar health improvements at a smaller cost to the principal. ${ }^{37}$ Although we were unable to the experiment over a range of payment rates for inputs and outputs, we note that other studies that experimented with different payment rates for output contracts have found the relevant elasticity to be significant (Luo et al. 2015).

\subsection{The Role of Skills in in Provider Responses to Output and Input Incentive Contracts}

As our conceptual framework in section 2 suggests, we expect provider skills to play an important role in determining the effectiveness (and relative effectiveness) of output and input incentive contracts. With input incentive contracts, providers are paid to use explicitly-specified inputs ("follow orders"), hence provider skill may be less relevant. Alternatively, with output incentive contracts, provider skill may play a much more important role as more skilled providers are better able to choose the optimal combination of inputs using local/contextual information (albeit with less control over contracted outcomes - and therefore more uncertainty about incentive payments).

We examine differences in providers' behavioral responses to incentive contracts by level of skill, measuring skills according to whether or not providers have medical degrees with

\footnotetext{
${ }^{37}$ We are grateful to Oriana Bandiera and Paul Gertler for helpful discussions on this point.
} 
specific obstetric training ("MBBS plus" providers) qualifying them to provide maternity care ${ }^{38}$. Table 6 shows that in the output contract group, "MBBS plus" providers (column 1) produced PPH rates that were 9 percentage points lower on average than providers without obstetric qualifications. In contrast, "MBBS plus" providers performed no better (or worse) than less qualified providers in the input contract group. These results are consistent with output incentive contracts leading providers to use local/contextual information to improve care beyond simple guideline adherence - but only when they also have sufficient complementary skills to do so.

To explore high-skilled provider use of local/contextual information under output incentive contracts further, we also directly examine providers' reports of implementing new delivery strategies since our baseline survey. Table 7 shows that output contracts increased the probability that "MBBS plus" providers implemented new strategies by $0.364(0.364=$ $0.165+0.529 ; \mathrm{se}=0.142$ ), which is statistically different from zero. In contrast, the input contract did not increase the use of new strategies among "MBBS plus" providers $(0.143=-0.263+0.406$; se $=0.167)$. The first two rows also show that neither type of contract increased the probability that less qualified providers implemented new strategies.

\section{$\underline{4.5 \text { Expectations and Multi-tasking }}$}

Although our incentive contracts generally cover all domains of maternity care provision, a natural concern with performance incentives is 'multi-tasking' (or the reduction of effort on unrewarded margins - or those for which expected net benefits are lower) (Holmstrom and Milgrom 1991, Prendergast 1999). Without knowing the underlying production function and cost functions, it was not possible to know ex-ante if the contracts rewarded some outcomes more

\footnotetext{
${ }^{38}$ The basic medical education at the level of MBBS and BAMS includes a few months of training in obstetrics that gives only introductory level of skills. Such providers are able to conduct normal deliveries but do not have training in management of complications or the surgical skills that are acquired as part of advanced obstetric training programs (typically 2 to 3 years of training after completing medical school) (Mahal and Mohanan 2006).
} 
generously (net of the full cost of providing them) than others. Importantly, this depends on providers' expectations about their ability to improve outcomes (in both absolute and relative terms).

In Table 4 Column 10, we find a 0.14 point decline in the postnatal newborn care counseling index among output contract group providers ( $\mathrm{p}<0.01$ after correcting for multiple comparisons), which may reflect a reduction in effort devoted towards newborn care. To explore this possibility further, we use measures of provider beliefs about their ability to improve each of the four major health outcomes (i.e., outputs) that we collected prior to introducing incentive contracts. About $35 \%$ of providers rated neonatal mortality as the most difficult one to improve among the four outcomes. Instead, providers generally attributed neonatal mortality to the actions of caregivers at home (driven by traditional beliefs that colostrum is 'witch's milk', for example) and beyond providers' control. Moreover, when asked which of the four major health outcomes was most important to improve based on patients' clinical needs, only $9 \%$ said neonatal mortality - while 75\% said PPH (Figure 4). This pattern of beliefs is consistent with output contract providers diverting effort away from postnatal newborn care (and preventing neonatal mortality) and towards preventing and treating PPH. In contrast, Table 4, Column 10, shows no commensurate reduction in postnatal newborn care counseling delivered by providers in the input contract group. Because postnatal newborn care counseling largely comprised of giving information to mothers about how to care for the newborns and detect birth-related complications at home, it is reasonable that input contract providers responded to performance incentives to deliver this counseling despite believing that it would have little effect on mothers' care for their babies at home. 
Taken together, our results suggest that improvements in PPH under incentive contracts may have come at the expense of some reduction in newborn care - and did so only under circumstances in which providers believed that effort on newborn care was particularly unlikely to be rewarded (i.e., output incentive contracts).

\section{CONCLUSION}

The use of performance incentives in public service delivery has grown rapidly in developing countries in recent years (Wagstaff 2015). The World Bank alone currently supports more than 40 such large-scale programs in the health sector (World Bank 2016). However, very little empirical research examines key contract design issues that should guide these programs (Miller and Babiarz 2014). Theory suggests that two central considerations are (a) the trade-off between rewarding the production of outputs versus the use of inputs and (b) how this trade-off may vary with worker/agent skill. While performance incentives rewarding outputs may encourage innovation and efficiency in context-dependent input choices, they also impose more risk on agents as well. Moreover, suitable skills may be necessary for agents to innovate or deviate efficiently from pre-specified input combinations.

Through a maternity care experiment in India, our paper provides empirical evidence that output and input incentive contracts produced comparable health gains - a reduction in postpartum hemorrhage $(\mathrm{PPH})$ exceeding 20\%. This result is important given that PPH is the leading cause of maternal mortality worldwide, and India's maternal mortality ratio continues to be very high (174 per 1000 live births in 2015) (World Health Organization 2015). Moreover, agents (health providers) responded very differently to the incentive contracts according to their underlying qualifications and skills. With output incentive contracts, those with advanced 
qualifications reduced PPH substantially, implementing new delivery strategies to do so - while those lacking appropriate qualifications failed to reduce PPH. Alternatively, those with varying qualifications performed equivalently under input incentive contracts, following guidelines in similar ways.

Overall, our findings suggest that the focus on input incentives among many 'pay-forperformance' programs in developing country health sectors may be appropriate despite the lack of previous empirical evidence on the underlying rationale (Das, Gopalan and Chandramohan 2016, Fritsche, Soeters and Meessen 2014). In particular, health providers in low-income countries often have relatively little training, and our results suggest that output incentives may be particularly ineffective in improving their performance - but that incentives for adherence to established clinical guidelines may be an appropriate strategy.

\section{SUPPLEMENTARY MATERIAL:}

Appendix materials for online publication are included at the end of this manuscript. 


\section{REFERENCES:}

Anderson, Michael L., "Multiple Inference and Gender Differences in the Effects of Early Intervention: A Reevaluation of the Abecedarian, Perry Preschool, and Early Training Projects," JASA: Journal of the American Statistical Association, 103 (2008), 45.

Ashraf, Nava, Oriana Bandiera, and B. Kelsey Jack, "No margin, no mission? A field experiment on incentives for public service delivery," Journal of Public Economics, 120 (2014), 117.

Basinga, Paulin, Paul Gertler, A Binagwaho, AL Soucat, J Sturdy, and CM Vermeersch, " Effect on maternal and child health services in Rwanda of payment to primary healthcare providers for performance: an impact evaluation," The Lancet, 377 (2011), 14211428.

Begley, C. M., G. M. Gyte, D. Devane, W. McGuire, and A. Weeks, "Active versus expectant management for women in the third stage of labour," Cochrane Database Syst Rev, (2011), Cd007412.

Behrman, Jere, Susan Parker, Petra Todd, and Kenneth Wolpin, "Aligning Learning Incentives of Students and Teachers: Results from a Social Experiment in Mexican High Schools," Journal of Political Economy, 123 (2015), 325-364.

Callen, Michael, Saad Gulzar, Ali Hasanain, Yasir Khan, and Arman Rezaee, "Personalities and Public Sector Performance: Evidence from a Health Experiment in Pakistan," National Bureau of Economic Research Working Paper Series, 21180 (2015).

Celhay, Pablo, Paul Gertler, Paula Giovagnoli, and Christel Vermeersch, "Temporary Incentives and Long-Run Medical Care Performance: Evidence from A Field Experiment. NBER Working Paper No. 21361," (2015). 
Chaudhury, Nazmul, Jeffrey Hammer, Michael Kremer, Karthik Muralidharan, and F. Halsey Rogers, "Missing in Action: Teacher and Health Worker Absence in Developing Countries," The Journal of Economic Perspectives, 20 (2006), 91-116.

Das, Ashis, Saji S. Gopalan, and Daniel Chandramohan, "Effect of pay for performance to improve quality of maternal and child care in low- and middle-income countries: a systematic review," BMC Public Health, 16 (2016), 321.

Das, Jishnu, and Jeffrey Hammer, "Quality of Primary Care in Low-Income Countries: Facts and Economics," Annual Review of Economics, 6 (2014), 525-553.

Das, Jishnu, Jeffrey Hammer, and Carolina Sánchez-Paramo, "The impact of recall periods on reported morbidity and health seeking behavior," Journal of Development Economics, 98 (2012), 76-88.

Das, Jishnu, Alaka Holla, Veena Das, Manoj Mohanan, Diana Tabak, and Brian Chan, "In Urban And Rural India, A Standardized Patient Study Showed Low Levels Of Provider Training And Huge Quality Gaps," Health Affairs, 31 (2012), 2774-2784.

Das, Jishnu, Alaka Holla, Aakash Mohpal, and Karthik Muralidharan, "Quality and Accountability in Healthcare Delivery: Audit Evidence from Primary Care Providers in India," American Economic Review, 106 (2016), 3765-3799.

Dupas, Pascaline, and Edward Miguel, "Impacts and Determinants of Health Levels in LowIncome Countries. NBER Working Paper No. 22235," (Cambridge, MA, 2016).

Filippi, Veronique, Carine Ronsmans, Timothee Gandaho, and Wendy Graham, "Women's reports of severe (near-miss) obstetric complications in Benin," Studies in family planning, 31 (2000), 309. 
Finan, Frederico, Benjamin A. Olken, and Rohini Pande, "The Personnel Economics of the State. NBER Working Paper No. 21825," (2015).

Fritsche, György Bèla, Robert Soeters, and Bruno Meessen, Performance-Based Financing Toolkit. (Washington, DC: World Bank, 2014).

Ganguly, Nirmal, N. Arora, Sujith Chandy, Mohamed Fairoze, J. P. Gill, Usha Gupta, Shah Hossain, Sadhna Joglekar, P. Joshi, Manish Kakkar, Anita Kotwani, Ashok Rattan, H. Sudarshan, Kurien Thomas, Chand Wattal, Alice Easton, and Ramanan Laxminarayan, "Rationalizing antibiotic use to limit antibiotic resistance in India [sup]+," Indian Journal of Medical Research, 134 (2011), 281.

Gertler, Paul, Paula Giovagnoli, and Sebastian Martinez, "Rewarding Performance to Enable a Healthy Start to Life: The Impact of Plan Nacer on Birth Outcomes," in Policy Research Working Paper; No. 6884, (World Bank, Washington DC, 2014).

Gertler, Paul, and Christel Vermeersch, "Using Performance Incentives to Improve Medical Care Productivity and Health Outcomes. NBER Working Paper 19046," (2013).

Glewwe, Paul, Nauman Ilias, and Michael Kremer, "Teacher Incentives," American Economic Journal: Applied Economics, 2 (2010), 205-227.

Government of India, MOHFW, "State Factsheet - Karnataka, National Family Health Survey 4," (New Delhi, 2016).

Hall, Brian J., and Jeffrey B. Liebman, "Are CEOs really paid like bureaucrats?," The Quarterly Journal of Economics, 113 (1998), 653-691.

Holmstrom, Bengt, and Paul Milgrom, "Multitask Principal-Agent Analyses: Incentive Contracts, Asset Ownership, and Job Design," Journal of Law, Economics, and Organization, 7 (1991), 24-52. 
Jensen, Michael C., and Kevin J. Murphy, "Performance Pay and Top-Management Incentives," The Journal of Political Economy, 98 (1990), 225.

Khalil, Fahad, and Jacques Lawarree, "Input versus output monitoring: Who is the residual claimant?," Journal of Economic Theory, 66 (1995), 139.

Laffont, Jean-Jacques, and David Martimort, The theory of incentives: the principal-agent model (Princeton University Press, 2009).

Lavy, Victor, "Evaluating the Effect of Teachers' Group Performance Incentives on Pupil Achievement.," Journal of Political Economy, 110 (2002), 1286-1317.

Lazear, Edward P., "The power of incentives," The American Economic Review, 90 (2000), 410414.

Luo, Renfu, Grant Miller, Scott Rozelle, Sean Sylvia, and Marcos Vera-Hernández, "Can Bureaucrats Really Be Paid Like CEOs? School Administrator Incentives for Anemia Reduction in Rural China. NBER Working Paper No. 21302," (2015).

Mahal, Ajay, and Manoj Mohanan, "Growth of private medical education in India," Medical Education, 40 (2006), 1009-1011.

Miller, Grant, and Kimberly S. Babiarz, "Pay-for-Performance Incentives in Low- and MiddleIncome Country Health Programs," in Encyclopedia of Health Economics, Anthony $\mathbf{J}$ Culyer, ed. (San Diego: Elsevier, 2014).

Miller, Grant, Renfu Luo, Linxiu Zhang, Sean Sylvia, Yaojiang Shi, Patricia Foo, Qiran Zhao, Reynaldo Martorell, Alexis Medina, and Scott Rozelle, "Effectiveness of provider incentives for anaemia reduction in rural China: A cluster randomised trial," BMJ, 345 (2012), e4809-e4809. 
Mohanan, Manoj, M. Vera-Hernández, V. Das, and et al., "The know-do gap in quality of health care for childhood diarrhea and pneumonia in rural india," JAMA Pediatr, 169 (2015), 349-357.

Mol, Ben W. J., Claire T. Roberts, Shakila Thangaratinam, Laura A. Magee, Christianne J. M. de Groot, and G. Justus Hofmeyr, "Pre-eclampsia," The Lancet, 387 (2016), 999-1011.

Mony, Prem K., Krishnamurthy Jayanna, Swarnarekha Bhat, Suman V. Rao, Maryann Crockett, Lisa Avery, B. M. Ramesh, Stephen Moses, and James Blanchard, "Availability of emergency neonatal care in eight districts of Karnataka state, southern India: a crosssectional study," BMC Health Serv Res, 15 (2015), 1-9.

Mullen, Kathleen J., Richard G. Frank, and Meredith B. Rosenthal, "Can you get what you pay for? Pay-for-performance and the quality of healthcare providers," The Rand Journal of Economics, 41 (2010), 64-91.

Muralidharan, Karthik, and Venkatesh Sundararaman, "Teacher Performance Pay: Experimental Evidence from India," Journal of Political Economy, 119 (2011), 39-77.

NHM, "Statewise Information: Karnataka," (http://nrhm.gov.in/nrhm-in-state/state-wiseinformation/karnataka.html: Government of Karnataka, 2013).

NRHM, "RMNCH+A: Maternal Health Background ", (National Health Mission, MOHFW, Government of India, 2015).

Olken, Benjamin A., Junko Onishi, and Susan Wong, "Should Aid Reward Performance? Evidence from a Field Experiment on Health and Education in Indonesia," American Economic Journal: Applied Economics, 6 (2014), 1-34.

Patel, A., S. S. Goudar, S. E. Geller, B. S. Kodkany, S. A. Edlavitch, K. Wagh, S. S. Patted, V. A. Naik, N. Moss, and R. J. Derman, "Drape estimation vs. visual assessment for 
estimating postpartum hemorrhage," International Journal of Gynecology and Obstetrics, 93 (2006), 220-224.

Peabody, John, Riti Shimkhada, Stella Quimbo, Jhiedon Florentino, Marife Bacate, Charles E. McCulloch, and Orville Solon, "Financial Incentives And Measurement Improved Physicians' Quality Of Care In The Philippines," Health Affairs, 30 (2011), 773-781.

Phipps, Elizabeth, Devika Prasanna, Wunnie Brima, and Belinda Jim, "Preeclampsia: Updates in Pathogenesis, Definitions, and Guidelines," Clinical Journal of the American Society of Nephrology, 11 (2016), 1102-1113.

Prendergast, Canice, "The provision of incentives in firms," Journal of economic literature, 37 (1999), 7-63.

---, "The tenuous trade-off between risk and incentives," Journal of Political Economy, 110 (2002), 1071-1102.

---, "What have we learnt about pay for performance?: Geary Lecture winter 2010," Economic and Social Review, 42 (2011), 113-134.

Raith, Michael, "Specific Knowledge and Performance Measurement," The Rand Journal of Economics, 39 (2008), 1059-1079.

Roland, Martin, "Linking Physicians' Pay to the Quality of Care - A Major Experiment in the United Kingdom," The New England Journal of Medicine, 351 (2004), 1448-1454.

Rosenthal, Meredith B., Rushika Fernandopulle, HyunSook Ryu Song, and Bruce Landon, "Paying For Quality: Providers' Incentives For Quality Improvement," Health Affairs, 23 (2004), 127-141. 
Sherry, Tisamarie B., Sebastian Bauhoff, and Manoj Mohanan, "Multitasking and Heterogeneous Treatment Effects in Pay-for-Performance in Health Care: Evidence from Rwanda," American Journal of Health Economics, (2017), 1-35.

Singh, Prakarsh, "Performance pay and information: Reducing child undernutrition in India," Journal of Economic Behavior \& Organization, 112 (2015), 141-163.

Soeters, Robert, Peter Bob Peerenboom, Pacifique Mushagalusa, and Célestin Kimanuka, "Performance-Based Financing Experiment Improved Health Care In The Democratic Republic Of Congo," Health Affairs, 30 (2011), 1518-1527.

Stanton, Cynthia K., Barbara Rawlins, Mary Drake, Matias dos Anjos, David Cantor, Lidia Chongo, Leonardo Chavane, Maria da Luz Vaz, and Jim Ricca, "Measuring Coverage in MNCH: Testing the Validity of Women's Self-Report of Key Maternal and Newborn Health Interventions during the Peripartum Period in Mozambique," PLoS One, 8 (2013), e60694.

Steegers, Eric A. P., Peter von Dadelszen, Johannes J. Duvekot, and Robert Pijnenborg, "Preeclampsia," The Lancet, 376 (2010), 631-644.

Stewart, M. Kathryn, and Mario Festin, "Validation study of women's reporting and recall of major obstetric complications treated at the Philippine General Hospital," International Journal of Gynecology and Obstetrics, 48 (1995), S53-S66.

Tunçalp, Özge, João Paulo Souza, and Metin Gülmezoglu, "New WHO recommendations on prevention and treatment of postpartum hemorrhage," International Journal of Gynecology \& Obstetrics, 123 (2013), 254-256. 
Urner, Fiona, Roland Zimmermann, and Alexander Krafft, "Manual Removal of the Placenta after Vaginal Delivery: An Unsolved Problem in Obstetrics," Journal of Pregnancy, 2014 (2014), 5 .

Van de Poel, Ellen, Gabriela Flores, Por Ir, and Owen O'Donnell, "Impact of Performance-Based Financing in a Low-Resource Setting: A Decade of Experience in Cambodia," Health Economics, 25 (2016), 688-705.

Wagstaff, Adam, "Financial incentives in health: the magic bullet we were hoping for?," World Bank Chief Economist, ed. (https://blogs.worldbank.org/developmenttalk/financialincentives-health-magic-bullet-we-were-hoping: World Bank, 2015).

Westfall, Peter H, and S Stanley Young, Resampling-based multiple testing: Examples and methods for p-value adjustment (John Wiley \& Sons, 1993).

World Bank, "Results Based Financing Health Projects," (Washington DC: World Bank, 2016).

World Health Organization, "Maternal mortality in 1990-2015: India," UNICEF WHO, UNFPA, World Bank Group, and United Nations Population Division, and Maternal Mortality Estimation Inter-Agency Group, eds.

(http://www.who.int/gho/maternal_health/countries/ind.pdf: World Health Organization, 2015). 
TABLE I

PROVIDER SAMPLING AND ATTRITION

\begin{tabular}{|c|c|c|c|}
\hline & Control & $\begin{array}{c}\text { Input } \\
\text { contract }\end{array}$ & $\begin{array}{c}\text { Output } \\
\text { contract }\end{array}$ \\
\hline A. Providers identified from government survey data & 42 & 38 & 40 \\
\hline B. Additional eligible providers identified during fieldwork for verification & 5 & 2 & 13 \\
\hline C. Attrited from survey & 3 & 2 & 0 \\
\hline Final Analytical Sample $(\mathrm{A}+\mathrm{B}-\mathrm{C})$ & 44 & 38 & 53 \\
\hline
\end{tabular}

Notes: This table reports counts of the universe of providers identified as eligible for the study by randomly assigned treatment arm. Because providers identified during fieldwork were assigned to study arms based on a randomized list of sequence numbers (unknown to field enumerators, and the sequence was not predictable) it was not possible to ensure an equal number of providers across arms. Providers identified as attritors in row $\mathrm{C}$ declined to participate in the study during or after signing the contract. The last row includes the final sample of providers used in the analysis. 
TABLE II

SUMMARY STATISTICS AND BALANCE

\begin{tabular}{lccccc}
\hline \hline Variables & All & $\begin{array}{c}\text { Input } \\
\text { Group }\end{array}$ & $\begin{array}{c}\text { Output } \\
\text { Group }\end{array}$ & $\begin{array}{c}\text { Control } \\
\text { Group }\end{array}$ & $\begin{array}{c}\text { Test of } \\
\text { Equality } \\
\text { (p-value) }\end{array}$ \\
\hline Female provider (percent) & 0.56 & 0.55 & 0.57 & 0.55 & 0.98 \\
MBBS plus (percent) & $(0.5)$ & $(0.5)$ & $(0.5)$ & $(0.5)$ & \\
& 0.59 & 0.45 & 0.64 & 0.64 & 0.14 \\
MBBS (percent) & $(0.49)$ & $(0.5)$ & $(0.48)$ & $(0.49)$ & \\
& 0.21 & 0.26 & 0.19 & 0.2 & 0.71 \\
BAMS (percent) & $(0.41)$ & $(0.45)$ & $(0.39)$ & $(0.41)$ & \\
& 0.16 & 0.26 & 0.15 & 0.09 & 0.13 \\
Other qualification (percent) & $(0.37)$ & $(0.45)$ & $(0.36)$ & $(0.29)$ & \\
& 0.04 & 0.03 & 0.02 & 0.07 & 0.52 \\
Provider Age (mean) & $(0.19)$ & $(0.16)$ & $(0.14)$ & $(0.25)$ & \\
& 47.01 & 46.42 & 47.45 & 46.98 & 0.89 \\
Years practicing (mean) & $(10.29)$ & $(9.14)$ & $(11.33)$ & $(10.12)$ & \\
Years clinic operating (mean) & 19.93 & 19.68 & 20.98 & 18.89 & 0.64 \\
N & $(10.68)$ & $(9.95)$ & $(11)$ & $(11.04)$ & \\
\hline \hline
\end{tabular}

Notes: This table reports mean provider characteristics by study group. Provider characteristics are self-reported and measured through interviews with the provider or with a staff member. Rows 2-4 refer to provider training: MBBS plus is a Bachelor of Medicine degree with a specialization such as obstetrics, MBBS is a Bachelor of Medicine degree with no additional specialization, BAMS is a degree in Ayurveda medicine. Standard deviations are reported in parentheses. P-values in the final column are associated with F-tests of joint equality across the three study groups. 
TABLE III

IMPACT OF PROVIDER INCENTIVES ON OUTPUTS

\begin{tabular}{|c|c|c|c|c|c|c|c|c|}
\hline & \multicolumn{2}{|c|}{ Postpartum Hemorrhage } & \multicolumn{2}{|c|}{ Pre-eclampsia } & \multicolumn{2}{|c|}{ Sepsis } & \multicolumn{2}{|c|}{ Neonatal Death } \\
\hline & $(1)$ & $(2)$ & $(3)$ & (4) & $(5)$ & (6) & $(7)$ & $(8)$ \\
\hline Input incentives & $\begin{array}{c}-0.0842 * * * \\
(0.0297)\end{array}$ & $\begin{array}{c}-0.0843 * * * \\
(0.0284)\end{array}$ & $\begin{array}{c}0.0312 \\
(0.0450)\end{array}$ & $\begin{array}{c}0.0573 \\
(0.0434)\end{array}$ & $\begin{array}{c}0.0333 \\
(0.0228)\end{array}$ & $\begin{array}{c}0.0369 \\
(0.0253)\end{array}$ & $\begin{array}{l}-0.0073 \\
(0.0087)\end{array}$ & $\begin{array}{c}0.0032 \\
(0.0051)\end{array}$ \\
\hline Output incentives & $\begin{array}{c}-0.0622 * * \\
(0.0286)\end{array}$ & $\begin{array}{c}-0.0742 * * \\
(0.0294)\end{array}$ & $\begin{array}{c}0.0466 \\
(0.0325)\end{array}$ & $\begin{array}{c}0.0611 \\
(0.0328)\end{array}$ & $\begin{array}{c}0.0065 \\
(0.0198)\end{array}$ & $\begin{array}{c}0.0208 \\
(0.0225)\end{array}$ & $\begin{array}{l}-0.0091 \\
(0.0111)\end{array}$ & $\begin{array}{c}0.0079 \\
(0.0067)\end{array}$ \\
\hline $\begin{array}{l}\text { District \& Enumerator } \\
\text { fixed effects }\end{array}$ & Yes & Yes & Yes & Yes & Yes & Yes & Yes & Yes \\
\hline $\begin{array}{l}\text { Household- and provider- } \\
\text { level controls }\end{array}$ & No & Yes & No & Yes & No & Yes & No & Yes \\
\hline Control mean & 0.365 & 0.365 & 0.179 & 0.179 & 0.0651 & 0.0651 & 0.0121 & 0.0121 \\
\hline Observations & 2890 & 2748 & 2894 & 2748 & 2891 & 2748 & 2894 & 2748 \\
\hline $\mathrm{R}^{2}$ & 0.266 & 0.279 & 0.255 & 0.271 & 0.106 & 0.119 & 0.0582 & 0.0565 \\
\hline
\end{tabular}

Notes: Estimates obtained through OLS. Robust standard errors, clustered at the provider level, are reported in parentheses.*,**, and $* * *$ denote statistical significance based on pvalues less than 0.1, 0.05 and 0.01, adjusted for multiple hypotheses tested and calculated using the free step-down resampling method. Each specification includes district and

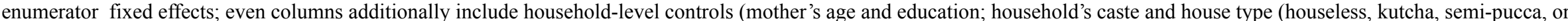
pucca); head of household's religion; mother's history of hypertension, diabetes, asthma, hyper- or hypothyroidism, and convulsions; whether the mother has had a previous stomach

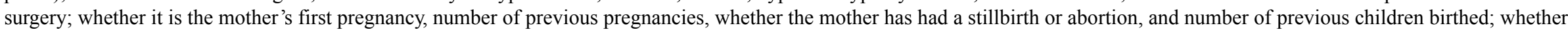

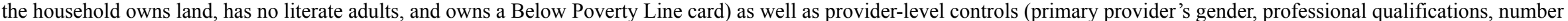

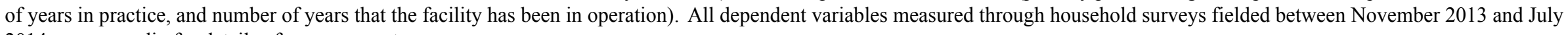
2014; see appendix for details of measurement. 
TABLE IV

IMPACT OF PROVIDER INCENTIVES ON INPUTS

\begin{tabular}{|c|c|c|c|c|c|c|c|c|c|c|}
\hline & \multicolumn{2}{|c|}{ Pregnancy Care } & \multicolumn{2}{|c|}{ Childbirth Care } & \multicolumn{2}{|c|}{$\begin{array}{c}\text { Postnatal Maternal Care } \\
\text { Counseling }\end{array}$} & \multicolumn{2}{|c|}{ Newborn Care } & \multicolumn{2}{|c|}{$\begin{array}{c}\text { Postnatal Newborn Care } \\
\text { Counseling }\end{array}$} \\
\hline & (1) & (2) & (3) & (4) & $(5)$ & $(6)$ & (7) & (8) & $(9)$ & $(10)$ \\
\hline Input incentives & $\begin{array}{l}-0.0106 \\
(0.0455)\end{array}$ & $\begin{array}{c}0.0029 \\
(0.0458)\end{array}$ & $\begin{array}{l}-0.0203 \\
(0.0338)\end{array}$ & $\begin{array}{c}0.0146 \\
(0.0284)\end{array}$ & $\begin{array}{c}0.0380 \\
(0.0390)\end{array}$ & $\begin{array}{c}0.0422 \\
(0.0392)\end{array}$ & $\begin{array}{l}-0.0545 \\
(0.0350)\end{array}$ & $\begin{array}{l}-0.0288 \\
(0.0371)\end{array}$ & $\begin{array}{l}-0.0650 \\
(0.0576)\end{array}$ & $\begin{array}{l}-0.0065 \\
(0.0577)\end{array}$ \\
\hline Output incentives & $\begin{array}{l}-0.0529 \\
(0.0373)\end{array}$ & $\begin{array}{l}-0.0551 \\
(0.0401)\end{array}$ & $\begin{array}{l}-0.0311 \\
(0.0268)\end{array}$ & $\begin{array}{l}-0.0191 \\
(0.0250)\end{array}$ & $\begin{array}{c}0.0674 \\
(0.0354)\end{array}$ & $\begin{array}{c}0.0773 \\
(0.0358)\end{array}$ & $\begin{array}{l}-0.0285 \\
(0.0322)\end{array}$ & $\begin{array}{l}-0.0146 \\
(0.0360)\end{array}$ & $\begin{array}{c}-0.1610 * * * \\
(0.0435)\end{array}$ & $\begin{array}{c}-0.1386 * * * \\
(0.0437)\end{array}$ \\
\hline $\begin{array}{l}\text { District \& enumerator } \\
\text { fixed effects }\end{array}$ & Yes & Yes & Yes & Yes & Yes & Yes & Yes & Yes & Yes & Yes \\
\hline $\begin{array}{l}\text { Household- and } \\
\text { provider-level controls }\end{array}$ & No & Yes & No & Yes & No & Yes & No & Yes & No & Yes \\
\hline Control mean & -0.0621 & -0.0621 & -0.00480 & -0.00480 & -0.0876 & -0.0876 & -0.00203 & -0.00203 & -0.0680 & -0.0680 \\
\hline Observations & 2890 & 2748 & 2894 & 2748 & 2891 & 2748 & 2894 & 2748 & 2894 & 2748 \\
\hline $\mathrm{R}^{2}$ & 0.355 & 0.361 & 0.356 & 0.382 & 0.406 & 0.422 & 0.427 & 0.447 & 0.471 & 0.490 \\
\hline
\end{tabular}

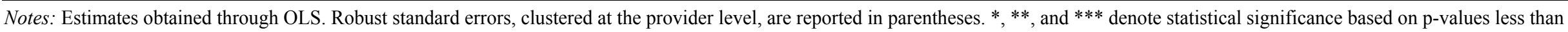

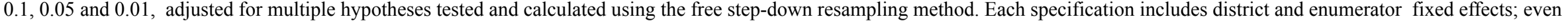

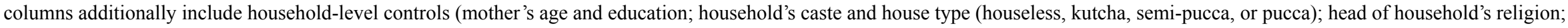

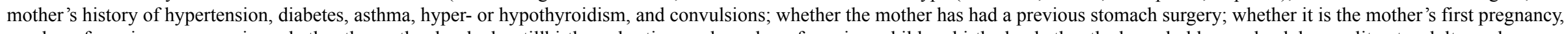

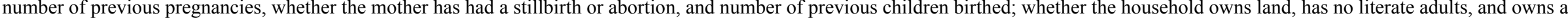

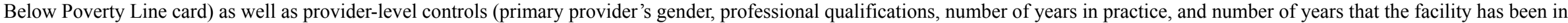

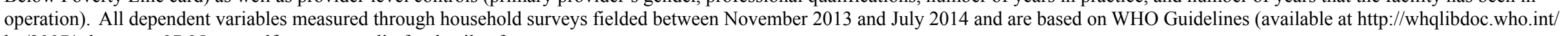
hq/2007/who_mps_07.05_eng.pdf); see appendix for details of measurement. 
TABLE V

IMPACT OF PROVIDER INCENTIVES ON PPH PREVENTION AND MANAGEMENT

\begin{tabular}{|c|c|c|c|c|c|c|c|c|}
\hline & \multicolumn{2}{|c|}{$\begin{array}{c}\text { Parenteral Oxytocic Drugs } \\
\text { Available }\end{array}$} & \multicolumn{2}{|c|}{$\begin{array}{l}\text { Medicine Use to Reduce } \\
\text { Bleeding After Delivery }\end{array}$} & \multicolumn{2}{|c|}{$\begin{array}{c}\text { Massage Abdomen After } \\
\text { Delivery }\end{array}$} & \multicolumn{2}{|c|}{ Placenta Manually Removed } \\
\hline & $(1)$ & $(2)$ & $(3)$ & $(4)$ & $(5)$ & $(6)$ & $(7)$ & $(8)$ \\
\hline Input incentives & $\begin{array}{l}0.0722 * \\
(0.0415)\end{array}$ & $\begin{array}{l}0.0760 * \\
(0.0443)\end{array}$ & $\begin{array}{l}0.0636 * * \\
(0.0322)\end{array}$ & $\begin{array}{c}0.0305 \\
(0.0290)\end{array}$ & $\begin{array}{c}0.0518 \\
(0.0322)\end{array}$ & $\begin{array}{l}0.0718^{*} \\
(0.0427)\end{array}$ & $\begin{array}{l}-0.0786 \\
(0.0483)\end{array}$ & $\begin{array}{l}-0.0504 \\
(0.0437)\end{array}$ \\
\hline Output incentives & $\begin{array}{l}0.0730 * \\
(0.0422)\end{array}$ & $\begin{array}{l}0.0694 * \\
(0.0417)\end{array}$ & $\begin{array}{l}0.0623 * * \\
(0.0286)\end{array}$ & $\begin{array}{c}0.0382 \\
(0.0266)\end{array}$ & $\begin{array}{l}0.00517 \\
(0.0289)\end{array}$ & $\begin{array}{l}-0.0106 \\
(0.0353)\end{array}$ & $\begin{array}{l}-0.0666^{*} \\
(0.0386)\end{array}$ & $\begin{array}{l}-0.0722 * \\
(0.0381)\end{array}$ \\
\hline $\begin{array}{l}\text { District \& enumerator } \\
\text { fixed effects }\end{array}$ & Yes & Yes & Yes & Yes & Yes & Yes & Yes & Yes \\
\hline $\begin{array}{l}\text { Household- and provider- } \\
\text { level controls }\end{array}$ & No & Yes & No & Yes & No & Yes & No & Yes \\
\hline Control mean & 0.932 & 0.932 & 0.460 & 0.460 & 0.517 & 0.517 & 0.289 & 0.289 \\
\hline Observations & 135 & 135 & 2791 & 2656 & 1707 & 1610 & 1665 & 1571 \\
\hline $\mathrm{R}^{2}$ & 0.260 & 0.292 & 0.322 & 0.340 & 0.372 & 0.393 & 0.266 & 0.277 \\
\hline
\end{tabular}

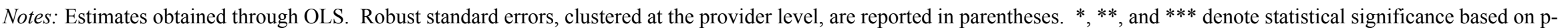
values less than $0.1,0.05$ and 0.01 . All specifications include district and enumerator fixed effects; even columns additionally include household-level controls (mother's age and education; household's caste and house type (houseless, kutcha, semi-pucca, or pucca); head of household's religion; mother 's history of hypertension, diabetes, asthma, hyper- or

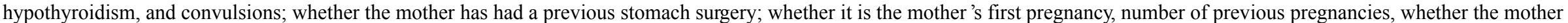

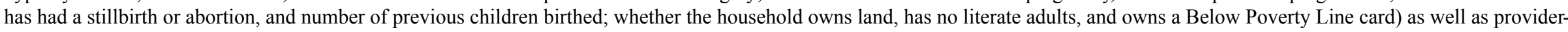

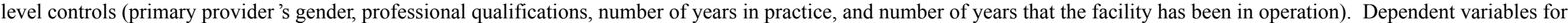

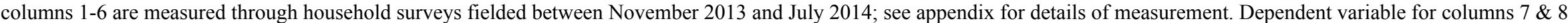

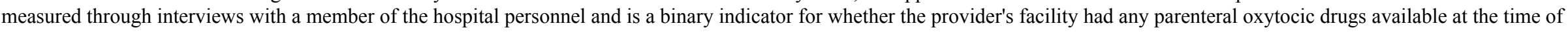
the survey at the end of the study period. 
TABLE VI

IMPACT OF InCENTIVES ON Post PARTUM HEMORRHAGe, BY PROVIDER QUALIFICATIONS

MBBS Plus -0.002

$(0.052)$

Input incentives

$-0.052$

(0.043)

Output incentives

Input X MBBS-Plus

Output X MBBS-Plus

$-0.094 *$

$(0.052)$

$\begin{array}{lc}\text { District \& Enumerator fixed effects } & \text { Yes } \\ \text { Household- and provider-level controls } & \text { Yes } \\ \text { Observations } & 2748 \\ \mathrm{R}^{2} & 0.280\end{array}$

Notes: Estimates from OLS regression on PPH and includes an interaction with the indicated provider qualification category. The MBBS plus variable takes value 1 if the provider holds an MBBS degree (Bachelor of Medicine, Bachelor of Surgery) with advanced medical training in obstetrics and gynecology, 0 otherwise. Robust standard errors, clustered at the provider level, are reported in parentheses. Each specification includes district and enumerator fixed effects, household-level controls (mother's age and education; household's caste and house type (houseless, kutcha, semi-pucca, or pucca); head of household's religion; mother's history of hypertension, diabetes, asthma, hyper- or hypothyroidism, and convulsions; whether the mother has had a previous stomach surgery; whether it is the mother's first pregnancy, number of previous pregnancies, whether the mother has had a stillbirth or abortion, and number of previous children birthed; whether the household owns land, has no literate adults, and owns a Below Poverty Line card) as well as provider-level controls (primary provider's gender, number of years in practice, and number of years that the facility has been in operation). The dependent variable (PPH) is measured through household surveys fielded between November 2013 and July 2014; see appendix for details of measurement. 
Provider QualificAtions AND AsSOCIATION With IMPLEMENTING NEW STRATEGIES

\begin{tabular}{|c|c|}
\hline Panel A: Regressions & $\begin{array}{c}\text { Implement New } \\
\text { Strategies } \\
(1)\end{array}$ \\
\hline Input incentives & $\begin{array}{c}-0.263 \\
(0.168)\end{array}$ \\
\hline Output incentives & $\begin{array}{r}-0.165 \\
(0.158)\end{array}$ \\
\hline Input incentives X MBBS plus & $\begin{array}{l}0.406^{*} \\
(0.244)\end{array}$ \\
\hline Output incentives X MBBS plus & $\begin{array}{c}0.529 * * \\
(0.218)\end{array}$ \\
\hline MBBS plus & $\begin{array}{c}-0.446 * * * \\
(0.150)\end{array}$ \\
\hline Panel B: Results from Linear Combinations & \\
\hline Effect of Input Contracts on MBBS plus & $\begin{array}{c}0.143 \\
(0.167)\end{array}$ \\
\hline Effect of Output Contracts on MBBS plus & $\begin{array}{c}0.364 * * * \\
(0.142)\end{array}$ \\
\hline District fixed effects & Yes \\
\hline Provider-level controls & Yes \\
\hline Observations & 135 \\
\hline R-squared & 0.378 \\
\hline
\end{tabular}

Notes: Estimates obtained through OLS. The dependent variable is an indicator for if the provider reported implementing any new strategies since signing the contract, measured through a survey at the first post-contract provider visit. The MBBS plus variable takes value 1 if the provider holds an MBBS degree (Bachelor of Medicine, Bachelor of Surgery) with advanced medical training in obstetrics and gynecology, 0 otherwise. The specification also includes district fixed effects as well as provider-level controls (primary provider's gender, number of years in practice, and number of years that the facility has been in operation). Robust standard errors, clustered at the provider level, are reported in parentheses. 
FIGURE I

TIMELINE OF INTERVENTIONS AND DATA COLLECTION

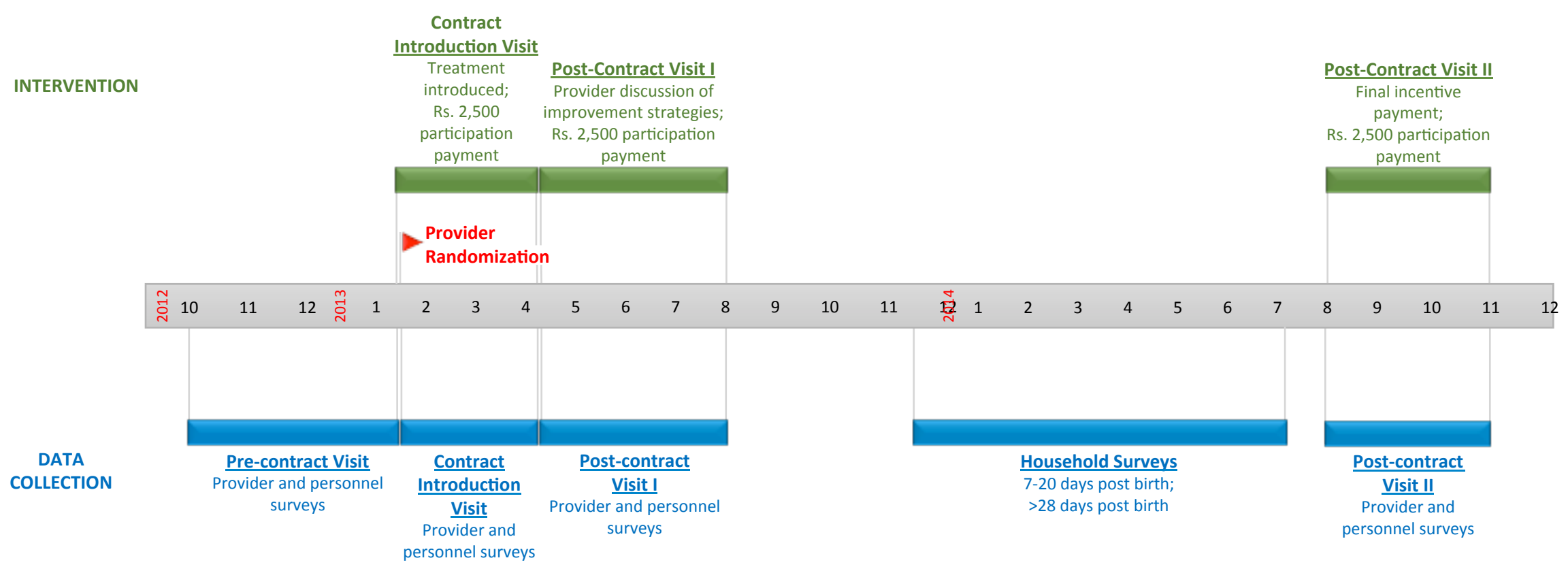

Notes: The timeline shows study implementation period from October 2012 to November 2014. The timing of interventions are labeled (in green) above the timeline, and all data collection and surveys are labeled (in blue) below the timeline. Providers were randomized into treatment arm in early 2014, and contracts signed during January - April 2013. Providers were visited again during May - August 2013 to discuss strategies and collect provider data. Household surveys (of mothers who delivered babies at study providers' facilities) were conducted between December 2013 and July 2014. The providers were visited again at the end of the study to make the incentive payments as specified in contracts, and collect data 
FIGURE II

DisTRIBUTION OF ACTUAL AND COUNTERFACTUAL PAYMENTS FOR INPUTS GROUP

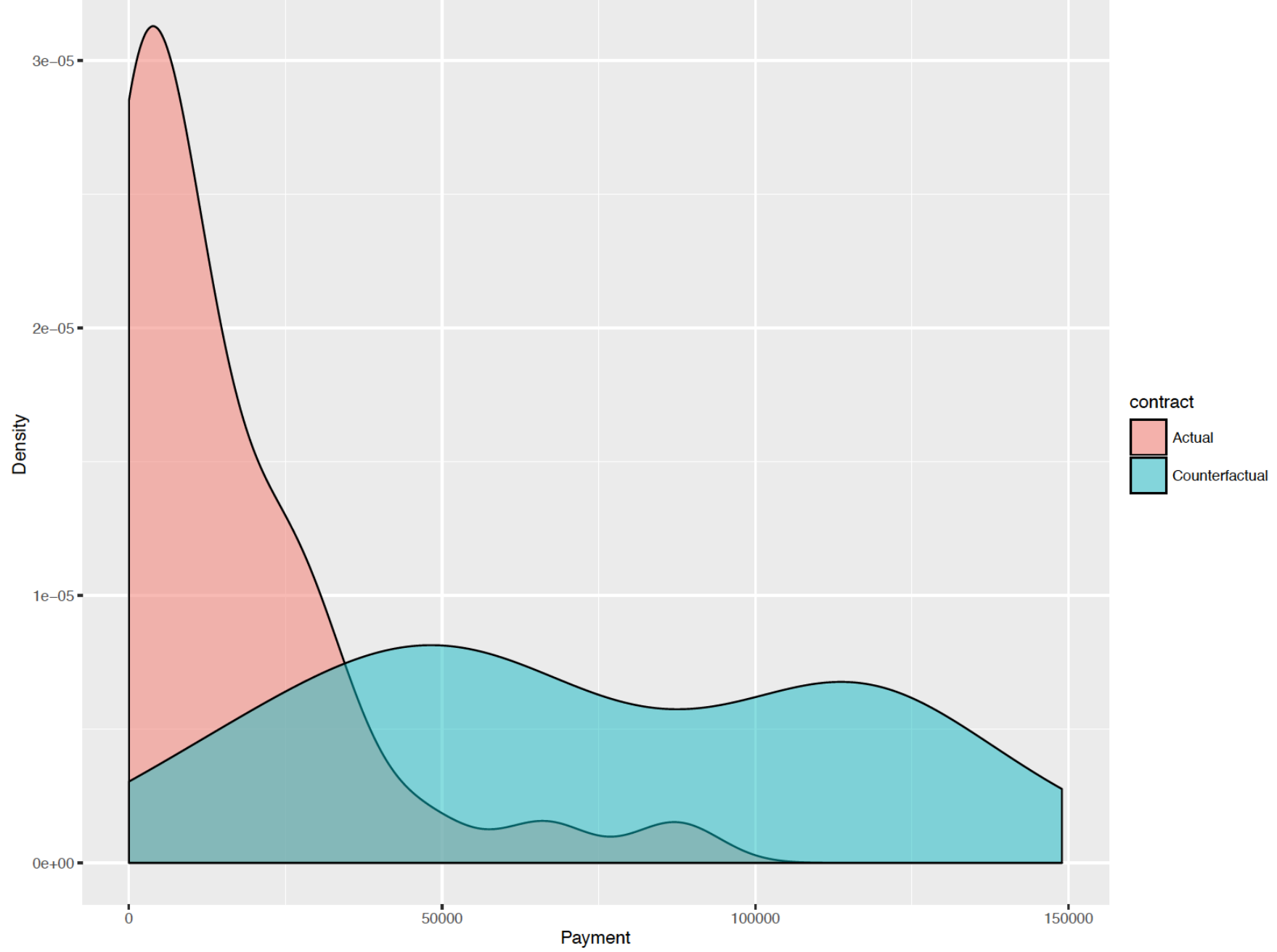

Notes: The distributions show payments made to providers in the input contracts arm. Actual payments are amounts paid out to providers at the end of the experiment based on levels of inputs provided. The distribution labeled "counterfactual" show the payments that might have been made to the same providers if they had been paid based on outcomes instead. 
FigURE III

Distribution of ACTUAL AND COUNTERFACTUAL PAYMENTS FOR OUTPUTS GROUP

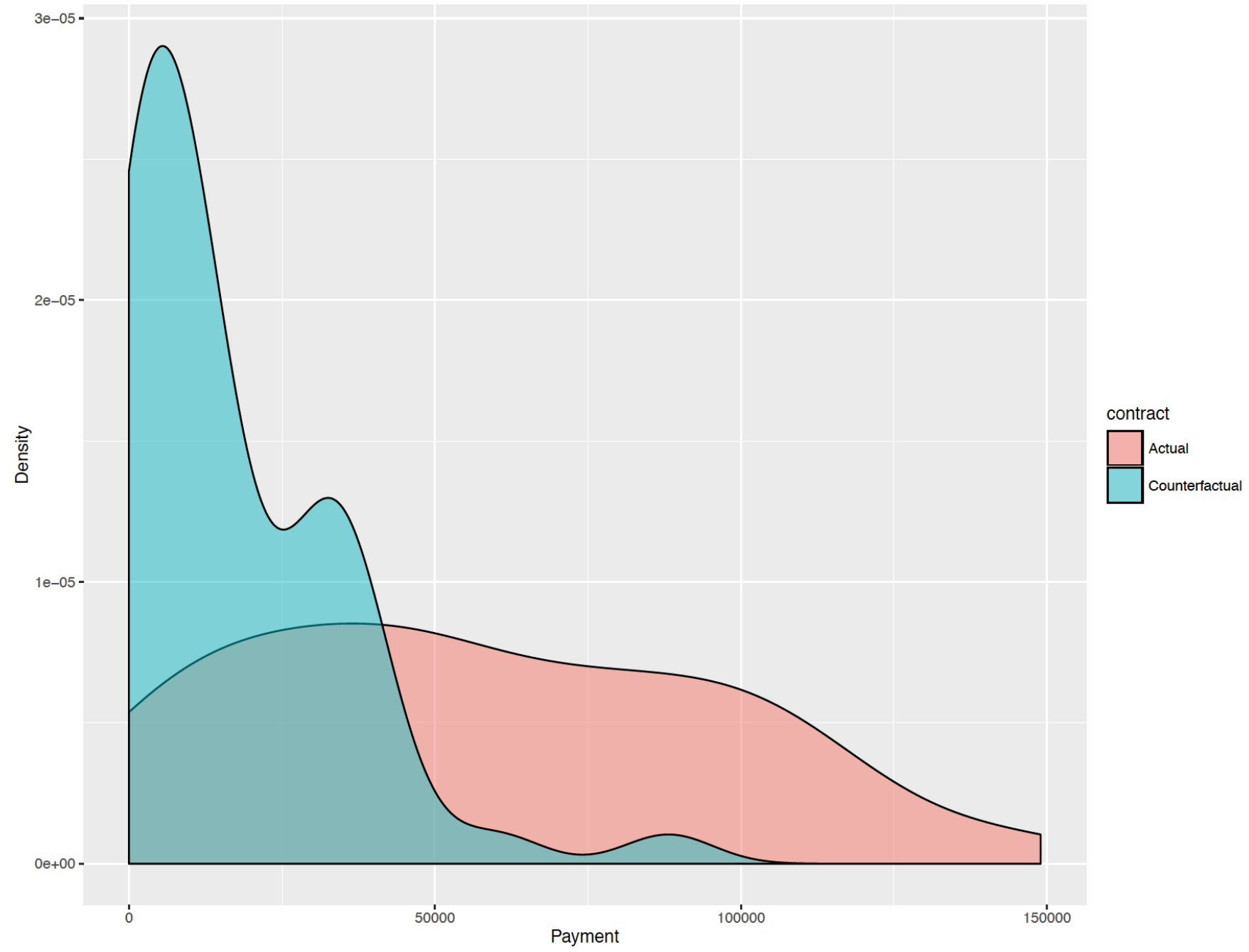

Notes: The distributions show payments made to providers in the output contracts arm. Actual payments are amounts paid out to providers at the end of the experiment, based on their performance on contracted outputs. The distribution labeled "counterfactual" show the payments that might have been made to the same providers if they had been paid based on inputs provided instead. 


\section{FIGURE IV}

PROVIDER EXPECTATIONS ABOUt IMPROVEMENTS IN OUTCOMES

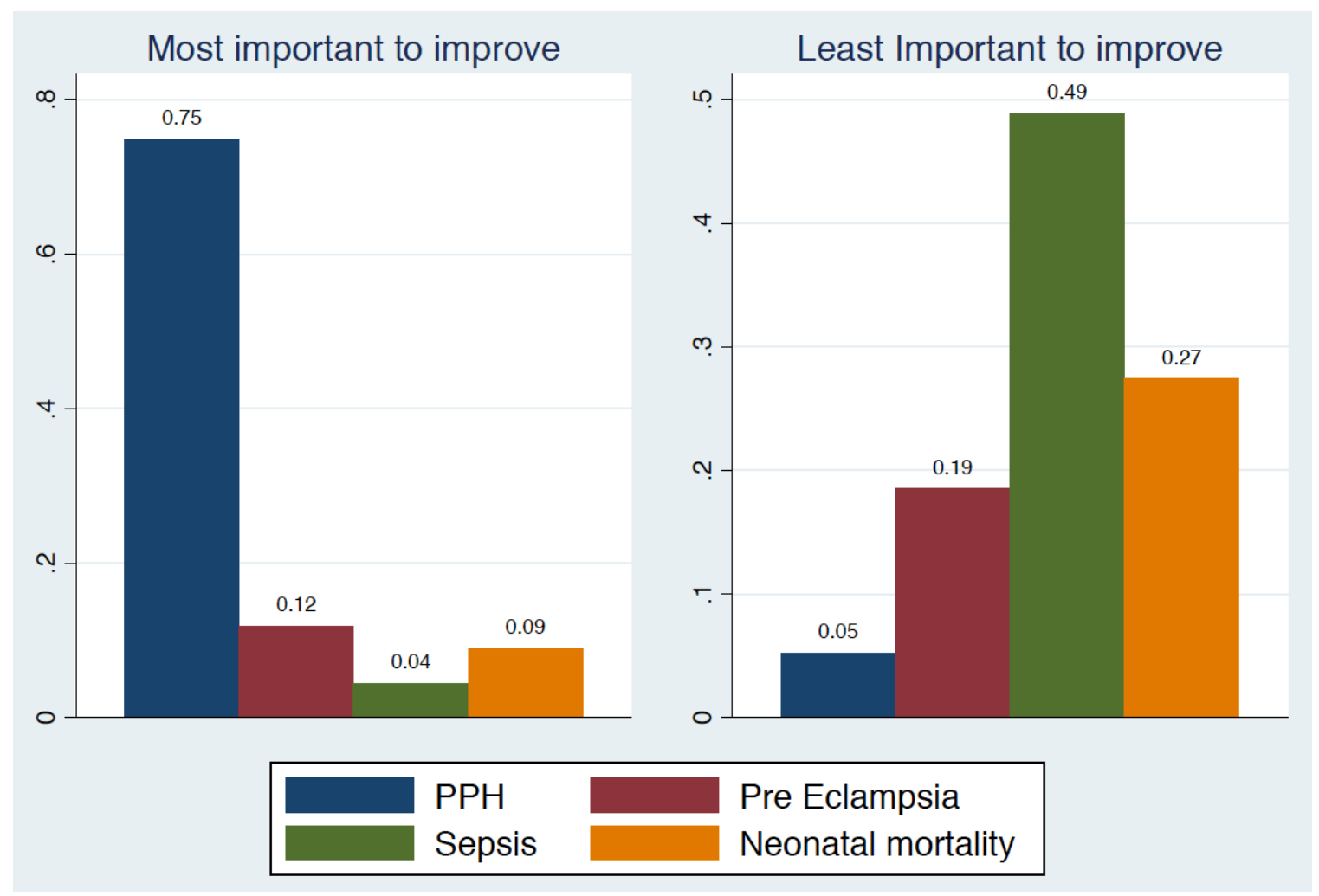

Notes: Figure on the left shows providers' response to question asking them to rank the four outcomes based on which one was most important to improve among their own patients. Bars indicate percentage of providers who responded that a given outcome was most important. The bars in the figure on the right shows providers' responses indicating outcomes that they thought were least important to improve among their patients. 


\section{For Online Publication}

Appendix Materials

For

Mohanan et al (2017) "Different strokes for different folks:

Experimental evidence on the effectiveness of input and output based contracts for health care providers with different levels of skills"

\section{Contents:}

- Appendix Tables 1-4

- Appendix 1: Sample Contracts and Guidelines

- Appendix 2: Calculations and Measurement of Inputs and Outputs 


\section{APPENDIX TABLE A1 \\ JOINT TEST OF ORTHOGONALITY}

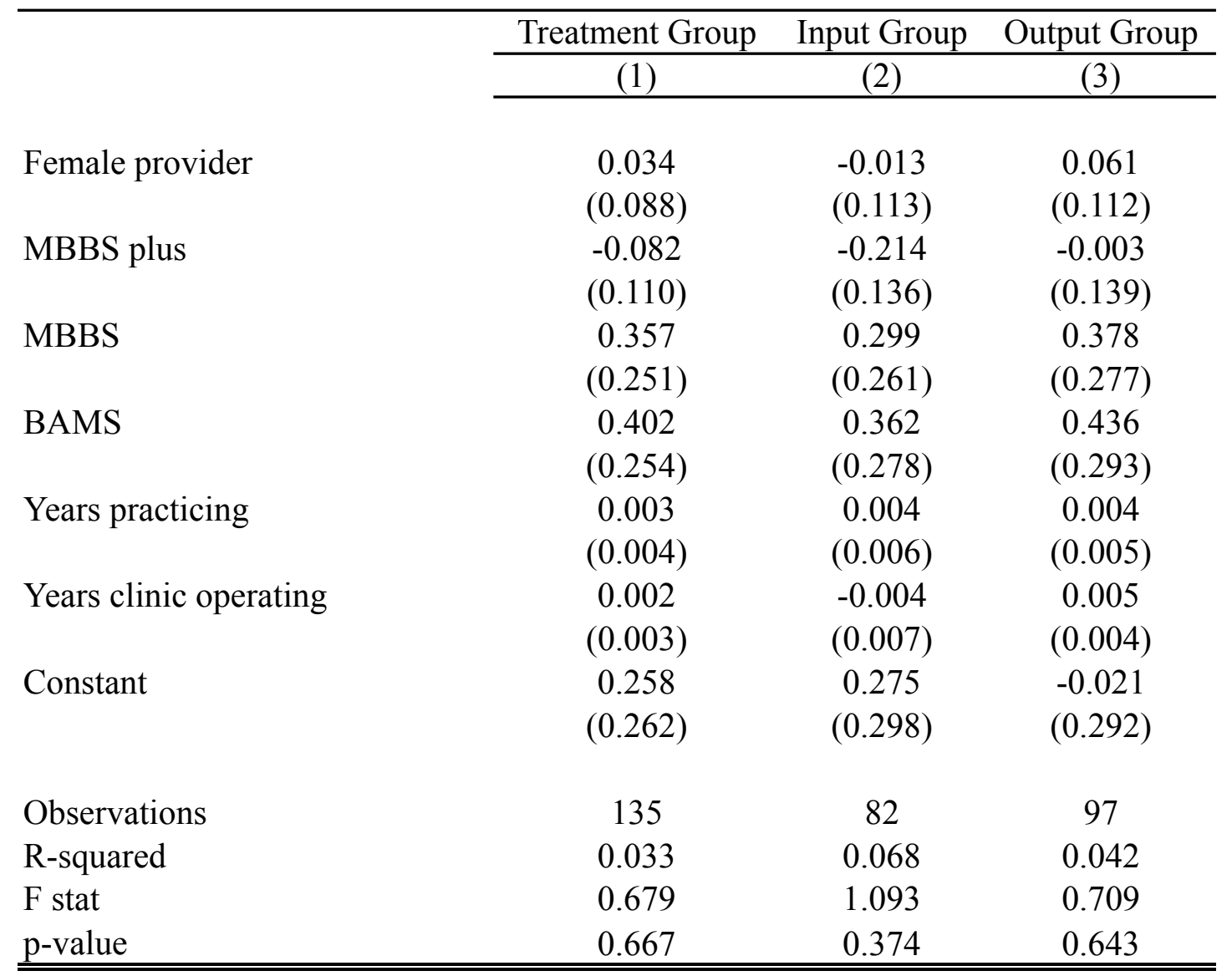

Notes: Robust standard errors are reported in parentheses. The dependent variable in the first specification is an indicator for being in the treatment group, in the second an indicator for being in the input treatment group (excluding those in the output group), and in the third it is an indicator for being in the output group (excluding those in the input group). Provider characteristics are selfreported and measured through interviews with the provider or with a staff member. The following variables measure provider training: MBBS plus is a Bachelor of Medicine degree with a specialization such as obstetrics, MBBS is a Bachelor of Medicine degree with no additional specialization, BAMS is a degree in Ayurveda medicine. The last two rows report the F-statistic and associated p-value associated with a test that all coefficients jointly equal zero. 
APPENDIX TABLE A2

NUMBER OF PROVIDERS, BY TREATMENT GROUP

\begin{tabular}{lccccc}
\hline & Total (N) & Input (N) & Output (N) & Control (N) & $\begin{array}{c}\text { Test of } \\
\text { Equality } \\
\text { (p-value) }\end{array}$ \\
\cline { 2 - 6 } In final sample & 135 & 38 & 53 & 44 & 0.078 \\
Attrition & 5 & 2 & 0 & 3 & \\
\hline Total & 140 & 40 & 53 & 47 & \\
\hline \hline
\end{tabular}

Notes: This table reports counts of the universe of providers identified as eligible for the study by randomly assigned treatment arm. Because providers identified during fieldwork were assigned to study arms based on a randomized list of sequence numbers (unknown to field enumerators, and the sequence was not predictable) it was not possible to ensure an equal number of providers across arms. Providers identified as attritors declined to participate in the study during or after signing the contract. The P-value in the final column is associated with F-tests of joint equality from a regression of treatment indicators on a binary indicator for refusing to participate. 
APPENDIX TABLE A3

IMPACT OF PROVIDER INCENTIVES ON OUTPUTS - CORRECTING FOR MULTIPLE HYPOTHESIS TESTING

\begin{tabular}{|c|c|c|c|c|}
\hline & $\begin{array}{l}\text { Postpartum } \\
\text { Hemorrhage }\end{array}$ & Sepsis & Neonatal Death & Pre-eclampsia \\
\hline & $(1)$ & $(2)$ & $(3)$ & $(4)$ \\
\hline \multirow[t]{2}{*}{ Input incentives } & -0.0843 & 0.0369 & 0.0032 & 0.0573 \\
\hline & $(0.0284)$ & $(0.0253)$ & $(0.0051)$ & $(0.0434)$ \\
\hline Unadjusted p-value & 0.004 & 0.147 & 0.532 & 0.189 \\
\hline Adjusted p-value & 0.010 & 0.441 & 0.611 & 0.188 \\
\hline \multirow[t]{2}{*}{ Output incentives } & -0.0742 & 0.0208 & 0.0079 & 0.0611 \\
\hline & $(0.0294)$ & $(0.0225)$ & $(0.0067)$ & $(0.0328)$ \\
\hline Unadjusted $\mathrm{p}$-value & 0.013 & 0.356 & 0.237 & 0.065 \\
\hline Adjusted p-value & 0.031 & 0.611 & 0.566 & 0.116 \\
\hline District fixed effects & Yes & Yes & Yes & Yes \\
\hline Enumerator fixed effects & Yes & Yes & Yes & Yes \\
\hline Household- and provider-level controls & Yes & Yes & Yes & Yes \\
\hline Control mean & 0.365 & 0.0651 & 0.0121 & 0.179 \\
\hline Observations & 2748 & 2748 & 2748 & 2748 \\
\hline $\mathrm{R}^{2}$ & 0.280 & 0.119 & 0.0576 & 0.271 \\
\hline
\end{tabular}

Notes: Each column reports estimates obtained through an OLD regression; robust standard errors, clustered at the provider level, are reported in parentheses and the associated p-value is reported below. The adjusted p-values are calculated (in italics) using the free step-down resampling method and implemented using code from Soledad Giardili and Marcos Vera Hernandez, accounting for the grouping of PPH, Sepsis and NNM into outputs that are primary influenced by care at the time of delivery across two treatment arms. Each specification includes district and enumerator fixed effects and household-level controls (mother's age and education; household's caste and house type (houseless, kutcha, semi-pucca, or pucca); head of household's religion; mother's history of hypertension, diabetes, asthma, hyper- of hypothyroidism, and convulsions; whether the mother has had a previous stomach surgery; whether it is the mother's first pregnancy, number of previous pregnancies, whether the mother has had a stillbirth or abortion, and number of previous children birthed; whether the household owns land, has no literate adults, and owns a Below Poverty Line card) as well as provider-level controls (primary provider's gender, professional qualifications, number of years in practice, and number of years that the facility has been in operation). All dependent variables are measured through household surveys fielded between November 2013 and July 2014; see appendix for details of measurement. 
APPENDIX TABLE A4

IMPACT OF PROVIDER INCENTIVES ON INPUTS - CORRECTING FOR MULTIPLE HYPOTHESIS TESTING

\begin{tabular}{|c|c|c|c|c|c|}
\hline & Childbirth Care & $\begin{array}{c}\text { Postnatal Maternal } \\
\text { Care } \\
\end{array}$ & Newborn Care & Pregnancy Care & $\begin{array}{c}\text { Postnatal Newborn } \\
\text { Care } \\
\end{array}$ \\
\hline & $(1)$ & $(2)$ & $(3)$ & & \\
\hline \multirow[t]{2}{*}{ Input incentives } & 0.0146 & 0.0422 & -0.0288 & 0.0029 & -0.0065 \\
\hline & $(0.0284)$ & $(0.0392)$ & $(0.0371)$ & $(0.0458)$ & $(0.0577)$ \\
\hline Unadjusted p-value & 0.608 & 0.283 & 0.439 & 0.949 & 0.910 \\
\hline Adjusted p-value & 0.879 & 0.781 & 0.879 & 0.948 & 0.910 \\
\hline \multirow[t]{2}{*}{ Output incentives } & -0.0191 & 0.0773 & -0.0146 & -0.0551 & -0.1386 \\
\hline & $(0.0250)$ & $(0.0358)$ & $(0.0360)$ & $(0.0401)$ & $(0.0437)$ \\
\hline Unadjusted p-value & 0.447 & 0.033 & 0.686 & 0.172 & 0.002 \\
\hline Adjusted p-value & 0.879 & 0.156 & 0.879 & 0.276 & 0.003 \\
\hline District fixed effects & Yes & Yes & Yes & Yes & Yes \\
\hline Enumerator fixed effects & Yes & Yes & Yes & Yes & Yes \\
\hline Household- and provider-level controls & Yes & Yes & Yes & Yes & Yes \\
\hline Control mean & -0.00480 & -0.0876 & -0.00203 & -0.0621 & -0.0680 \\
\hline Observations & 2739 & 2739 & 2740 & 2748 & 2748 \\
\hline $\mathrm{R}^{2}$ & 0.383 & 0.423 & 0.449 & 0.361 & 0.490 \\
\hline
\end{tabular}

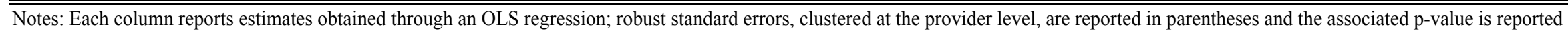

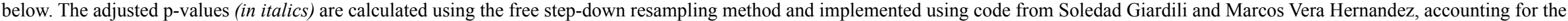

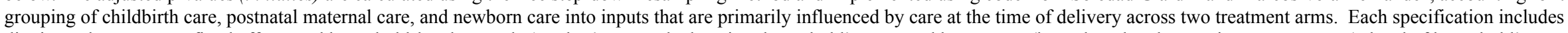
district and enumerator fixed effects and household-level controls (mother's age and education; household's caste and house type (houseless, kutcha, semi-pucca, or pucca); head of household's religion; mother's history of hypertension, diabetes, asthma, hyper- of hypothyroidism, and convulsions; whether the mother has had a previous stomach surgery; whether it is the mother's first

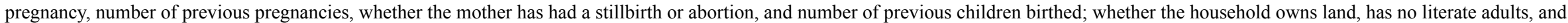

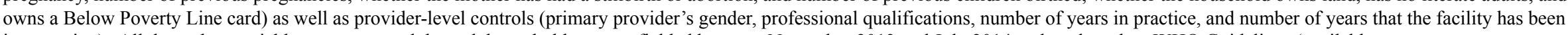
in operation). All dependent variables are measured through household surveys fielded between November 2013 and July 2014 and are based on WHO Guidelines (available at http://whqlibdoc.who.int/hq/2007/who_mps_07.05_eng.pdf); see appendix for details of measurement. 
APPENDIX 1: Contracts

Contents:

1. WHO Guidelines (2009) - given to all providers

2. Sample Input contract

3. Sample Output contract

4. Sample Control contract 
Table 1. Care in pregnancy, childbirth and postpartum period for mother and newborn infant

\begin{tabular}{|c|c|c|c|}
\hline & $\begin{array}{c}\text { Routine care } \\
\text { (offered to all women and babies) }\end{array}$ & $\begin{array}{c}\text { Additional care } \\
\text { (for women and babies with moderately } \\
\text { severe diseases and complications) }\end{array}$ & $\begin{array}{c}\text { Specialized - obstetrical and } \\
\text { neonatal care } \\
\text { (for women and babies with severe } \\
\text { diseases and complications) }\end{array}$ \\
\hline $\begin{array}{l}\text { Pregnancy care - } \\
4 \text { visits } \\
\text { Essential }\end{array}$ & $\begin{array}{l}\text { - Confirmation of pregnancy } \\
\text { - Monitoring of progress of pregnancy } \\
\text { and assessment of maternal and fetal } \\
\text { well-being } \\
\text { - Detection of problems complicating } \\
\text { pregnancy (e.g., anaemia, hypertensive } \\
\text { disorders, bleeding, malpresentations, } \\
\text { multiple pregnancy } \\
\text { - Respond to other reported complaints. } \\
\text { - Tetanus immunization, anaemia } \\
\text { prevention and control (iron and folic } \\
\text { acid supplementation) } \\
\text { - Information and counselling on self } \\
\text { care at home, nutrition, safer sex, } \\
\text { breastfeeding, family planning, healthy } \\
\text { lifestyle } \\
\text { - Birth planning, advice on danger signs } \\
\text { and emergency preparedness } \\
\text { - Recording and reporting } \\
\text { - Syphilis testing }\end{array}$ & $\begin{array}{l}\text { - Treatment of mild to moderate } \\
\text { pregnancy complications: } \\
\text { - } \text { mild to moderate anaemia } \\
\text { - urinary tract infection } \\
\text { - vaginal infection } \\
\text { - Post abortion care and family planning } \\
\text { - Pre-referral treatment of severe } \\
\text { complications } \\
\text { - pre-eclampsia } \\
\text { - eclampsia } \\
\text { - bleeding } \\
\text { - infection } \\
\text { - complicated abortion } \\
\text { - Support for women with special needs } \\
\text { e.g. adolescents, women living with } \\
\text { violence } \\
\text { - Treatment of syphilis (woman and her } \\
\text { partner) }\end{array}$ & $\begin{array}{l}\text { - Treatment of severe pregnancy } \\
\text { complications: } \\
\text { - } \text { anaemia } \\
\text { - } \text { severe pre-eclampsia } \\
\text { - eclampsia } \\
\text { - } \text { bleeding } \\
\text { - } \text { infection } \\
\text { - } \text { other medical complications } \\
\text { - Treatment of abortion complications }\end{array}$ \\
\hline Situational & $\begin{array}{l}\text { - HIV testing and counselling } \\
\text { - Antimalarial Intermittent preventive } \\
\text { treatment (IPT) and promotion of } \\
\text { insecticide treated nets (ITN) } \\
\text { - Deworming } \\
\text { - Assessment of female genital } \\
\text { mutilation (FGM) }\end{array}$ & $\begin{array}{l}\text { - Prevention of mother to child } \\
\text { transmission of HIV (PMTCT) by } \\
\text { antiretroviral treatment (ART), infant } \\
\text { feeding counselling, mode of delivery } \\
\text { advice } \\
\text { - Treatment of mild to moderate } \\
\text { opportunistic infections } \\
\text { - Treatment of uncomplicated malaria }\end{array}$ & $\begin{array}{l}\text { - Treatment of severe HIV infection } \\
\text { - Treatment of complicated malaria }\end{array}$ \\
\hline $\begin{array}{l}\text { Childbirth Care } \\
\text { (labour, delivery, and } \\
\text { immediate postpartum) } \\
\text { Essential }\end{array}$ & $\begin{array}{l}\text { - Care during labour and delivery } \\
\text { - } \quad \text { Diagnosis of labour } \\
\text { monitoring progress of labour, } \\
\text { partograph } \\
\text { - } \quad \text { Providing supportive care and pain } \\
\text { relief } \\
\text { - } \text { Detection of problems } \\
\text { and complications (e.g. } \\
\text { malpresentations, prolonged and/or } \\
\text { obstructed labour, hypertension, } \\
\text { bleeding, and infection) } \\
\text { - } \text { Delivery and immediate care of } \\
\text { the newborn baby, initiation of } \\
\text { breastfeeding } \\
\text { - Newborn resuscitation } \\
\text { - } \quad \text { Active management of third stage } \\
\text { of labour } \\
\text { - Immediate postnatal care of mother } \\
\text { - } \quad \text { Monitoring and assessment of } \\
\text { maternal well being, prevention } \\
\text { and detection of complications (e.g. } \\
\text { hypertension, infections, bleeding, } \\
\text { anaemia) } \\
\text { - Treatment of moderate post- } \\
\text { haemorrhagic anaemia } \\
\text { - Information and counselling on } \\
\text { home self care, nutrition, safe sex, } \\
\text { breast care and family planning } \\
\text { - Postnatal care planning, advice } \\
\text { on danger signs and emergency } \\
\text { preparedness } \\
\text { Recording and reporting }\end{array}$ & $\begin{array}{l}\text { - Treatment of abnormalities and } \\
\text { complications (e.g. prolonged } \\
\text { labour, vacuum extraction; breech } \\
\text { presentation, episiotomy, repair of } \\
\text { genital tears, manual removal of } \\
\text { placenta) } \\
\text { - Pre-referral management of serious } \\
\text { complications (e.g. obstructed labour, } \\
\text { fetal distress, preterm labour, severe } \\
\text { peri- and postpartum haemorrhage) } \\
\text { - Emergency management of } \\
\text { complications if birth imminent } \\
\text { - Support for the family if maternal } \\
\text { death }\end{array}$ & $\begin{array}{l}\text { - Treatment of severe complications } \\
\text { in childbirth and in the immediate } \\
\text { postpartum period, including caesarean } \\
\text { section, blood transfusion and } \\
\text { hysterectomy): } \\
\text { - obstructed labour } \\
\text { - malpresentations } \\
\text { - eclampsia } \\
\text { - } \text { severe infection } \\
\text { - } \text { bleeding } \\
\text { - Induction and augmentation of labour }\end{array}$ \\
\hline Situational & - Vitamin A administration & $\begin{array}{l}\text { Prevention of mother-to-child } \\
\text { transmission of HIV by mode of } \\
\text { delivery, guidance and support for } \\
\text { chosen infant feeding option }\end{array}$ & $\begin{array}{l}\text { - Management of complications related } \\
\text { to FGM }\end{array}$ \\
\hline
\end{tabular}




\begin{tabular}{|c|c|c|c|}
\hline & $\begin{array}{c}\text { Routine care } \\
\text { (offered to all women and babies) }\end{array}$ & $\begin{array}{c}\text { Additional care } \\
\text { (for women and babies with moderately } \\
\text { severe diseases and complications) }\end{array}$ & $\begin{array}{c}\text { Specialized - obstetrical and } \\
\text { neonatal care } \\
\text { (for women and babies with severe } \\
\text { diseases and complications) }\end{array}$ \\
\hline $\begin{array}{l}\text { Postnatal maternal care } \\
\text { (up to } 6 \text { weeks) } \\
\text { Essential }\end{array}$ & $\begin{array}{l}\text { - Assessment of maternal wellbeing } \\
\text { - Prevention and detection of } \\
\text { complications (e.g. infections, bleeding, } \\
\text { anaemia) } \\
\text { - Anaemia prevention and control (iron } \\
\text { and folic acid supplementation) } \\
\text { - Information and counselling on } \\
\text { nutrition, safe sex, family planning } \\
\text { and provision of some contraceptive } \\
\text { methods } \\
\text { - Postnatal care planning, advice } \\
\text { on danger signs and emergency } \\
\text { preparedness } \\
\text { - Provision of contraceptive methods }\end{array}$ & $\begin{array}{l}\text { - Treatment of some problems (e.g. mild } \\
\text { to moderate anaemia, mild puerperal } \\
\text { depression) } \\
\text { - Pre-referral treatment of some } \\
\text { problems (e.g. severe postpartum } \\
\text { bleeding, puerperal sepsis) }\end{array}$ & $\begin{array}{l}\text { - Treatment of all complications } \\
\text { - } \text { severe anaemia } \\
\text { - severe postpartum bleeding } \\
\text { - severe postpartum infections } \\
\text { - } \text { severe postpartum depression } \\
\text { - Female sterilization }\end{array}$ \\
\hline Situational & - Promotion of ITN use & - Treatment of uncomplicated malaria & - Treatment of complicated malaria \\
\hline $\begin{array}{l}\text { Newborn care } \\
\text { (birth and immediate } \\
\text { postnatal) } \\
\text { Essential }\end{array}$ & $\begin{array}{l}\text { - Promotion, protection and support for } \\
\text { breastfeeding } \\
\text { - Monitoring and assessment of } \\
\text { wellbeing, detection of complications } \\
\text { (breathing, infections, prematurity, low } \\
\text { birthweight, injury, malformation) } \\
\text { - Infection prevention and control, } \\
\text { rooming-in } \\
\text { - Eye care } \\
\text { - Information and counselling on home } \\
\text { care, breastfeeding, hygiene } \\
\text { - Postnatal care planning, advice } \\
\text { on danger sign and emergency } \\
\text { preparedness } \\
\text { - Immunization according to the national } \\
\text { guidelines (BCG, HepB, OPV-0) } \\
\text { - Kangaroo Mother Care follow-up }\end{array}$ & $\begin{array}{l}\text { - Care if moderately preterm, low } \\
\text { birth weight or twin: support for } \\
\text { breastfeeding, warmth, frequent } \\
\text { assessment of wellbeing and detection } \\
\text { of complications e.g. feeding difficulty, } \\
\text { jaundice, other perinatal problems } \\
\text { - Kangaroo Mother Care follow-up } \\
\text { - Treatment of mild to moderate } \\
\text { - local infections (cord, skin, eye, } \\
\text { - } \text { thrush) } \\
\text { - } \text { - Prirth injuries } \\
\text { with severe problems: } \\
\text { - } \quad \text { very preterm babies and/or birth } \\
\text { - weight very low } \\
\text { - } \quad \text { severe complications } \\
\text { - } \text { malformations } \\
\text { - Supporting mother if perinatal death }\end{array}$ & $\begin{array}{l}\text { Management of severe newborn } \\
\text { problems - general care for the sick } \\
\text { newborn and management of specific } \\
\text { problems: } \\
\text { - } \text { preterm birth } \\
\text { - } \text { breathing difficulty } \\
\text { - } \text { sepsis } \\
\text { - } \text { severe birth trauma and asphyxia } \\
\text { - } \text { severe jaundice } \\
\text { - Kangaroo Mother Care (KMC) } \\
\text { Management of correctable } \\
\text { malformations }\end{array}$ \\
\hline Situational & - Promotion of sleeping under ITN & $\begin{array}{l}\text { - Presumptive treatment of congenital } \\
\text { syphilis } \\
\text { - Prevention of mother-to-child } \\
\text { transmission of HIV by ART } \\
\text { - Support for infant feeding of maternal } \\
\text { choice }\end{array}$ & $\begin{array}{l}\text { - Treatment of: } \\
\text { - } \text { congenital syphilis } \\
\text { - neonatal tetanus }\end{array}$ \\
\hline $\begin{array}{l}\text { Postnatal newborn care } \\
\text { (visit from/at home) } \\
\text { Essential }\end{array}$ & $\begin{array}{l}\text { - Assessment of infant's wellbeing and } \\
\text { breastfeeding } \\
\text { - Detection of complications and } \\
\text { responding to maternal concerns } \\
\text { - Information and counselling on home } \\
\text { care } \\
\text { - Additional follow-up visits for high } \\
\text { risk babies (e.g. preterm, after severe } \\
\text { problems, on replacement feeding) }\end{array}$ & $\begin{array}{l}\text { - Management of: } \\
\text { - } \text { minor to moderate problems and } \\
\text { - } \text { feeding difficulties } \\
\text { Pre-referral management of severe } \\
\text { problems: } \\
\text { - convulsions } \\
\text { - inability to feed } \\
\text { - Supporting the family if perinatal death }\end{array}$ & $\begin{array}{l}\text { - Management of severe newborn } \\
\text { problems: } \\
\text { - } \text { sepsis } \\
\text { - } \text { other infections } \\
\text { - } \text { jaundice } \\
\text { - failure to thrive }\end{array}$ \\
\hline
\end{tabular}

\section{Routine care}

\section{Specialized - Obstetrical and neonatal care}


Table 2. Place of care, providers, interventions and commodities

\begin{tabular}{|c|c|c|c|c|}
\hline Health care & $\begin{array}{c}\text { Level of } \\
\text { health care }\end{array}$ & Venue / place & Provider & $\begin{array}{l}\text { Interventions and } \\
\text { commodities }\end{array}$ \\
\hline \multicolumn{5}{|c|}{ Pregnancy (antenatal) care } \\
\hline Routine & Primary & $\begin{array}{l}\text { - Health centre in the community } \\
\text { - Outpatient clinic of a hospital } \\
\text { - Outreach home visit }\end{array}$ & $\begin{array}{l}\text { - Health worker with midwifery } \\
\text { skills* }^{\star}\end{array}$ & $\begin{array}{l}\text { - On site tests (Hb, syphilis) } \\
\text { - Maternal health record } \\
\text { - Vaccine } \\
\text { - Basic oral medicines }\end{array}$ \\
\hline Situational & Primary & $\begin{array}{l}\text { - Health centre in the community } \\
\text { - Outpatient clinic of a hospital } \\
\text { - Outreach home visits }\end{array}$ & $\begin{array}{l}\text { - Health worker with midwifery } \\
\text { skills* }^{\star}\end{array}$ & $\begin{array}{l}\text { - On site tests (HIV) } \\
\text { - Insecticide treated nets (ITN) }\end{array}$ \\
\hline Additional & Primary & $\begin{array}{l}\text { - Health centre in the community } \\
\text { - Outpatient clinic of a hospital }\end{array}$ & $\begin{array}{l}\text { - Health worker with midwifery and } \\
\text { selected obstetric and neonatal } \\
\text { skills* }\end{array}$ & $\begin{array}{l}\text { - IV fluids } \\
\text { - Parenteral drugs (antibiotics, } \\
\text { MgS04, antimalarial) } \\
\text { - Manual Vacuum Aspiration (MVA) } \\
\text { - Anti-retroviral therapy (ART) } \\
\end{array}$ \\
\hline Specialized & Secondary & - Hospital & $\begin{array}{l}\text { - Team of doctors, midwives and } \\
\text { nurses }\end{array}$ & $\begin{array}{l}\text { All of the above plus: } \\
\text { - Blood transfusion } \\
\text { - Surgery } \\
\text { - Laboratory tests } \\
\text { - Obstetric care }\end{array}$ \\
\hline \multicolumn{5}{|c|}{ Childbirth (mother and baby) } \\
\hline Routine & Primary & $\begin{array}{l}\text { - Health centre in the community } \\
\text { - Maternity ward of a hospital } \\
\text { - Outreach home care }\end{array}$ & $\begin{array}{l}\text { - Health worker with midwifery } \\
\text { skills* }^{*}\end{array}$ & $\begin{array}{l}\text { - Delivery set } \\
\text { - Oxytocin } \\
\text { - Partograph }\end{array}$ \\
\hline Situational & Primary & $\begin{array}{l}\text { - Health centre in the community } \\
\text { - Maternity ward of a hospital } \\
\text { - Outreach home care }\end{array}$ & $\begin{array}{l}\text { - Health worker with midwifery } \\
\text { skills }^{*}\end{array}$ & - ART \\
\hline Additional & Primary & $\begin{array}{l}\text { - Health centre in the community } \\
\text { - Maternity ward of a hospital }\end{array}$ & $\begin{array}{l}\text { - Health worker with midwifery and } \\
\text { selected obstetric and neonatal } \\
\text { skills* }\end{array}$ & $\begin{array}{l}\text { - Vacuum extraction } \\
\text { - Manual removal of placenta } \\
\text { - Repair of genital tears } \\
\text { - IV fluids } \\
\text { - MgS04, parenteral uterotonics, and } \\
\text { antibiotics } \\
\text { - Newborn resuscitation }\end{array}$ \\
\hline Specialized Mother & Secondary & - Hospital & $\begin{array}{l}\text { Team of doctors, midwives and } \\
\text { nurses with neonatal care skills }\end{array}$ & $\begin{array}{l}\text { All of the above plus: } \\
\text { - Surgery } \\
\text { - Blood transfusion }\end{array}$ \\
\hline $\begin{array}{l}\text { Specialized } \\
\text { Newborn }\end{array}$ & Secondary & - Hospital & $\begin{array}{l}\text { - Team of doctors and nurses with } \\
\text { obstetric and nursing skills }\end{array}$ & $\begin{array}{l}\text { - Oxygen } \\
\text { - IV fluids } \\
\text { - Parenteral antebiotics } \\
\text { - Blood transfusion } \\
\text { - Laboratory - biochemical and } \\
\text { microbiology (small blood samples) }\end{array}$ \\
\hline \multicolumn{5}{|c|}{ Postpartum (mother), postnatal (newborn infant) } \\
\hline Routine & Primary & $\begin{array}{l}\text { - Health centre in the community } \\
\text { - Outpatient clinic of a hospital } \\
\text { - Outreach home visit }\end{array}$ & $\begin{array}{l}\text { - Health worker with midwifery } \\
\text { skills* }\end{array}$ & $\begin{array}{l}\text { - On site tests (Hb, syphilis) } \\
\text { - Vaccines } \\
\text { - Basic oral medicines }\end{array}$ \\
\hline Situational & Primary & $\begin{array}{l}\text { - Health centre in the community } \\
\text { - Outpatient clinic of a hospital }\end{array}$ & $\begin{array}{l}\text { - Health worker with midwifery } \\
\text { skills* }^{\star}\end{array}$ & $\begin{array}{l}\text { - On site tests (HIV) } \\
\text { - ART }\end{array}$ \\
\hline Additional & Primary & $\begin{array}{l}\text { - Health centre in the community } \\
\text { - Outpatient clinic of a hospital }\end{array}$ & $\begin{array}{l}\text { - Health worker with midwifery and } \\
\text { selected obstetric and neonatal } \\
\text { skills* }\end{array}$ & $\begin{array}{l}\text { - IV fluids } \\
\text { - Parenteral drugs (antibiotics, } \\
\text { MgS04, antimalarial) } \\
\text { - Manual removal of placenta }\end{array}$ \\
\hline Specialized Mother & Secondary & - Hospital & $\begin{array}{l}\text { - Team of doctors, midwives and } \\
\text { nurses }\end{array}$ & $\begin{array}{l}\text { All of the above plus: } \\
\text { - Blood transfusion } \\
\text { - Surgery } \\
\text { - Laboratory tests } \\
\text { - Obstetric care }\end{array}$ \\
\hline $\begin{array}{l}\text { Specialized } \\
\text { Newborn }\end{array}$ & Secondary & - Hospital & $\begin{array}{l}\text { - Team of doctors, midwives and } \\
\text { nurses with neonatal skills }\end{array}$ & $\begin{array}{l}\text { - Oxygen } \\
\text { - IV fluids } \\
\text { - Parenteral antebiotics } \\
\text { - Blood transfusion } \\
\text { - Laboratory - biochemical and } \\
\text { microbiology (small samples) }\end{array}$ \\
\hline
\end{tabular}


Table 3. Home care, family, community and workplace support for the woman
during pregnancy and childbirth and for the newborn infant

\begin{tabular}{|c|c|c|}
\hline & Home/family & Community and workplace \\
\hline Pregnancy & $\begin{array}{l}\text { - Safe and nutritive diet } \\
\text { - Safe sexual practices } \\
\text { - Support for quitting smoking } \\
\text { - Protection from passive tobacco smoking } \\
\text { - Support for avoiding hard work } \\
\text { - Planning for birth, and emergencies -mother and baby } \\
\text { - Knowledge and support for the birth and emergency plan } \\
\text { - Recognition of labour and danger signs } \\
\text { - Support for compliance with preventive treatments } \\
\text { - Support / accompaniment for pregnancy care visits } \\
\text { - Adolescent girls encouraged to continue going to school } \\
\text { - Participation in improving quality of services } \\
\text { - Participation in transport and financing scheme }\end{array}$ & $\begin{array}{l}\text { - Maternity protection } \\
\text { - Time off for antenatal care visits } \\
\text { - Safe and clean workplace } \\
\text { - Tobacco free working environment } \\
\text { - Pregnant adolescents kept at school }\end{array}$ \\
\hline Situational & - Support for taking ART and for coping with its side effects & - Support for HIV positive women \\
\hline Childbirth & $\begin{array}{l}\text { - Accompanying and supporting the woman in childbirth } \\
\text { - Support and care for the rest of the family } \\
\text { - Organize transport and financial support }\end{array}$ & $\begin{array}{l}\text { - Support for the family during childbirth and immediate } \\
\text { postpartum }\end{array}$ \\
\hline $\begin{array}{l}\text { Postpartum and } \\
\text { beyond }\end{array}$ & $\begin{array}{l}\text { - Support for exclusive breastfeeding/replacement feeding } \\
\text { - Personal hygiene } \\
\text { - Safe disposal / washing of pads } \\
\text { - Support for rest and less work load } \\
\text { - Safe and nutritive diet } \\
\text { - Safe sexual practices } \\
\text { - Motivation for prescribed treatments } \\
\text { - Recognition of dangers signs, including blues / depression } \\
\text { - Optimal pregnancy spacing } \\
\text { - Reporting birth and death (vital registration) } \\
\text { - Participation in improving quality of services } \\
\text { - Participation in transport and financing scheme }\end{array}$ & $\begin{array}{l}\text { - Maternity leave } \\
\text { - Breastfeeding breaks } \\
\text { - Time off for postpartum and baby care visits } \\
\text { - If mother referred to hospital, support that she is ac- } \\
\text { companied with the baby }\end{array}$ \\
\hline $\begin{array}{l}\text { Newborn and young } \\
\text { infant }\end{array}$ & $\begin{array}{l}\text { - Exclusive breastfeeding } \\
\text { - Hygiene (cord care, washing, clothes) } \\
\text { - Avoiding contacts with sick family members } \\
\text { - Clean, warm and quiet place, tobacco and fire smoke free } \\
\text { - Extra care for small babies (preterm, low birth weight) including KMC } \\
\text { - Support for routine and follow up visits } \\
\text { - Motivation for home treatment of minor problems } \\
\text { - Recognition of danger signs } \\
\text { - Safe disposal of baby stool } \\
\text { - Care seeking at health facility or hospital }\end{array}$ & $\begin{array}{l}\text { - Promotion, protection and support for breast feeding. } \\
\text { - Keeping mother with the baby in hospital for breast- } \\
\text { feeding } \\
\text { - Supporting the family during maternal absence } \\
\text { - Support for referral care for sick newborn. }\end{array}$ \\
\hline Situational & - Sleeping under ITN & \\
\hline
\end{tabular}

Table 4. Care for the woman before and between pregnancies

\begin{tabular}{l|l|l|l}
\hline & \multicolumn{1}{|c|}{ Care by health services } & \multicolumn{1}{c}{ Home/family } & \multicolumn{1}{c}{ Community and workplace } \\
\hline Adolescence & $\begin{array}{l}\text { - Immunization according to national } \\
\text { policy (tetanus and rubella) } \\
\text { - Family planning } \\
\text { - HIV prevention including VCT }\end{array}$ & $\begin{array}{l}\text { - Delayed childbearing } \\
\bullet \text { Healthy lifestyle } \\
- \text { Balanced diet, including iodized salt }\end{array}$ & $\begin{array}{l}\text { Education } \\
\text { Information on prevention of HIV and } \\
\text { STI infections }\end{array}$ \\
\hline $\begin{array}{l}\text { All women of } \\
\text { reproductive age }\end{array}$ & $\begin{array}{l}\text { - Family planning } \\
\text { - Assessment and management of STls } \\
\text { - HIV prevention including testing and } \\
\text { counselling }\end{array}$ & & \\
\hline
\end{tabular}

Table 5. Pregnant women not wanting child

\begin{tabular}{l|l|l|c}
\hline & \multicolumn{1}{|c|}{ Care by health services } & Home/family & Community and workplace \\
\hline $\begin{array}{l}\text { Pregnant woman not } \\
\text { wanting child }\end{array}$ & $\begin{array}{l}\text { - Safe abortion (where legal) } \\
\text { - Post-abortion care and family planning }\end{array}$ & $\bullet$ Care for unwanted pregnancy & \\
\hline
\end{tabular}




\section{Integrated Management of Pregnancy and Childbirth (IMPAC) Guidelines}

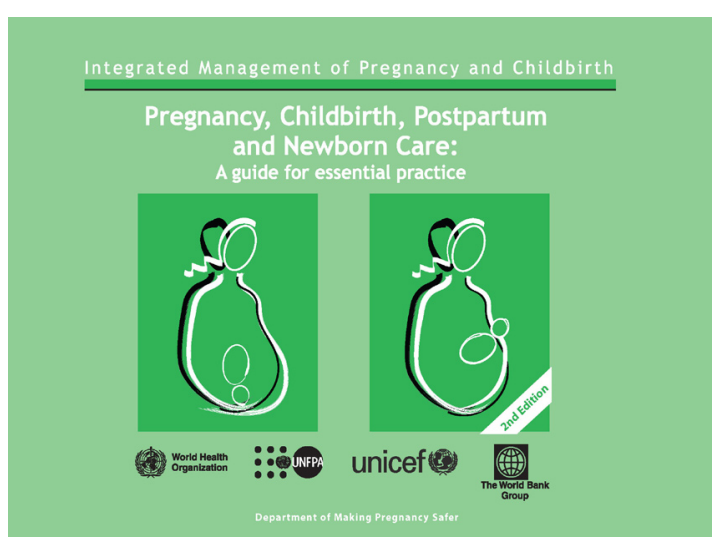

Pregnancy, childbirth, postpartum and newborn care: a guide for essential practice

This guide provides evidence-based recommendations to guide health-care professionals in the management of women during pregnancy, childbirth and postpartum, and post abortion, and newborns during their first week of life. It is a guide for clinical decision-making. It facilitates the collection, analysis, classification and use of relevant information by suggesting key questions, essential observations and/or examinations, and recommending appropriate research-based interventions. It promotes the early detection of complications and the initiation of early and appropriate treatment, including timely referral, if necessary.

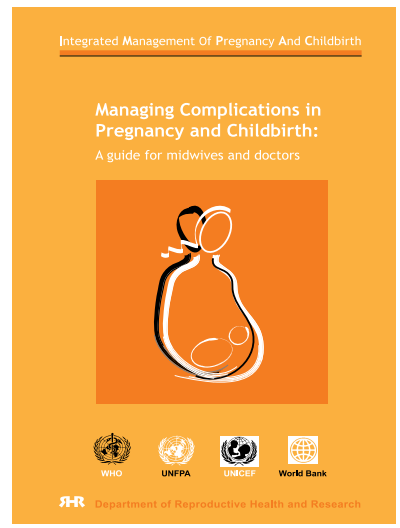

\section{Managing complications in pregnancy and childbirth: a guide for midwives and doctors}

This easy-to-use manual is arranged by symptoms (e.g. vaginal bleeding in early pregnancy). Because this symptom-based approach is different from most medical texts, which are arranged by disease, corresponding diagnosis tables are provided. Links have been used extensively to facilitate navigation between symptoms and diagnoses. The clinical action steps are based on clinical assessment with limited reliance on laboratory or other tests and most can be performed in a variety of clinical settings (e.g. district hospital or health centre).

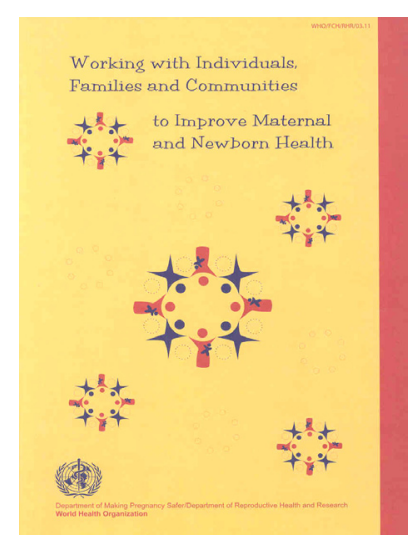

Working with individuals, families and communities to improve maternal and newborn health

The purpose of this document is to establish a common vision and approach, as well as to identify the role of maternal and newborn health programmes, for working with women, men, families and communities to improve maternal and newborn health. Part 1 of the document defines the concepts, values and guiding principles. Part 2 presents strategies, settings, and priority areas for intervention. Part 3 proposes an implementation process; and, finally, Part 4 considers the role and functions of WHO.

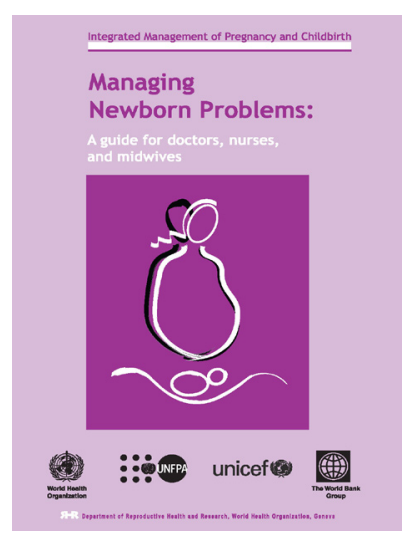

\section{Managing newborn problems: a guide for doctors, nurses and midwives}

This guide is designed to assist countries with limited resources in their efforts to reduce neonatal mortality and to ensure care for newborn babies with problems due to complications of pregnancy and childbirth, such as asphyxia, sepsis, and low birth weight or preterm birth. The main section of this guide is arranged by clinical signs or findings, which facilitates early identification of illness, and provides up-to-date guidelines for clinical management. 
INPUT CONTRACT 
OFFER OF REWARD PAYMENTS FOR IMPROVEMENT IN PROVISION OF MATERNAL AND NEONATAL HEALTH CARE

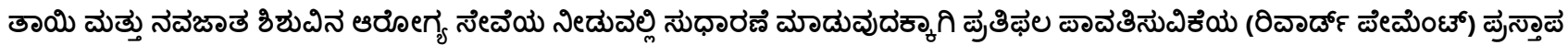

Date:

Dr.

Dear

Thank you for taking the time today to learn about our ongoing project to develop innovative ways to partner with private sector doctors in Karnataka. This project has been jointly funded by the World Bank, the International Initiative for Impact Evaluation (3ie), the UK Department for International Development (DFID), and the Government of Karnataka and is focused on the health of women and infants in the time surrounding pregnancy, delivery, and the months following.

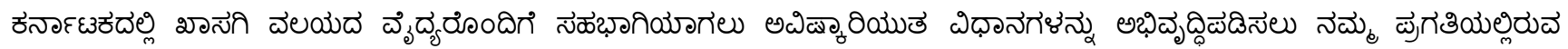

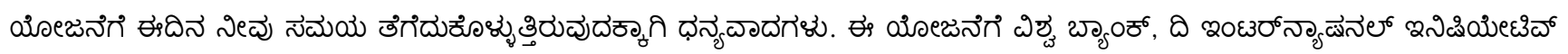

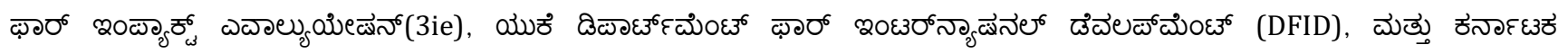

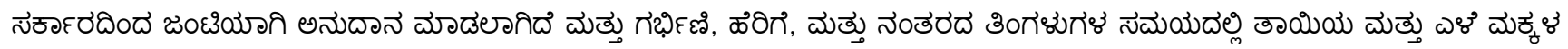

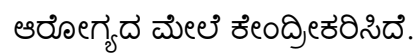

As part of this project, Sambodhi Research \& Communications Pvt. Ltd (New Delhi), in collaboration with COHESIVE-India ${ }^{1}$, is pleased to offer you reward payments based on the quality of medical care that your facility provides to pregnant women and infants. Quality of care is measured in terms of clinically relevant actions to promote a healthy pregnancy and delivery for mothers and infants. Following the WHO guidelines that we are pleased to share with you today, these actions fall into the following five domains:

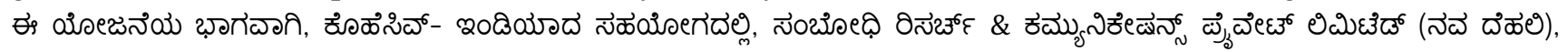

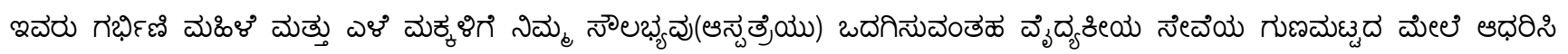

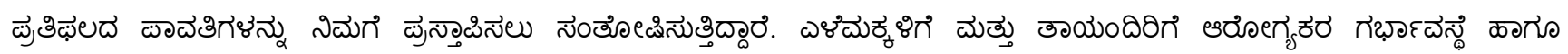

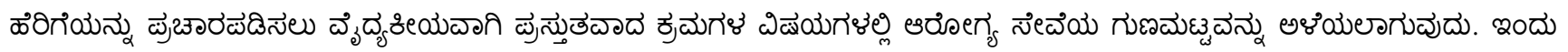
నిదై

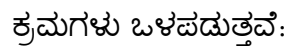

${ }^{1}$ COHESIVE-India is a collaboration of researchers from Duke Universitv (USA). Stanford Universitv (USA). Universitv 
1. Pregnancy care గోభి६ణి ఆర్ృార

2. Childbirth care $\vec{\omega}) \vec{\omega} \omega$ ఆర్ృ 8

3. Postnatal maternal care

4. Newborn care, నేదెజాత్ కిరు ఆరైశి,

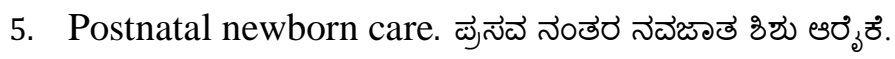

Structure of Payments: ఱాదేతిగెళ రజజన:

\section{Participation (today's visit)}

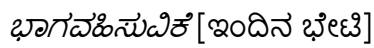

- You will receive Rs. 2,500 for agreement to participate in the reward payments program and for participation in a brief survey; you will be provided with documentation (paper and CD) on standard obstetric care and management of common obstetric complications and a general explanation of the program.

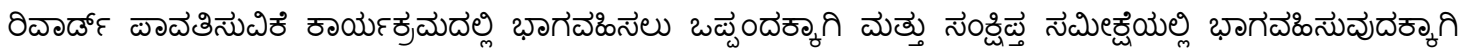

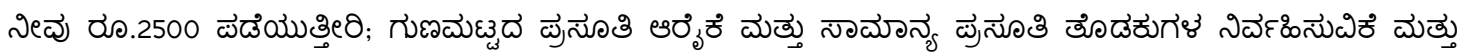
రాయభణర్లదుద సౌదోన్య

2. Discussion of Strategies (1 - 2 months from now)

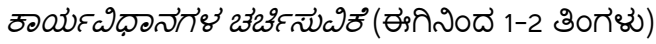

- You will receive an additional Rs. 2,500 for discussing the strategies that you might pursue to provide the highest quality of care to pregnant women and infants who may come to you for care, and for participation in a brief survey.

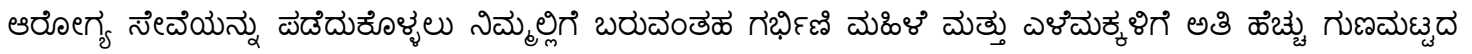

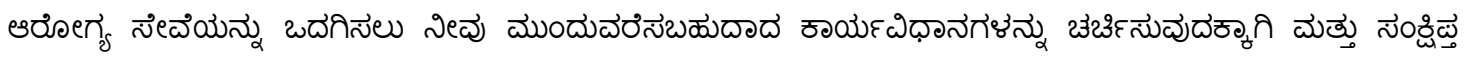

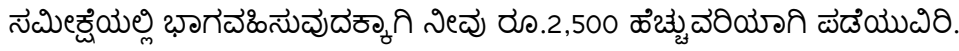

3. Reward Payment (12 - 14 months from now)

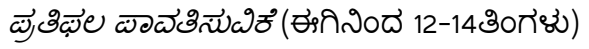

- You will receive Rs. 2,500 for participation in a brief survey and a final reward payment up to Rs. $1,69,750^{2}$, based on your facility's performance in the five identified quality of care domains.

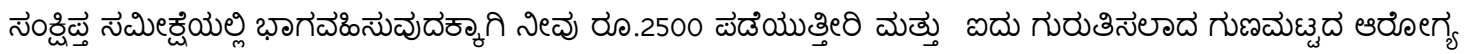

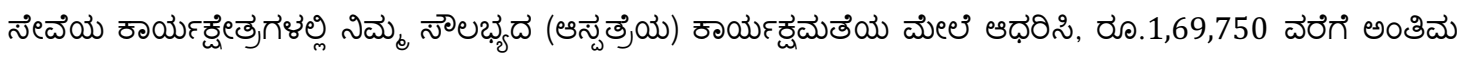

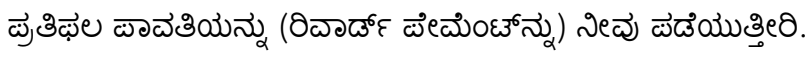

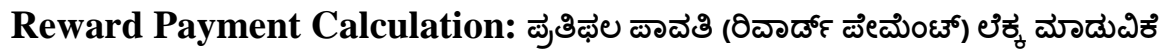

The five domains of care are based on the priorities of the fourth and fifth Millennium Development Goals (MDGs) related to maternal and child health, with consideration for the specific health challenges in Karnataka and India in general. Performance in each domain is measured as the share of your patients receiving all of the recommended care that falls under that domain, as identified in the WHO pamphlet.

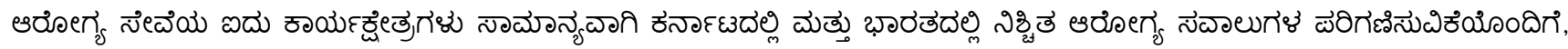

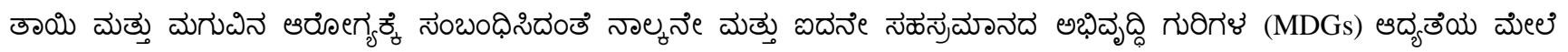

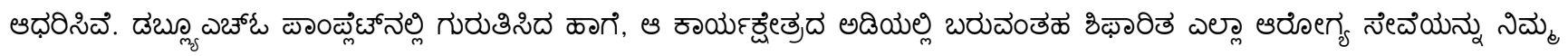

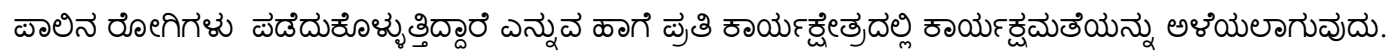

\footnotetext{
2 The amount for the final reward payment is linked to the USD-INR exchange rate and may vary slightly depending on the USD-INR exchange rate at the time of the third visit.
} 
Column 2 of the table below lists the minimum performance levels in each domain that should already be easily attainable by the most doctors in Karnataka. Coverage at or below these Minimum Performance Levels will not receive any reward payments. Column 3 lists the amount of reward that will be paid for every percentage point in performance over the Minimum Performance Level listed in Column 2. The performance reward amounts in Column 3 take into account the relative difficulty of providing high quality care in each of the domains in Karnataka.

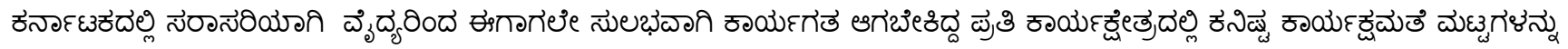

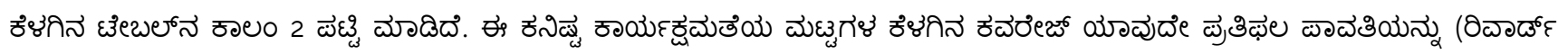

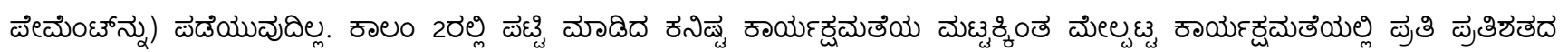

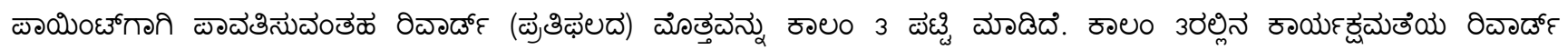

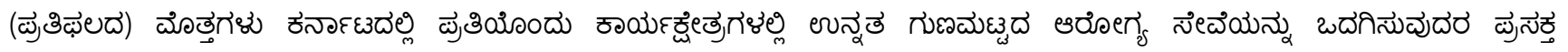

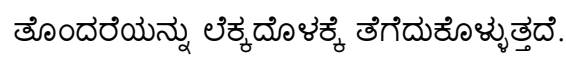

Column 4 lists the Target Performance Levels that experts believe all doctors should be able to achieve with concerted effort to follow the WHO guidelines. Finally, Column 5 lists the amount that would be earned in each domain if these Target Performance Levels are obtained. (Note that reward payments could exceed those listed in Column 5 if performance levels exceed those of the targets in Column 4.)

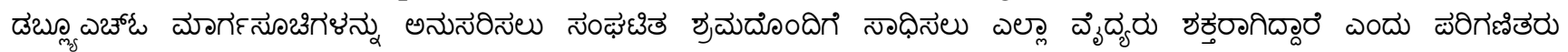

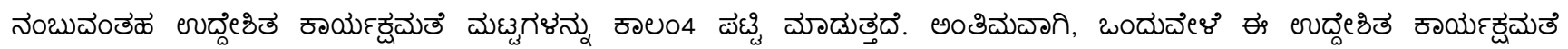

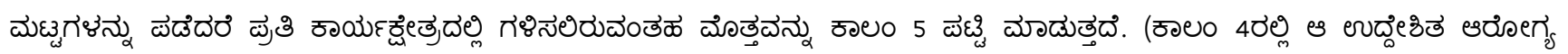

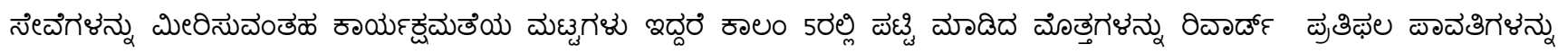

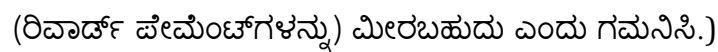

Table 1:

\begin{tabular}{|c|c|c|c|c|}
\hline 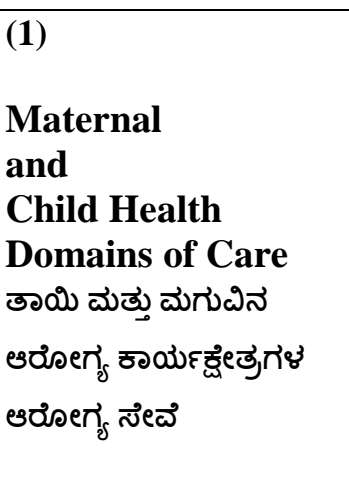 & 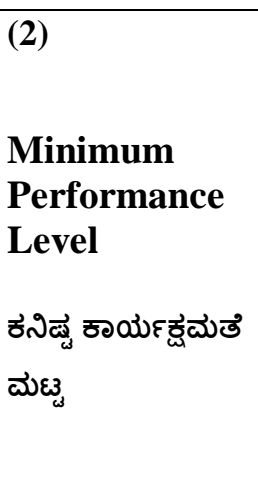 & 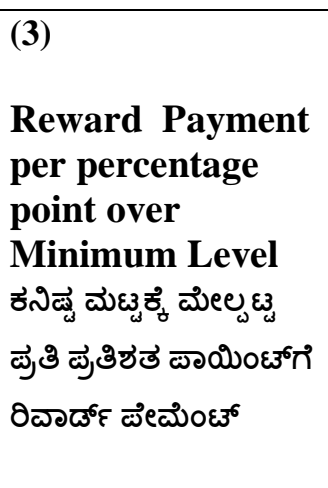 & 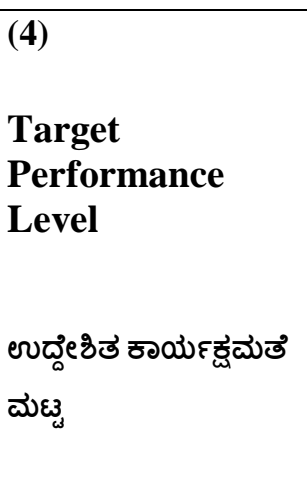 & 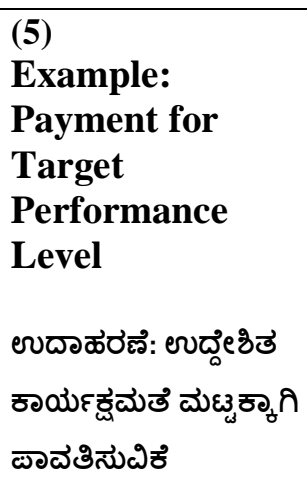 \\
\hline $\begin{array}{l}\text { 1. Pregnancy care } \\
\text { గిభి६ణి ఆర్ృిరే }\end{array}$ & $85 \%$ & Rs. 3,700 & $95 \%$ & Rs. 37,000 \\
\hline $\begin{array}{l}\text { 2. Childbirth care } \\
\vec{\omega} \vec{\omega} \vec{\sim} \vec{\omega} \Theta_{3} \vec{\jmath}\end{array}$ & $65 \%$ & Rs. 750 & $85 \%$ & Rs. 15,000 \\
\hline 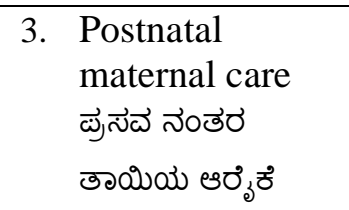 & $50 \%$ & Rs. 450 & $75 \%$ & Rs. 11,250 \\
\hline $\begin{array}{ll}\text { 4. } & \text { Newborn care } \\
\text { నేదెడాత కిరు ఆర్ృృళ }\end{array}$ & $80 \%$ & Rs. 1,850 & $90 \%$ & Rs. 18,500 \\
\hline 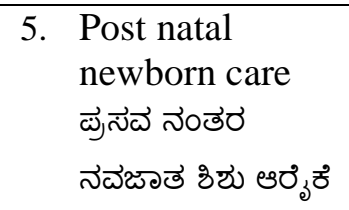 & $70 \%$ & Rs. 950 & $85 \%$ & Rs. 14,250 \\
\hline
\end{tabular}


For example, if your facility's performance in Domain 1: Pregnancy Care is measured at 90\%, your reward payment in that category will be Rs. $18,500(5 *$ Rs. 3,700); if it is $95 \%$, your reward payment in that category will be Rs. $37,000(10 *$ Rs. 3,700$)$; and if it is $100 \%$, your reward payment in that category will be Rs. 55,500 (15* Rs. 3,700).

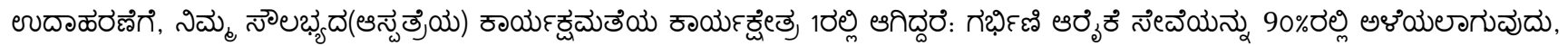

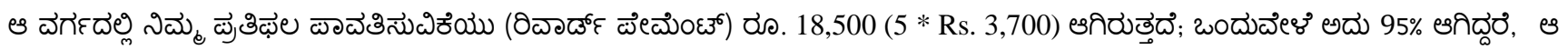

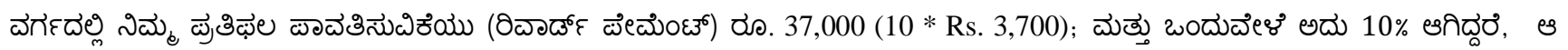

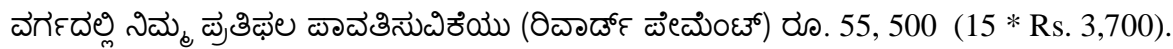

On the other hand, if your facility's performance in Domain 1: Pregnancy Care is measured at 70\% (or any other level at or below 85\%), you would not receive any reward payment for this domain because it is below the threshold set in Column 2. Note that performance below the thresholds set in Column 2 will never detract from your overall payout, and that you will never be in a position to owe money.

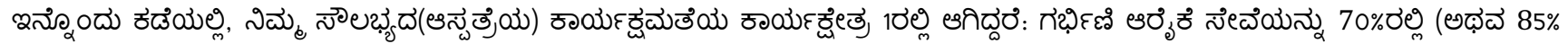

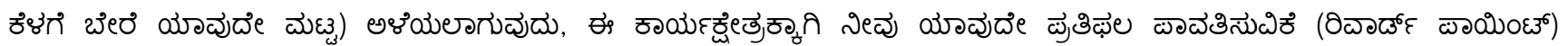

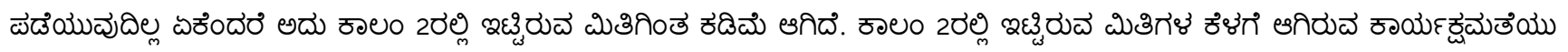

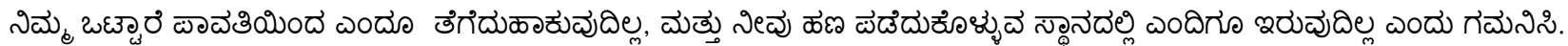

A graphical representation of the reward payment strategy is shown in Figure 1 below.

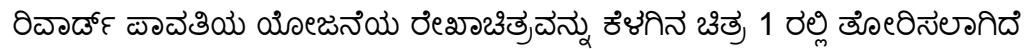

Figure 1:

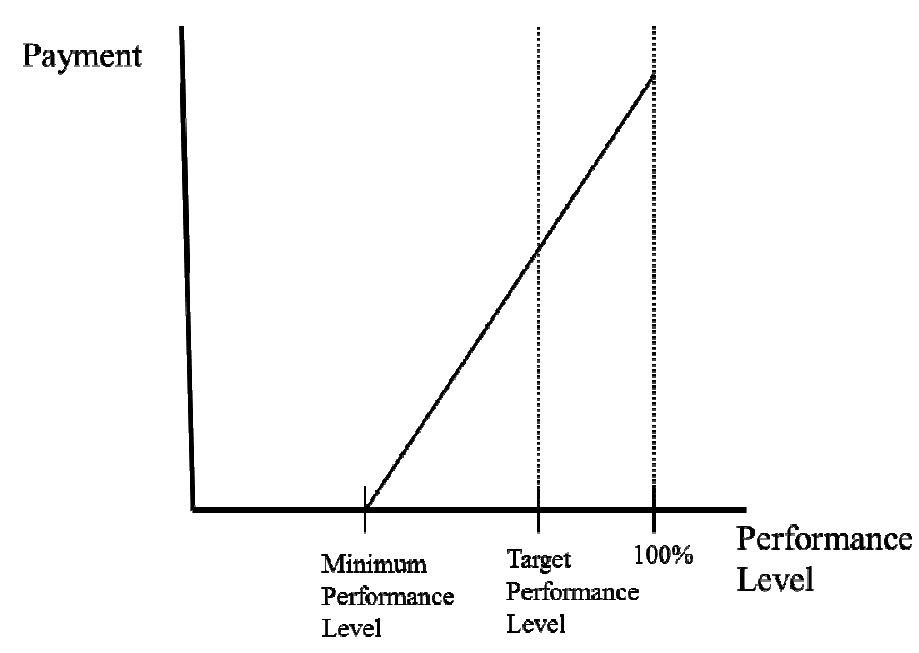

Over the next year, the quality of care provided in each of these domains will be measured through interviews with your patient population.

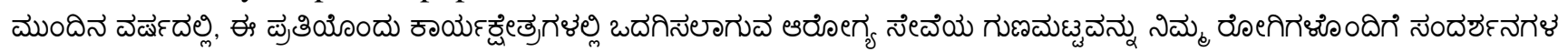

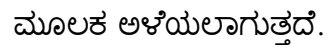

NOTE: It is very important that (a) patients are not refused treatment from your facility other than in medically appropriate referrals, and (b) we are able to work with your administrative staff to follow up on all patients who deliver at your facility.

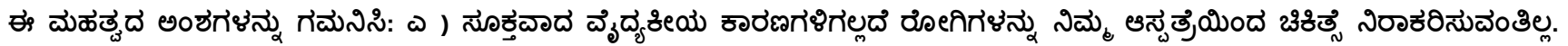

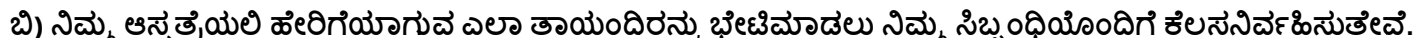


An independent research team will regularly visit the communities around your facility. Any extraordinary patterns of referral will result in investigations into the reasons for these referrals. If it is found that women have been turned away from your facility for any reason other than medically appropriate referrals to highertier facilities, then this can have an implication on your agreement with us and as a result no further payments will be made. Similarly, if it is found that there is selective reporting of the births that have taken place in your facility, then this can have an implication on your agreement with us and as a result no further payments will be made.

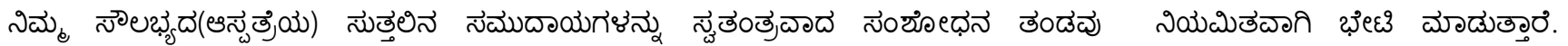

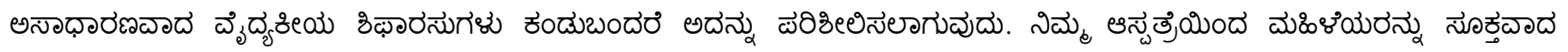

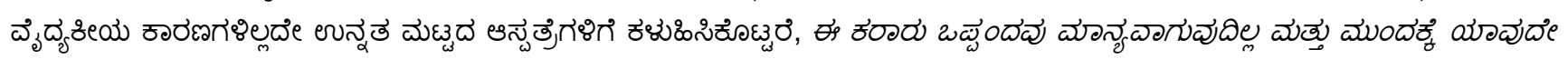

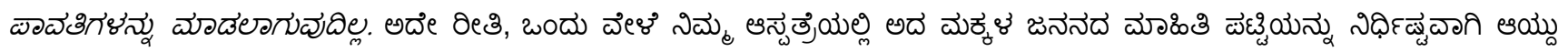

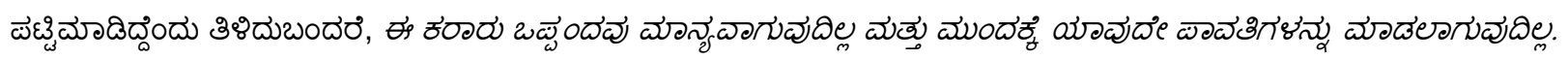

Please do not hesitate to contact us in case you have any questions or require further information.

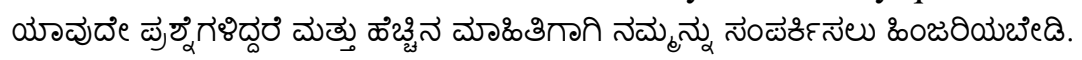

Thank you for your cooperation. We look forward to working with you.

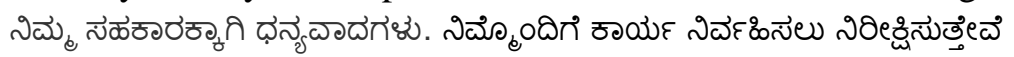

Sincerely, ఇo3e,

Kultar Singh
పుల్డిరా సింగా

Chief Executive Officer

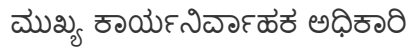

Anil M. Lobo

అనిలో ఉదో. లిలకబి

Manager - Research

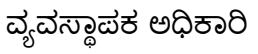

Sambodhi Research and Communications Pvt. Ltd.

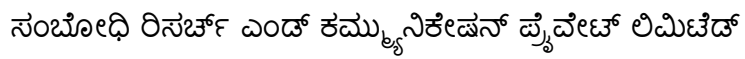

O-2, 2nd Floor, Lajpat Nagar-II, New Delhi 110024

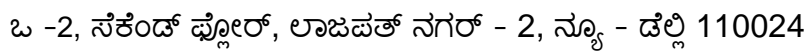

I agree to participate in the above mentioned study.

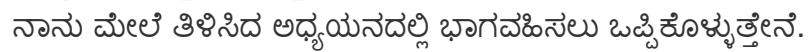

Name of Provider (Print)

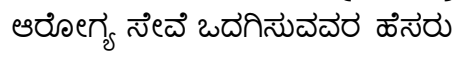

\author{
Signature of Provider
}

$\vec{\sim} b 0$
Date

దనాంక 
WHO Recommended Interventions for Improving Maternal and Newborn Health Routine Care in Pregnancy, Childbirth and Postpartum Period for Mother and Newborn Infant

\begin{tabular}{|c|c|}
\hline $\begin{array}{l}\text { Pregnancy } \\
\text { care - } \\
4 \text { visits }\end{array}$ & $\begin{array}{l}\text { - Confirmation of pregnancy } \\
\text { - Monitoring of progress of pregnancy and assessment of maternal and fetal well-being } \\
\text { - Detection of problems complicating pregnancy (e.g., anemia, hypertensive disorders, } \\
\text { bleeding, malpresentations, multiple pregnancy) } \\
\text { - Respond to other reported complaints } \\
\text { - Tetanus immunization, anemia prevention and control (iron and folic acid } \\
\text { - } \text { Inforplementation) } \\
\text { - } \text { family planning, healthy lifestyle } \\
\text { - Recording and reporting } \\
\text { - Syphilis testing }\end{array}$ \\
\hline $\begin{array}{l}\text { Childbirth } \\
\text { Care (labor, } \\
\text { delivery, and } \\
\text { immediate } \\
\text { postpartum) }\end{array}$ & $\begin{array}{l}\text { - Care during labor and delivery } \\
\circ \text { Diagnosis of labor } \\
\circ \text { Monitoring progress of labor, maternal and fetal well-being with partograph } \\
\circ \text { Providing supporting care and pain relief } \\
\circ \text { Detection of problems and complications (e.g. malpresentations, prolonged } \\
\text { and/or obstructed labor, hypertension, bleeding, and infection) } \\
\circ \text { Delivery and immediate care of the newborn baby, initiation of breastfeeding } \\
\circ \text { Newborn resuscitation } \\
\circ \text { Active management of third stage of labor } \\
\text { - Immediate postnatal care of mother } \\
\circ \text { Monitoring and assessment of maternal well being, prevention and detection } \\
\text { of complications (e.g. hypertension, infections, bleeding, anemia) } \\
\circ \text { Treatment of moderate post-hemorrhagic anemia } \\
\circ \text { Information and counseling on home self care, nutrition, safe sex, breast care } \\
\quad \text { and family planning } \\
\circ \text { Postnatal care planning, advice on danger signs and emergency preparedness } \\
\text { Recording and reporting }\end{array}$ \\
\hline $\begin{array}{l}\text { Postnatal } \\
\text { maternal } \\
\text { care } \\
\text { (up to } 6 \\
\text { weeks) }\end{array}$ & $\begin{array}{l}\text { - Assessment of maternal wellbeing } \\
\text { - Prevention and detection of complications (e.g. infections, bleeding, anemia) } \\
\text { - Anemia prevention and control (iron and folic acid supplementation) } \\
\text { - Information and counseling on nutrition, safe sex, family planning, and provision of } \\
\text { - } \text { some contraceptive methods } \\
\text { - Prostnatal care planning, advice on danger signs and emergency preparedness } \\
\text { Provision of contraceptive methods }\end{array}$ \\
\hline $\begin{array}{l}\text { Newborn } \\
\text { care } \\
\text { (birth and } \\
\text { immediate } \\
\text { postnatal) }\end{array}$ & $\begin{array}{l}\text { - Promotion, protection and support for breastfeeding } \\
\text { - Monitoring and assessment of wellbeing, detection of complications (breathing, } \\
\text { infections, prematurity, low birth weight, injury, malformation) } \\
\text { - Infection prevention and control, rooming in } \\
\text { - Eye care } \\
\text { - Information and counseling on home care, breastfeeding, hygiene } \\
\text { - Postnatal care planning, advice on danger signs and emergency preparedness } \\
\text { - Immunization according to the national guidelines (BCG, HepB, OPV-O) } \\
\text { - Kangaroo Mother Care follow-up }\end{array}$ \\
\hline $\begin{array}{l}\text { Postnatal } \\
\text { newborn care } \\
\text { (visit from/at } \\
\text { home) }\end{array}$ & $\begin{array}{l}\text { - Assessment of infant's wellbeing and breastfeeding } \\
\text { - Detection of complications and responding to maternal concerns } \\
\text { - Information and counseling on home care } \\
\text { - Additional follow-up visits for high risk babies (e.g. preterm, after severe problems, } \\
\text { on replacement feeding) }\end{array}$ \\
\hline
\end{tabular}


OUTPUT CONTRACT 
OFFER OF REWARD PAYMENTS FOR IMPROVEMENT IN PROVISION OF MATERNAL AND NEONATAL HEALTH CARE

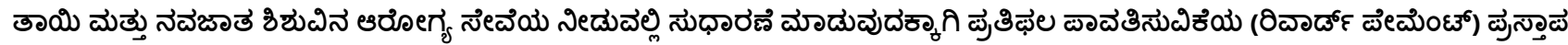

Date:

Dr.

Dear

Thank you for taking the time today to learn about our ongoing project to develop innovative ways to partner with private sector doctors in Karnataka. This project has been jointly funded by the World Bank, the International Initiative for Impact Evaluation (3ie), the UK Department for International Development (DFID), and the Government of Karnataka and is focused on the health of women and infants in the time surrounding pregnancy, delivery, and the months following.

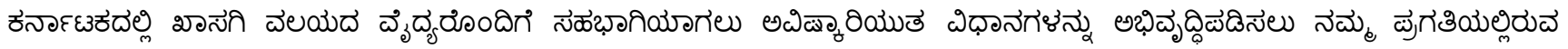

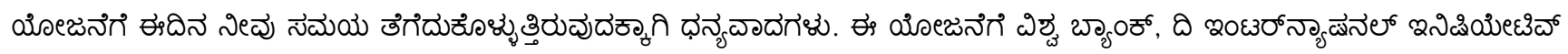

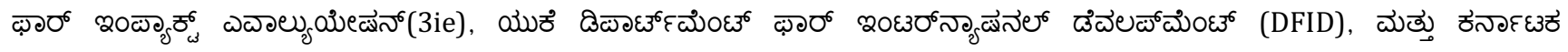

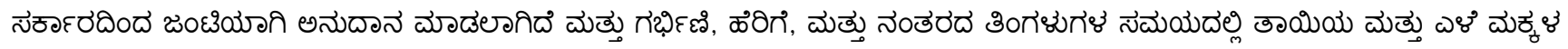

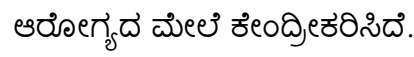

As part of this project, Sambodhi Research \& Communications Pvt. Ltd (New Delhi), in collaboration with COHESIVE-India ${ }^{1}$, is pleased to offer you reward payments based on the share of women and infants receiving care in your facility who face adverse health outcomes. Based on health statistics and expert judgment, the four most serious adverse health outcomes are:

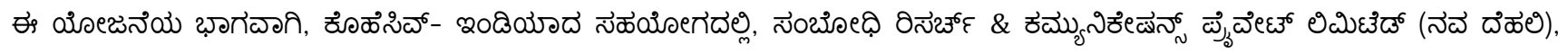

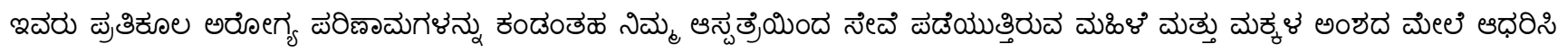

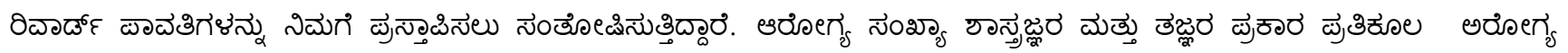
ఉరిణాడుగెళందెరి:

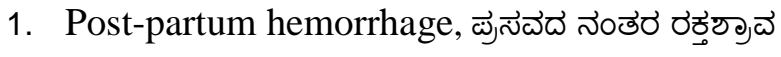

2. Pre-eclampsia, బసిరు నంంజు

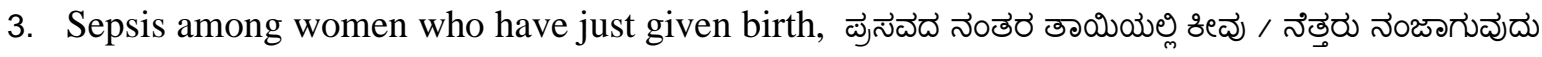

4. Neonatal death ఆగె తอనిల జనిసిదె డుగుదిన దురణణ

${ }^{1}$ COHESIVE-India is a collaboration of researchers from Duke Universitv (US). Stanford Universitv (US). Universitv College 
Structure of Payments:

1. Participation (today's visit)

- You will receive Rs. 2,500 for agreement to participate in the reward payments program and for participation in a brief survey; you will be provided with documentation (paper and CD) on standard obstetric care and management of common obstetric complications and a general explanation of the program

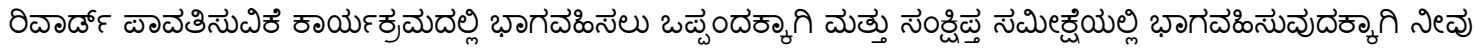

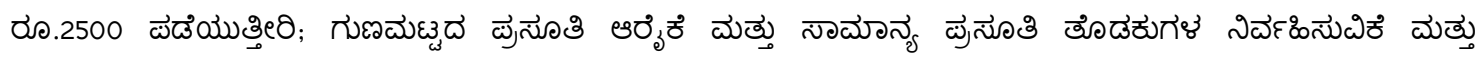

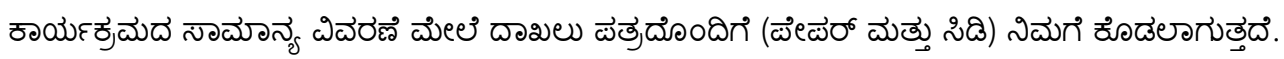

2. Discussion of strategies (1 - 2 months from now)

- You will receive an additional Rs. 2,500 for discussing the strategies that you might pursue to minimize adverse health outcomes among women and infants receiving care at your facility and for participation in a brief survey

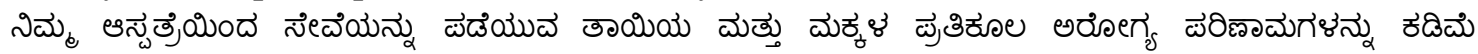

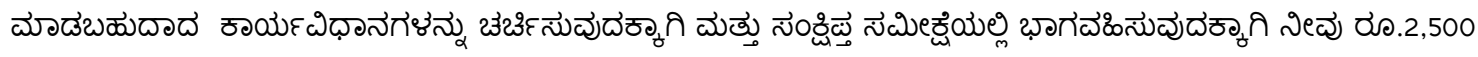

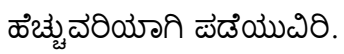

3. Reward Payout (12 - 14 months from now)

- You will receive Rs. 2,500 for participation in a brief survey and a final reward payment up to Rs. $148,950^{2}$, based on your facility's rates of the four identified adverse health outcomes among women and infants at your facility.

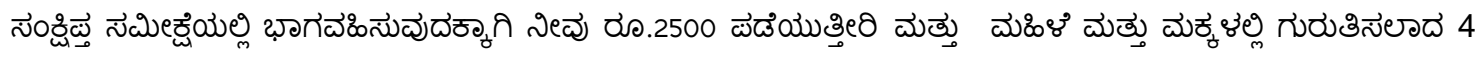

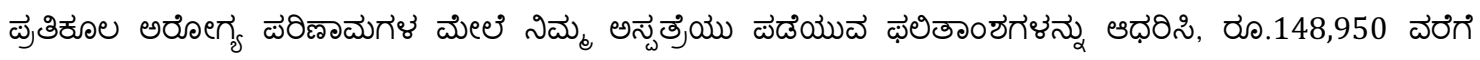

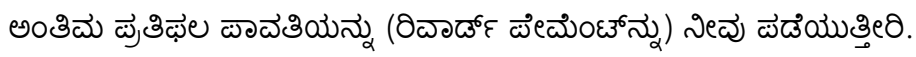

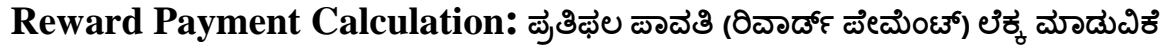

The four adverse health outcomes are based on the priorities of the fourth and fifth Millennium Development Goals (MDG's) related to maternal and child health, with consideration for the specific health challenges in Karnataka and India in general. Performance for each maternal health outcome is measured by the percentage of women who suffer from each of the identified adverse health outcomes.

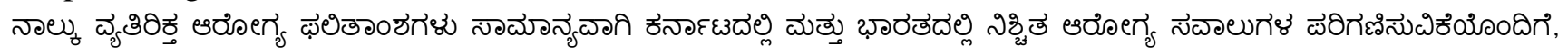

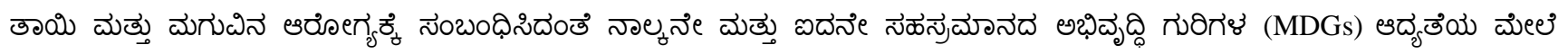

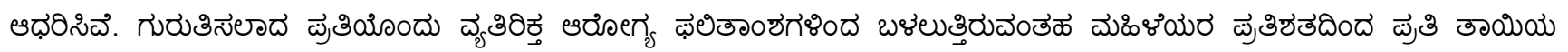

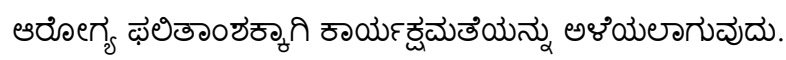

Column 2 of Table 1 below lists the Baseline Performance Levels in each maternal adverse health outcome that should already be easily attainable by the average doctor in Karnataka. Adverse health outcome rates above these baseline performance levels will not receive any reward payments. Column 3 lists the amount of reward that will be paid for every percentage point in performance under the baseline performance level listed in Column 2. The performance reward amounts in Column 3 take into account the relative difficulty of preventing each of the three maternal adverse health outcomes in Karnataka.

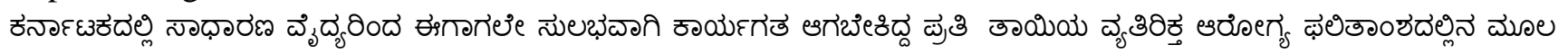

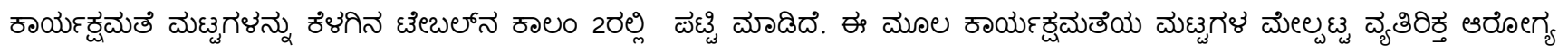

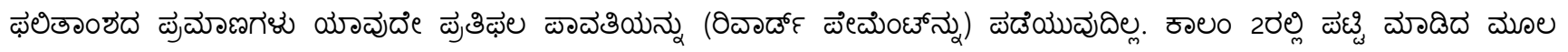

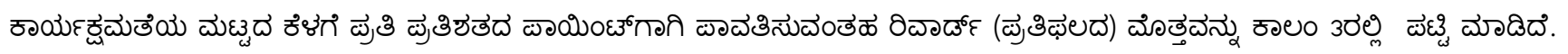

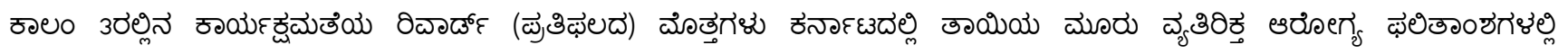

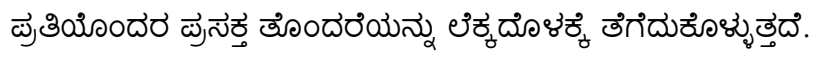

\footnotetext{
${ }^{2}$ The amount for the final reward payment is linked to the USD-INR exchange rate and may vary slightly depending on the
} USD-INR exchange rate at the time of the third visit 
Column 4 lists the Target Performance Levels that experts believe all doctors should be able to achieve with concerted effort. Finally, Column 5 lists the amount that would be earned for each of the maternal adverse health outcomes if these Target Performance Levels are obtained. (Note that reward payments could exceed those listed in Column 5 if performance is better than the targets in Column 4.)

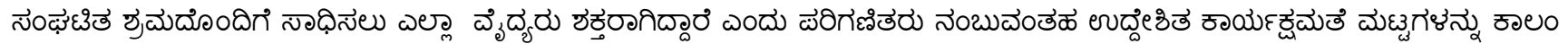

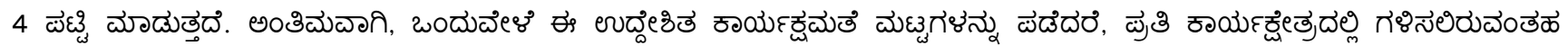

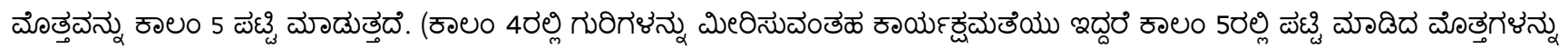

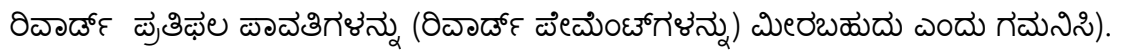

Table 1:

\begin{tabular}{|c|c|c|c|c|}
\hline (1) & (2) & (3) & (4) & (5) \\
\hline 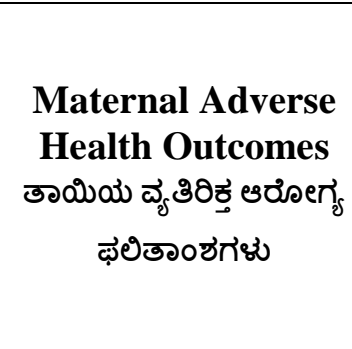 & 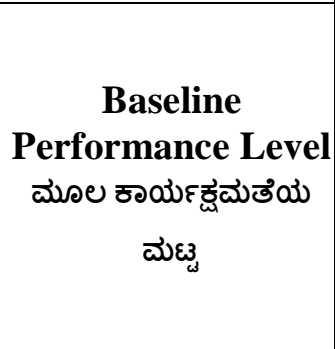 & 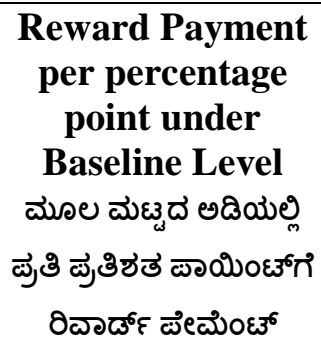 & $\begin{array}{c}\text { Target } \\
\text { Performance } \\
\text { Level } \\
\text { లుద్దిeశిత } \\
\text { రాయీక్షّముత దుణ్ట }\end{array}$ & 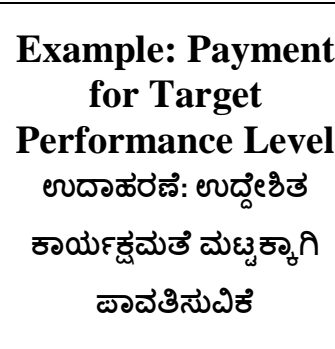 \\
\hline 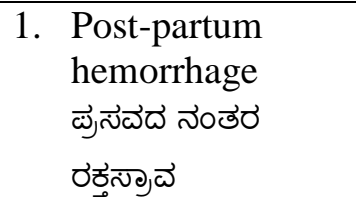 & $35 \%$ & Rs. 850 & $15 \%$ & Rs. 17,000 \\
\hline $\begin{array}{l}\text { 2. Pre-eclampsia } \\
\text { బసిరు నెంజు }\end{array}$ & $20 \%$ & Rs. 1,750 & $10 \%$ & Rs. 17,500 \\
\hline 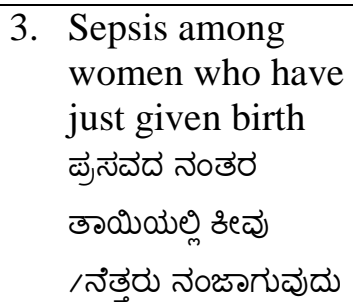 & $8 \%$ & Rs. 8,650 & $4 \%$ & Rs. 34,600 \\
\hline
\end{tabular}

For example, if your facility's rate of Outcome 1: Post-partum hemorrhage is measured at 30\%, your reward payment in that category will be Rs. $4,250(5 *$ Rs. 850$)$; if it is measured at $25 \%$, your reward payment in that category will be Rs. 8,500 (10* Rs. 850); and if it is measured at 20\%, your reward payment in that category will be Rs. 12,750 (15* Rs. 850).

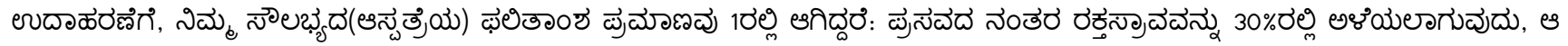

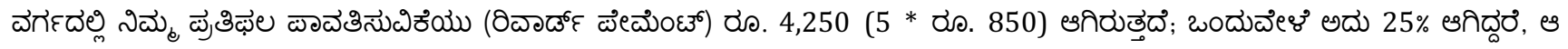

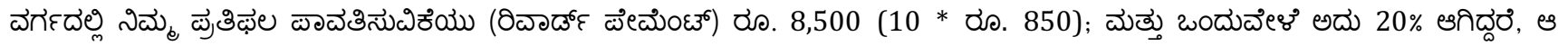

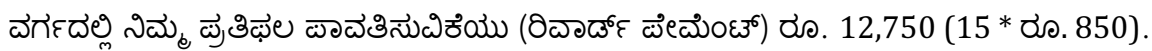

On the other hand, if your facility's rate of Outcome 1: Post-partum hemorrhage measured at $40 \%$ (or any other rate above 35\%), you would not receive any reward payment for this outcome because it is above the threshold set in Column 2. Note that performance rates above the thresholds set in Column 2 will never detract from your overall payout, and that you will never be in a position to owe money. 


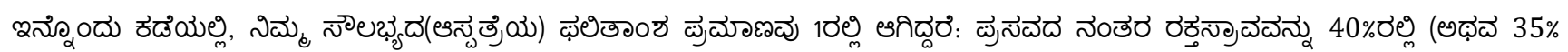

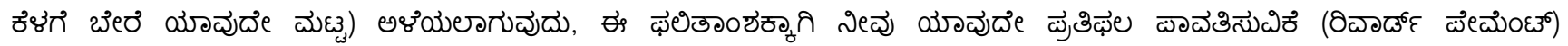

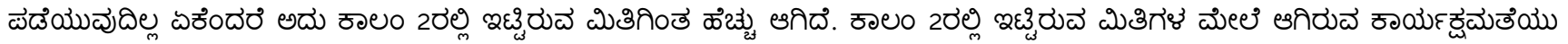

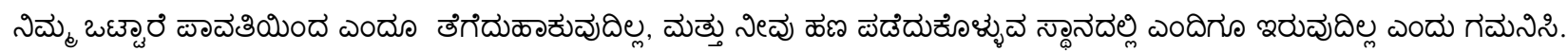

As shown in Table 2 below, a reward payment of Rs.15, 000 will be paid if there are 0 neonatal deaths over the course of the study.

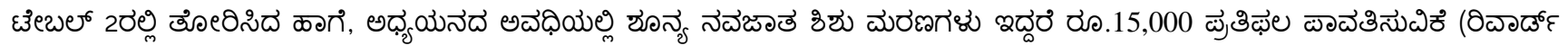

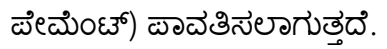

Table 2:

\begin{tabular}{|c|c|c|}
\hline$(1)$ & $(2)$ & (3) \\
\hline 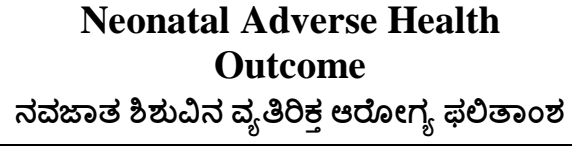 & 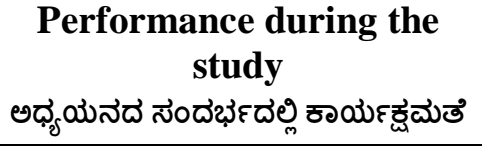 & 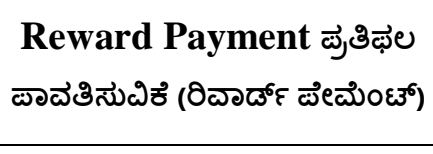 \\
\hline $\begin{array}{l}\text { 4. Neonatal mortality } \\
\text { నేదెజอత కిలుదిన దురెణ }\end{array}$ & 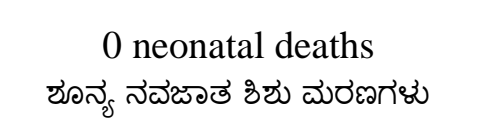 & Rs. 15,000 \\
\hline
\end{tabular}

Over the next year, the rates of these maternal and neonatal adverse health outcomes will be measured through interviews with your patient population.

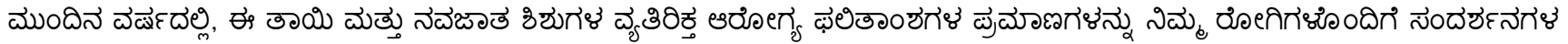

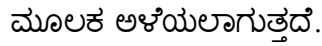

NOTE: It is critical that (a) patients are not refused treatment from your facility other than in medically appropriate referrals, and (b) we are able to work with your administrative staff to follow up on all patients who deliver at your facility.

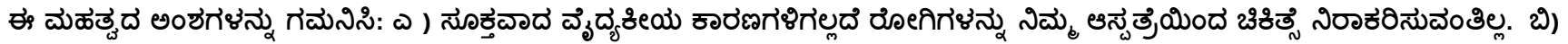

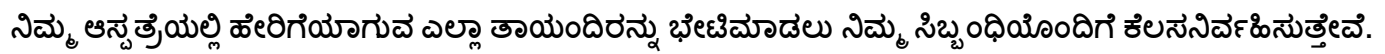

An independent research team will regularly visit the communities around your facility. Any extraordinary patterns of referral will result in investigations into the reasons for these referrals. If it is found that women have been turned away from your facility for any reason other than medically appropriate referrals to highertier facilities, then this can have an implication on your agreement with us and as a result no further payments will be made. Similarly, if it is found that there is selective reporting of the births that have taken place in your facility, then this can have an implication on your agreement with us and as a result no further payments will be made.

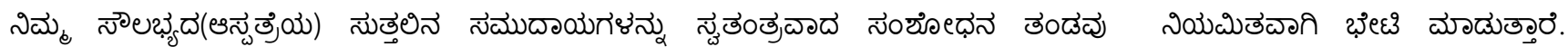

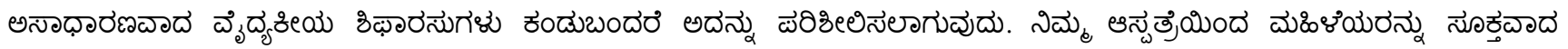

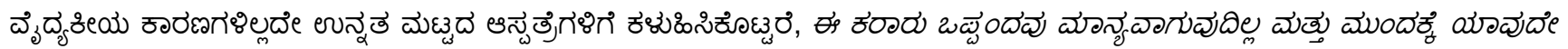

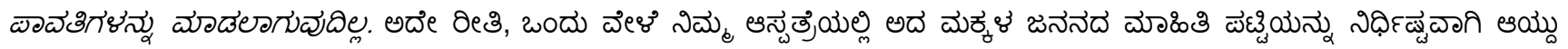

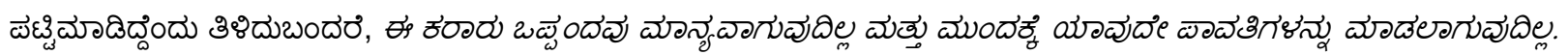


Please do not hesitate to contact us in case you have any questions or require further information.

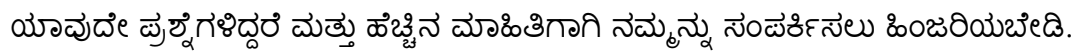

Thank you for your cooperation. We look forward to working with you.

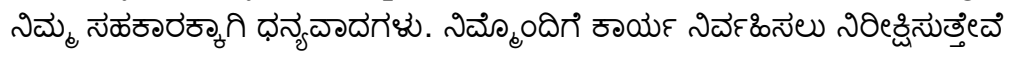

Sincerely, 203e

\section{Kultar Singh}

పుల్కారో సింగో

Chief Executive Officer

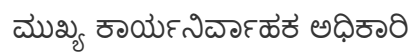

\author{
Anil M. Lobo

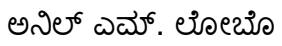 \\ Manager - Research

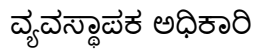

Sambodhi Research and Communications Pvt. Ltd.

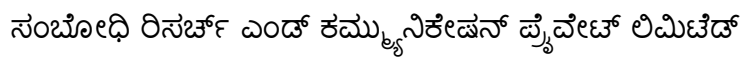

O-2, 2nd Floor, Lajpat Nagar-II, New Delhi 110024

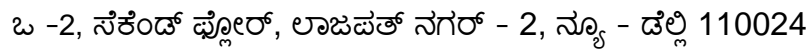

I agree to participate in the above mentioned study.

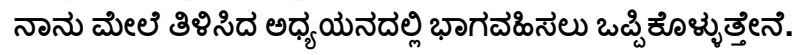

Name of Provider (Print)

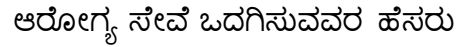

Signature of Provider

$\vec{\sim} b 0$
Date

దినాం 
CONTROL CONTRACT 


\section{Sambodhi Knowedge for change}

Date:

Dr.

Dear

Thank you for taking the time today to learn about our ongoing project to develop innovative ways to partner with private sector doctors in Karnataka. This project has been jointly funded by the World Bank, the International Initiative for Impact Evaluation (3ie), the UK Department for International Development (DFID), and the Government of Karnataka and is focused on the health of women and infants in the time surrounding pregnancy, delivery, and the months following. To this end, over the next year we would like to learn more from you and from your obstetric patients.

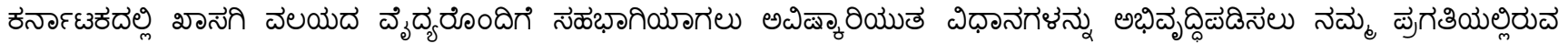

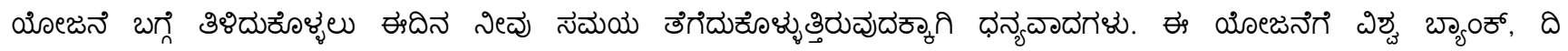

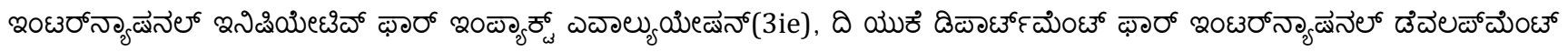

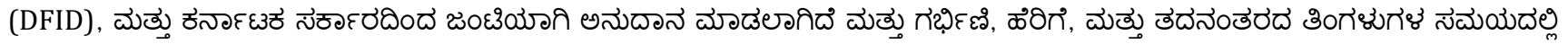

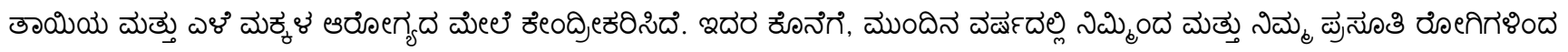

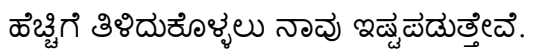

As part of this project, Sambodhi Research \& Communications Pvt. Ltd (New Delhi), in collaboration with COHESIVE-India ${ }^{1}$, would like to work with you over the year to understand the conditions of rural obstetric health care and maternal and neonatal health in the private sector, the difficulties that providers face in trying to provide care, and to investigate strategies to improve the quality of care and maternal and child health outcomes.

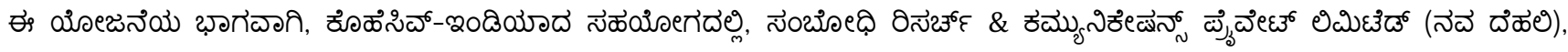

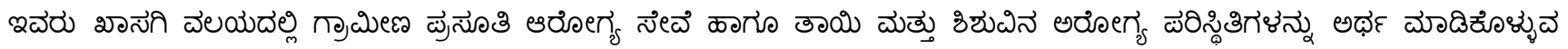

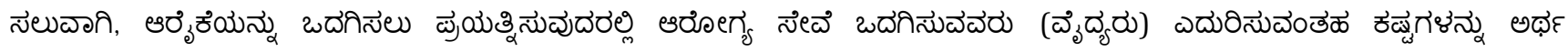

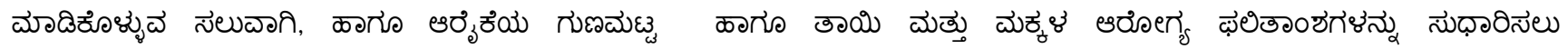

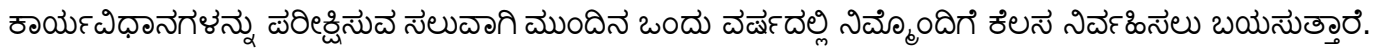

\footnotetext{
${ }^{1}$ COHESIVE-India is a collaboration of researchers from Duke Universitv (USA). Stanford Universitv (USA). Universitv
} 
Structure of Payments: ळౌదెతిగెళ రెజని:

1. Participation (today's visit)

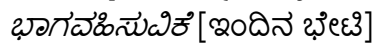

- You will receive Rs. 2,500 for agreement to participate in the research study and for participation in a brief survey; you will be provided with documentation (paper and $\mathrm{CD}$ ) on standard obstetric care and management of common obstetric complications

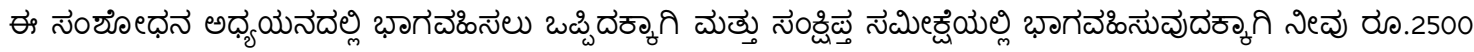

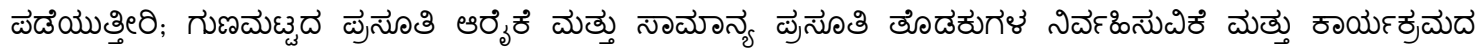

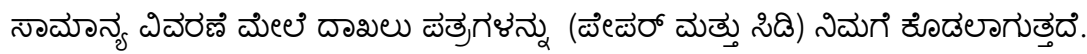

2. Discussion of strategies (1 - 2 months from now)

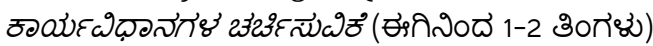

- You will receive an additional Rs. 2,500 for discussing the strategies that you might pursue to improve the health of women and infants who may come to you for care in the time surrounding pregnancy, delivery, and the months following, and for participation in a brief survey

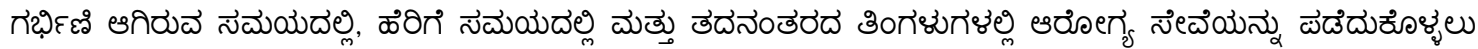

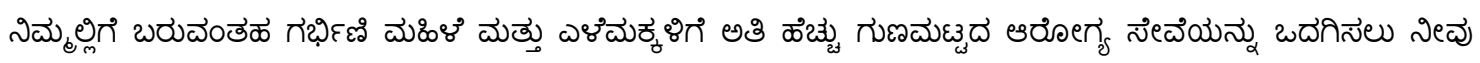

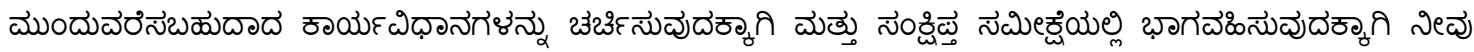

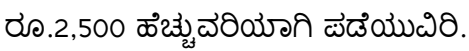

3. Final Debriefing (12 - 14 months from now)

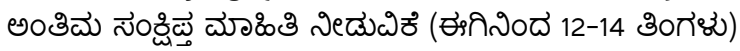

- You will receive an additional Rs. 2,500 for discussing your experiences with the strategies you identified in the second visit, and for participation in a brief survey

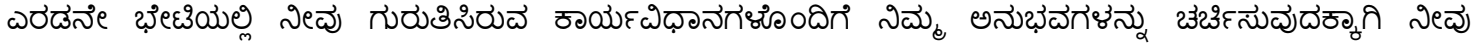

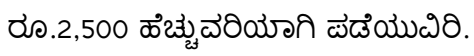

As part of this project, we would like to separately follow up with all women who come to your facility to deliver their babies. In our second visit to you 1-2 months from now, we will establish a mutually agreeable strategy for confidentially conveying your obstetric patient lists to our research team.

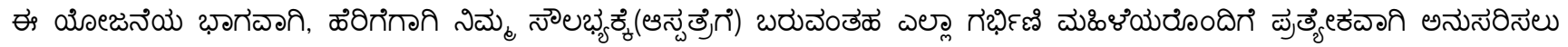

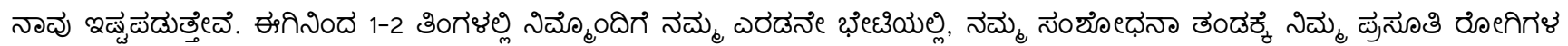

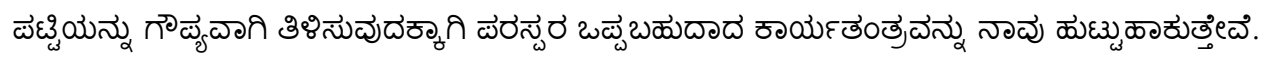

NOTE: It is critical that (a) patients are not refused treatment from your facility other than in medically appropriate referrals which we will verify through independent visits in the community around you, and (b) we are able to work with your administrative staff to follow up on all patients who deliver at your facility.

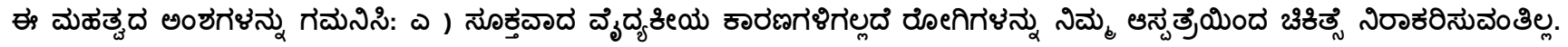

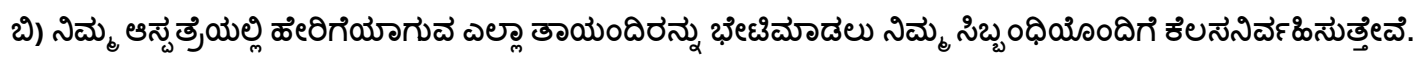


Please do not hesitate to contact us in case you have any questions or require further information.

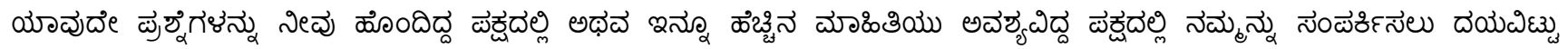
ஃంజరియ3బాeడి.

Thank you for your cooperation. We look forward to working with you.

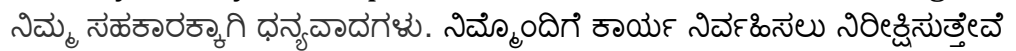

Sincerely, ఇo3e,

Kultar Singh

పుల్టారో సింగో

Chief Executive Officer

డొఖ్య ઇాయినిదాణळా అధిరారి

Sambodhi Research and Communications Pvt. Ltd.

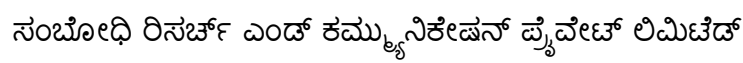

O-2, 2nd Floor, Lajpat Nagar-II, New Delhi 110024

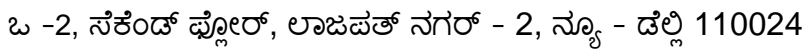

Anil M. Lobo

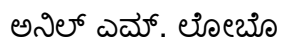

Manager - Research

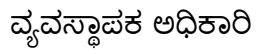

I agree to participate in the above mentioned study.

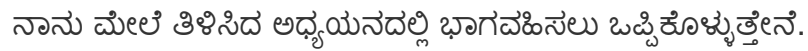

Name of Provider (Print)

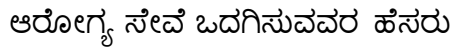

Signature of Provider

$\vec{\sim} \check{\sim}_{0}$
Date

దినాక 
Appendix 2: Calculation and Measurement of Inputs and Outputs 


\section{Performance Based Contracts in Healthcare: Experimental Evaluation of Contracting Based on Inputs and Health Outcomes}

\section{October 2014}

\section{Inputs Performance Calculations}

Evaluation of inputs is based on responses to questions asked during household interviews $7-20$ days after delivery. Rules for evaluating each domain of inputs are described in the fourth column and last two rows of each section. "Don't know/can't remember" responses are treated as missing; there is no penalty/gain to performance for missing responses, whether they arise from skip patterns or "don't know/can't remember" responses. Questions have been chosen to reflect factors that women could conceivably answer reliably and that do not depend on whether an adverse outcome occurred.

\section{SECTION A: PREGNANCY CARE (ANC)}

\begin{tabular}{|c|c|c|c|}
\hline WHO Recommendation & Qn \# & Question & $\begin{array}{l}\text { One point if: } \\
\text { ( } 0 \text { otherwise) }\end{array}$ \\
\hline \multirow{3}{*}{$\begin{array}{l}\text { Monitoring of progress of } \\
\text { pregnancy and assessment of } \\
\text { maternal and fetal well-being }\end{array}$} & Q301 & $\begin{array}{l}\text { During this pregnancy, did any health } \\
\text { worker see you/provide checkups or } \\
\text { advice? }\end{array}$ & A1. Yes \\
\hline & Q304 & $\begin{array}{l}\text { How many months were you when you } \\
\text { received first checkup for this last } \\
\text { pregnancy? }\end{array}$ & A2. $<5$ \\
\hline & Q305 & $\begin{array}{l}\text { How many times were you checked up } \\
\text { during this pregnancy? }\end{array}$ & A3. $>3$ \\
\hline \multirow{5}{*}{$\begin{array}{l}\text { Detection of problems } \\
\text { complicating pregnancy (e.g., } \\
\text { anemia, hypertensive } \\
\text { disorders, bleeding, } \\
\text { malpresentations, multiple } \\
\text { pregnancy) }\end{array}$} & Q306B & $\begin{array}{l}\text { As part of your checkups during this } \\
\text { pregnancy, were any of the following } \\
\text { tests or exams done at least once: } \\
\text { weight? }\end{array}$ & A4. Yes \\
\hline & Q306C & $\begin{array}{l}\text { As part of your checkups during this } \\
\text { pregnancy, were any of the following } \\
\text { tests or exams done at least once: blood } \\
\text { pressure? }\end{array}$ & A5. Yes \\
\hline & Q306D & $\begin{array}{l}\text { As part of your checkups during this } \\
\text { pregnancy, were any of the following } \\
\text { tests or exams done at least once: urine? }\end{array}$ & A6. Yes \\
\hline & Q306E & $\begin{array}{l}\text { As part of your checkups during this } \\
\text { pregnancy, were any of the following } \\
\text { tests or exams done at least once: blood } \\
\text { test? }\end{array}$ & A7. Yes \\
\hline & Q306F & $\begin{array}{l}\text { As part of your checkups during this } \\
\text { pregnancy, were any of the following }\end{array}$ & A8. Yes \\
\hline
\end{tabular}




\begin{tabular}{|c|c|c|c|c|}
\hline & & \multicolumn{2}{|c|}{$\begin{array}{l}\text { tests or exams done at least once: } \\
\text { abdomen/ internal/ vaginal exam? }\end{array}$} & \\
\hline & Q306H & \multicolumn{2}{|c|}{$\begin{array}{l}\text { As part of your checkups during this } \\
\text { pregnancy, were any of the following } \\
\text { tests or exams done at least once: } \\
\text { ultrasound/ sonogram? }\end{array}$} & A9. Yes \\
\hline & Q306I & \multicolumn{2}{|c|}{$\begin{array}{l}\text { As part of your checkups during this } \\
\text { pregnancy, were any of the following } \\
\text { tests or exams done at least once: } \\
\text { anemia test (in this test, blood is taken } \\
\text { from your finger tip or your eyes and } \\
\text { palm are checked)? }\end{array}$} & A10. Yes \\
\hline \multirow{3}{*}{$\begin{array}{l}\text { Tetanus immunization, } \\
\text { anemia prevention and } \\
\text { control (iron and folic acid } \\
\text { supplementation) }\end{array}$} & Q313 & \multicolumn{2}{|c|}{$\begin{array}{l}\text { During this pregnancy, were you given } \\
\text { an injection in the arm or shoulder or } \\
\text { other part of the body to prevent getting } \\
\text { tetanus? }\end{array}$} & A11. Yes \\
\hline & Q314 & \multicolumn{2}{|c|}{$\begin{array}{l}\text { During this pregnancy, did you consume } \\
\text { any iron tablets or iron syrup? }\end{array}$} & A12. Yes \\
\hline & Q315 & \multicolumn{2}{|c|}{$\begin{array}{l}\text { During this pregnancy, did you consume } \\
\text { folic acid? }\end{array}$} & A13. Yes \\
\hline \multirow{3}{*}{$\begin{array}{l}\text { Information and counseling } \\
\text { on self care at home, } \\
\text { nutrition, safer sex, } \\
\text { breastfeeding, family } \\
\text { planning, healthy lifestyle }\end{array}$} & Q308 & \multicolumn{2}{|c|}{$\begin{array}{l}\text { During your ANC checkups, were you } \\
\text { given any guidance about what kinds of } \\
\text { things you should eat during pregnancy? }\end{array}$} & A14. Yes \\
\hline & Q309 & \multicolumn{2}{|c|}{$\begin{array}{l}\text { During your ANC checkups, were you } \\
\text { given any guidance about breastfeeding? }\end{array}$} & A15. Yes \\
\hline & Q310 & \multicolumn{2}{|c|}{$\begin{array}{l}\text { During your ANC checkups, were you } \\
\text { given any guidance about family } \\
\text { planning? }\end{array}$} & A16. Yes \\
\hline \multirow[t]{2}{*}{$\begin{array}{l}\text { Birth planning, advice on } \\
\text { danger signs and } \\
\text { emergency preparedness }\end{array}$} & 311 & \multicolumn{2}{|c|}{$\begin{array}{l}\text { During your ANC checkups, were you } \\
\text { given any guidance about birth } \\
\text { planning? }\end{array}$} & A17. Yes \\
\hline & 312 & \multicolumn{2}{|c|}{$\begin{array}{l}\text { During your ANC checkups, were you } \\
\text { given any advice on danger signs } \\
\text { during pregnancy and emergency } \\
\text { preparedness? }\end{array}$} & A18. Yes \\
\hline \multicolumn{3}{|c|}{ Individual Level Inputs, Section A: Pregnancy Care (e.g., $\left.y_{i p}, y_{i c}\right)$ : } & \multicolumn{2}{|c|}{ IndInput $_{A}=\frac{\sum A 1: A 18}{18}$} \\
\hline \multicolumn{3}{|c|}{$\begin{array}{l}\text { Provider Level Inputs, Section A: Pregnancy Care (e.g., } \mathbf{y}_{\mathbf{p}} \text { ): } \\
\text { [Evaluated based on women who delivered at the provider's facility] }\end{array}$} & \multicolumn{2}{|c|}{ ProvInput $_{A}=\frac{\sum \text { IndInput }}{A}$} \\
\hline
\end{tabular}




\begin{tabular}{|c|c|c|c|}
\hline WHO Recommendation & Qn \# & Question & $\begin{array}{l}\text { One point if: } \\
\text { ( } 0 \text { otherwise) }\end{array}$ \\
\hline Diagnosis of labor & Q404 & $\begin{array}{l}\text { [For institutional deliveries] When you } \\
\text { arrived at the facility for delivery, were } \\
\text { you asked about the details of the pain } \\
\text { (onset/type, association of pain with } \\
\text { leaking) while the child was in your } \\
\text { womb? } \\
\text { [For attended home deliveries] When the } \\
\text { health provider reached your home for } \\
\text { delivery, were you asked about the } \\
\text { details of the pain (onset/type, } \\
\text { association with leaking) while the child } \\
\text { was in your womb? }\end{array}$ & B1. Yes \\
\hline \multirow{3}{*}{$\begin{array}{l}\text { Monitoring progress of } \\
\text { labor, maternal and fetal } \\
\text { well-being with partograph }\end{array}$} & Q405 & $\begin{array}{l}\text { Were you asked about the movement of } \\
\text { your baby in your womb? }\end{array}$ & B2. Yes \\
\hline & Q413 & $\begin{array}{l}\text { Was the heart rate of the baby checked } \\
\text { while the baby was still in your womb? }\end{array}$ & B3. Yes \\
\hline & Q416 & $\begin{array}{l}\text { Was a per vaginal examination (the } \\
\text { healthcare provider inserting fingers in } \\
\text { the mother's vagina) done to you? }\end{array}$ & B4. Yes \\
\hline $\begin{array}{l}\text { Providing supportive care } \\
\text { and pain relief }\end{array}$ & Q419 & Were you encouraged to bear down? & B5. Yes \\
\hline \multirow{8}{*}{$\begin{array}{l}\text { Detection of problems and } \\
\text { complications (e.g., } \\
\text { malpresentations, prolonged } \\
\text { and/or obstructed labor, } \\
\text { hypertension, bleeding, and } \\
\text { infection) }\end{array}$} & Q407 & $\begin{array}{l}\text { Were you asked about your previous } \\
\text { deliveries including live } \\
\text { birth/stillbirth/abortion, etc.? }\end{array}$ & B6. Yes \\
\hline & Q408 & $\begin{array}{l}\text { Were you asked if you have ever had } \\
\text { hypertension or high blood pressure? }\end{array}$ & B7. Yes \\
\hline & Q409 & $\begin{array}{l}\text { Were you asked whether you are } \\
\text { diabetic? }\end{array}$ & B8. Yes \\
\hline & Q410 & $\begin{array}{l}\text { Were you asked about whether you have } \\
\text { hyper or hypo thyroidism } \\
\text { (increased/decreased palpitation \& } \\
\text { perspiration for which is on treatment)? }\end{array}$ & B9. Yes \\
\hline & Q411 & $\begin{array}{l}\text { Were you asked whether you have } \\
\text { asthma? }\end{array}$ & B10. Yes \\
\hline & Q412 & Was your blood pressure checked? & B11. Yes \\
\hline & Q414 & $\begin{array}{l}\text { Was an anemia test done on you? In this } \\
\text { test, blood is taken from your finger tip, } \\
\text { your eyes and palm are checked, or blood } \\
\text { sample. }\end{array}$ & B12. Yes \\
\hline & Q415 & $\begin{array}{l}\text { Was a per abdominal examination } \\
\text { (touched and examined the bare } \\
\text { abdomen) done to you? }\end{array}$ & B13. Yes \\
\hline Delivery and immediate care & Q502 & Was the baby dried immediately after & B14. Yes \\
\hline
\end{tabular}




\begin{tabular}{|c|c|c|c|c|}
\hline \multirow{7}{*}{$\begin{array}{l}\text { of the newborn baby, } \\
\text { initiation of breastfeeding }\end{array}$} & & \multicolumn{2}{|l|}{ birth? } & \\
\hline & Q503 & \multicolumn{2}{|c|}{$\begin{array}{l}\text { Was the baby subsequently wrapped in } \\
\text { different clothes from what were used to } \\
\text { dry the baby? }\end{array}$} & B15. \\
\hline & Q504 & \multicolumn{2}{|c|}{ Was the head of the baby covered? } & B16. \\
\hline & Q506 & \multicolumn{2}{|c|}{$\begin{array}{l}\text { Was the heart rate of the baby checked } \\
\text { during the first five minutes after birth? }\end{array}$} & B17. Yes \\
\hline & Q507 & \multicolumn{2}{|c|}{$\begin{array}{l}\text { Were you counseled to start } \\
\text { breastfeeding shortly after delivery? }\end{array}$} & B18. Yes \\
\hline & Q508 & \multicolumn{2}{|c|}{$\begin{array}{l}\text { How long after birth did you put (BABY } \\
\text { NAME) to the breast? }\end{array}$} & $\begin{array}{l}\text { B19. Imme- } \\
\text { diately } \\
\text { (within } 1 \mathrm{hr} \text { ) }\end{array}$ \\
\hline & Q510 & \multicolumn{2}{|c|}{ Was (BABY NAME) weighed at birth? } & B20. Yes \\
\hline \multirow{2}{*}{$\begin{array}{l}\text { Active management of third } \\
\text { stage of labor }\end{array}$} & Q423 & \multicolumn{2}{|c|}{$\begin{array}{l}\text { Did the doctor/other assistants/nurses } \\
\text { press your abdomen after the delivery? }\end{array}$} & B21. Yes \\
\hline & Q605 & \multicolumn{2}{|c|}{$\begin{array}{l}\text { After delivery of your baby were you } \\
\text { given medicine/injections/drip (oxytocin) } \\
\text { to decrease bleeding? }\end{array}$} & B22. \\
\hline \multirow{4}{*}{$\begin{array}{l}\text { Monitoring and assessment } \\
\text { of maternal well being, } \\
\text { prevention and detection of } \\
\text { complications (e.g., } \\
\text { hypertension, infections, } \\
\text { bleeding, anemia) }\end{array}$} & Q601 & \multicolumn{2}{|c|}{$\begin{array}{l}\text { Was your blood pressure monitored after } \\
\text { delivery? }\end{array}$} & B23. Yes \\
\hline & Q602 & \multicolumn{2}{|c|}{$\begin{array}{l}\text { Was a vaginal examination done after } \\
\text { delivery? }\end{array}$} & B24. Yes \\
\hline & Q603 & \multicolumn{2}{|c|}{ Was your episiotomy checked? } & B25. Yes \\
\hline & Q417 & \multicolumn{2}{|c|}{$\begin{array}{l}\text { Did the healthcare provider wear gloves } \\
\text { while doing the per vaginal examination? }\end{array}$} & B26. Yes \\
\hline \multicolumn{3}{|c|}{$\begin{array}{l}\text { Individual Level Inputs, Section B: Childbirth Care (e.g., } y_{i p} \text {, } \\
\left.y_{i c}\right) \text { : }\end{array}$} & \multicolumn{2}{|c|}{ IndInput $t_{B}=\frac{\sum B 1: B 26}{26}$} \\
\hline \multicolumn{3}{|c|}{$\begin{array}{l}\text { Provider Level Inputs, Section B: Childbirth Care (e.g., } \mathbf{y}_{\mathbf{p}} \text { ): } \\
\text { [Evaluated based on women who delivered at the provider's facility] }\end{array}$} & \multicolumn{2}{|c|}{ ProvInput $_{B}=\frac{\sum \text { IndInput }}{B}$} \\
\hline
\end{tabular}




\begin{tabular}{|c|c|c|c|}
\hline WHO Recommendation & Qn \# & Question & $\begin{array}{l}\text { One point if: } \\
\text { ( } 0 \text { otherwise) }\end{array}$ \\
\hline $\begin{array}{l}\text { Anemia prevention and } \\
\text { control (iron and folic acid } \\
\text { supplementation) }\end{array}$ & Q802-3 & $\begin{array}{l}\text { [For institutional deliveries] Before } \\
\text { discharge, were you given counseling by } \\
\text { hospital staff on any of the following } \\
\text { topics? Iron and calcium intake for } 3 \\
\text { months } \\
\text { [For home deliveries] Before the } \\
\text { attending healthcare provider left, did } \\
\text { she give you any counseling on any of the } \\
\text { following topics? Iron and calcium intake } \\
\text { for } 3 \text { months }\end{array}$ & C1. Yes \\
\hline \multirow{2}{*}{$\begin{array}{l}\text { Information and counseling } \\
\text { on nutrition, safe sex, family } \\
\text { planning and provision of } \\
\text { some contraceptive } \\
\text { methods }\end{array}$} & Q802-2 & $\begin{array}{l}\text { [For institutional deliveries] Before } \\
\text { discharge, were you given counseling by } \\
\text { hospital staff on any of the following } \\
\text { topics? Normal diet } \\
\text { [For home deliveries] Before the } \\
\text { attending healthcare provider left, did } \\
\text { she give you any counseling on any of the } \\
\text { following topics? Normal diet }\end{array}$ & C2. Yes \\
\hline & Q802-4 & $\begin{array}{l}\text { [For institutional deliveries] Before } \\
\text { discharge, were you given counseling by } \\
\text { hospital staff on any of the following } \\
\text { topics? Family planning } \\
\text { [For home deliveries] Before the } \\
\text { attending healthcare provider left, did } \\
\text { she give you any counseling on any of the } \\
\text { following topics? Family planning }\end{array}$ & C3. Yes \\
\hline \multirow{5}{*}{$\begin{array}{l}\text { Postnatal care planning, } \\
\text { advice on danger signs and } \\
\text { emergency preparedness }\end{array}$} & Q807-1 & $\begin{array}{l}\text { Were you advised to report immediately } \\
\text { if you had any of the following? High } \\
\text { grade fever }\end{array}$ & C4. Yes \\
\hline & Q807-2 & $\begin{array}{l}\text { Were you advised to report immediately } \\
\text { if you had any of the following? Foul } \\
\text { smelling vaginal discharge }\end{array}$ & C5. Yes \\
\hline & Q807-3 & $\begin{array}{l}\text { Were you advised to report immediately } \\
\text { if you had any of the following? Excessive } \\
\text { bleeding }\end{array}$ & C6. Yes \\
\hline & Q807-4 & $\begin{array}{l}\text { Were you advised to report immediately } \\
\text { if you had any of the following? Wound } \\
\text { gaping or oozing wound }\end{array}$ & C7. Yes \\
\hline & Q807-5 & $\begin{array}{l}\text { Were you advised to report immediately } \\
\text { if you had any of the following? } \\
\text { Convulsions }\end{array}$ & C8. Yes \\
\hline \multicolumn{3}{|c|}{\begin{tabular}{l|l} 
Individual Level Inputs, Section C: Postnatal Maternal Care & \\
$\left(\right.$ e.g., $\left.y_{i p}, y_{i c}\right):$ & IndIn
\end{tabular}} & $u t_{C}=\frac{\sum C 1: C 8}{8}$ \\
\hline
\end{tabular}




\section{Provider Level Inputs, Section C: Postnatal Maternal Care}

(e.g., $\mathbf{y}_{\mathbf{p}}$ ):

ProvInput $_{C}=\frac{\sum \text { IndInput }_{C}}{\# \text { patients }}$

[Evaluated based on women who delivered at the provider's facility] 


\begin{tabular}{|c|c|c|c|}
\hline WHO Recommendation & Qn \# & Question & $\begin{array}{l}\text { One point if: } \\
\text { ( } 0 \text { otherwise) }\end{array}$ \\
\hline \multirow[b]{2}{*}{$\begin{array}{l}\text { Promotion, protection, and } \\
\text { support for breastfeeding }\end{array}$} & Q704 & $\begin{array}{l}\text { In the first } 12 \text { hours after birth, did the } \\
\text { health care provider/staff ask whether } \\
\text { the baby had been fed? }\end{array}$ & D1. Yes \\
\hline & Q803 & $\begin{array}{l}\text { [For institutional deliveries] Did you } \\
\text { receive advice on breastfeeding during } \\
\text { your stay in the hospital? } \\
\text { [For attended home deliveries] Before } \\
\text { the attending health care provider left, } \\
\text { did she give you any advice on } \\
\text { breastfeeding? }\end{array}$ & D2. Yes \\
\hline \multirow{3}{*}{$\begin{array}{l}\text { Monitoring and assessment } \\
\text { of wellbeing, detection of } \\
\text { complications (breathing, } \\
\text { infections, prematurity, low } \\
\text { birth weight, injury, } \\
\text { malformation) }\end{array}$} & Q701 & $\begin{array}{l}\text { Was the baby's heart rate checked during } \\
\text { the first } 6 \text { hours after birth? }\end{array}$ & D3. Yes \\
\hline & Q702 & $\begin{array}{l}\text { Was the baby's temperature measured } \\
\text { with a thermometer during the first } 12 \\
\text { hours after birth? }\end{array}$ & D4. Yes \\
\hline & Q703 & $\begin{array}{l}\text { Did the healthcare provider ask the } \\
\text { mother whether the baby has urinated or } \\
\text { was the urine checked directly by the } \\
\text { healthcare provider? }\end{array}$ & D5. Yes \\
\hline $\begin{array}{l}\text { Infection prevention and } \\
\text { control, rooming-in }\end{array}$ & Q708 & $\begin{array}{l}\text { Was the baby bathed within } 6 \text { hours after } \\
\text { birth? }\end{array}$ & D6. No \\
\hline Eye care & Q701A & $\begin{array}{l}\text { Was the baby given eyedrops in the first } \\
6 \text { hours after birth? }\end{array}$ & D7. Yes \\
\hline \multirow{3}{*}{$\begin{array}{l}\text { Information and counseling } \\
\text { on homecare, } \\
\text { breastfeeding, hygiene }\end{array}$} & Q802-1 & $\begin{array}{l}\text { [For institutional deliveries] Before } \\
\text { discharge, were you given counseling by } \\
\text { hospital staff on any of the following } \\
\text { topics? Exclusive breastfeeding } \\
\text { [For home deliveries] Before the } \\
\text { attending healthcare provider left, did } \\
\text { she give you any counseling on any of the } \\
\text { following topics? Exclusive breastfeeding }\end{array}$ & D8. Yes \\
\hline & Q804 & $\begin{array}{l}\text { Were you told that breast milk or formula } \\
\text { milk is better? }\end{array}$ & D9. Breast milk \\
\hline & Q802-5 & $\begin{array}{l}\text { [For institutional deliveries] Before } \\
\text { discharge, were you given counseling by } \\
\text { hospital staff on any of the following } \\
\text { topics? Hygiene } \\
\text { [For home deliveries] Before the } \\
\text { attending healthcare provider left, did } \\
\text { she give you any counseling on any of the } \\
\text { following topics? Hygiene }\end{array}$ & D10. Yes \\
\hline $\begin{array}{l}\text { Postnatal care planning, } \\
\text { advice on danger signs and }\end{array}$ & Q802-8 & $\begin{array}{l}\text { [For institutional deliveries] Before } \\
\text { discharge, were you given counseling by }\end{array}$ & D11. Yes \\
\hline
\end{tabular}




\begin{tabular}{|c|c|c|c|c|}
\hline emergency preparedness & & \multicolumn{2}{|c|}{$\begin{array}{l}\text { hospital staff on any of the following } \\
\text { topics? Warning signs indicating that you } \\
\text { should take the baby to see a doctor } \\
\text { [For home deliveries] Before the } \\
\text { attending healthcare provider left, did } \\
\text { she give you any counseling on any of the } \\
\text { following topics? Warning signs indicating } \\
\text { that you should take the baby to see a } \\
\text { doctor }\end{array}$} & \\
\hline \multirow{3}{*}{$\begin{array}{l}\text { Immunization according to } \\
\text { the national guidelines }\end{array}$} & Q706-1 & \multicolumn{2}{|c|}{$\begin{array}{l}\text { What immunizations did the baby } \\
\text { receive? BCG (right upper arm) }\end{array}$} & D12. Yes \\
\hline & Q706-2 & \multicolumn{2}{|c|}{$\begin{array}{l}\text { What immunizations did the baby } \\
\text { receive? HEP-B1 }\end{array}$} & D13. Yes \\
\hline & Q706-3 & \multicolumn{2}{|c|}{$\begin{array}{l}\text { What immunizations did the baby } \\
\text { receive? Polio (oral drops) }\end{array}$} & D14. Yes \\
\hline \multicolumn{3}{|c|}{$\begin{array}{l}\text { Individual Level Inputs, Section D: Newborn Care (e.g., } y_{i p} \text {, } \\
\left.y_{i c}\right) \text { : }\end{array}$} & \multicolumn{2}{|c|}{ IndInput $_{D}=\frac{\sum D 1: D 14}{14}$} \\
\hline \multicolumn{3}{|c|}{$\begin{array}{l}\text { Provider Level Inputs, Section D: Newborn Care (e.g., } \mathbf{y}_{\mathbf{p}} \text { ): } \\
\text { [Evaluated based on women who delivered at the provider's facility] }\end{array}$} & \multicolumn{2}{|c|}{ ProvInput $_{D}=\frac{\sum \text { IndInput }}{\#}$} \\
\hline
\end{tabular}


SECTION E: POSTNATAL NEWBORN CARE

\begin{tabular}{|c|c|c|c|c|}
\hline WHO Recommendation & Qn \# & \multicolumn{2}{|l|}{ Question } & $\begin{array}{l}\text { One point if: } \\
\text { ( } 0 \text { otherwise) }\end{array}$ \\
\hline $\begin{array}{l}\text { Detection of complications } \\
\text { and responding to maternal } \\
\text { concerns }\end{array}$ & Q808 & \multicolumn{2}{|c|}{$\begin{array}{l}\text { Were you given any contact number to } \\
\text { call during the time of emergency/need? }\end{array}$} & E1. Yes \\
\hline $\begin{array}{l}\text { Information and counseling } \\
\text { on home care }\end{array}$ & Q805 & \multicolumn{2}{|c|}{$\begin{array}{l}\text { Did the hospital staff/health care } \\
\text { provider advise you to keep the baby } \\
\text { warm? }\end{array}$} & E2. Yes \\
\hline \multicolumn{3}{|c|}{$\begin{array}{l}\text { Individual Level Inputs, Section E: Postnatal Newborn Care } \\
\left(\text { e.g., } y_{i p}, y_{i c}\right) \text { : }\end{array}$} & \multicolumn{2}{|c|}{ IndInput $_{E}=\frac{\sum E 1: E 2}{2}$} \\
\hline \multicolumn{3}{|c|}{$\begin{array}{l}\text { Provider Level Inputs, Section E: Postnatal Newborn Care } \\
\left.\text { (e.g., } \mathbf{y}_{\mathbf{p}}\right) \text { : } \\
\text { [Evaluated based on women who delivered at the provider's facility] }\end{array}$} & \multicolumn{2}{|c|}{ ProvInput $_{E}=\frac{\sum \text { IndInput }}{\#}$} \\
\hline
\end{tabular}




\section{Health Outcomes Calculations}

Evaluation of inputs is based on responses to questions asked during household interviews 7-20 days after delivery. Every output is a binary adverse health outcome when evaluated the individual level (e.g., $y_{i p}, y_{i c}$ ). Provider level outputs (e.g., $y_{p}$ ) represent the share of respondents who delivered at the provider's facility evaluated to have experience the health outcome. "Don't know/can't remember" responses are treated as missing; there is no penalty/gain for missing responses, whether they arise from skip patterns or "don't know/can't remember" responses.

\section{Pre-Eclampsia}

\begin{tabular}{|c|c|c|c|}
\hline Qn \# & \multicolumn{3}{|l|}{ Question } \\
\hline Q206 & \multicolumn{3}{|c|}{ Have you ever had a fit/convulsion when you were not pregnant? } \\
\hline Q316 & \multicolumn{3}{|c|}{ At any point during pregnancy did you have a fit/convulsion? } \\
\hline Q629 & \multicolumn{3}{|c|}{ Did you experience convulsions? [within $24 \mathrm{hrs}$ of delivery, $24 \mathrm{hrs}$ post-delivery -1 week post] } \\
\hline \multicolumn{2}{|c|}{$\begin{array}{l}\text { Pre-eclampsia } \\
\text { Identification Rule }\end{array}$} & $\begin{array}{r}\text { - No fit } \\
\text { - At lea } \\
0 \\
0 \\
0\end{array}$ & $\begin{array}{l}\text { or convulsion when not pregnant }(206=\text { no), and } \\
\text { one of: } \\
\text { Fit or convulsion during pregnancy }(316=\text { yes) } \\
\text { Convulsion within } 24 \text { hours of delivery }(629 a=\text { yes) } \\
\text { Convulsion in period from } 24 \text { hours post-birth to } 1 \text { week } \\
\text { post-birth ( } 629 b=\text { yes) }\end{array}$ \\
\hline
\end{tabular}

\section{Sepsis}

\begin{tabular}{|c|l|}
\hline Qn \# & Question \\
\hline Q426 & At any point during labor and delivery, did you have a fever? \\
\hline Q627 & $\begin{array}{l}\text { Did you experience high grade fever? [within 24 hrs of delivery, 24 hrs post-delivery - 1 wk } \\
\text { post] }\end{array}$ \\
\hline Q636 & Did you have foul smelling vaginal discharge or pus? \\
\hline \multicolumn{3}{|l|}{\begin{tabular}{rl|} 
At least one of: \\
Sepsis \\
Identification Rule
\end{tabular}} \\
\end{tabular}

\section{Postpartum Hemorrhage}

\begin{tabular}{|r|l|}
\hline Qn \# & Question \\
\hline 622 & $\begin{array}{l}\text { Did you have any bleeding along with experiencing dizziness? [within 24 hrs of delivery, } \\
24 \text { hrs post-delivery - 1 wk post] }\end{array}$ \\
\hline 623 & $\begin{array}{l}\text { Did you have any bleeding along with experiencing weakness? [within } 24 \text { hrs of } \\
\text { delivery, 24 hrs post-delivery - 1 wk post] }\end{array}$ \\
\hline 624 & Did you have any bleeding along with losing consciousness? [within 24 hrs of delivery, \\
\hline
\end{tabular}




\begin{tabular}{|c|c|c|}
\hline \multicolumn{3}{|c|}{$24 \mathrm{hrs}$ post-delivery - 1 wk post] } \\
\hline $\begin{array}{l}\text { PPH } \\
\text { Identification Rule }\end{array}$ & $\begin{array}{r}\text { - At lea } \\
0 \\
0 \\
0\end{array}$ & $\begin{array}{l}\text { t one of: } \\
\text { Bleeding along with experience dizziness (622a or } 622 b \\
=\text { yes) } \\
\text { Bleeding along with experiencing weakness (623a or } \\
623 b=\text { yes) } \\
\text { Bleeding along with losing consciousness ( } 624 a \text { or } 624 b \\
=\text { yes) }\end{array}$ \\
\hline
\end{tabular}

\section{Neonatal Mortality}

\begin{tabular}{|c|c|c|}
\hline Qn \# & \multicolumn{2}{|l|}{ Question } \\
\hline $117 a$ & \multicolumn{2}{|c|}{ Did the baby cry immediately after delivery? } \\
\hline 118 & \multicolumn{2}{|c|}{ Was the baby born alive? } \\
\hline $118 \mathrm{a}$ & \multicolumn{2}{|c|}{ Did the doctor/health care provider do anything to attempt to resuscitate the baby? } \\
\hline 119 & \multicolumn{2}{|c|}{ How is the baby doing now? } \\
\hline $\begin{array}{l}\text { MU } \\
201\end{array}$ & \multicolumn{2}{|c|}{ Is the baby still alive? [note this question is asked at least 28 days post birth] } \\
\hline $\begin{array}{l}\text { MU } \\
204\end{array}$ & \multicolumn{2}{|c|}{ When did the baby die? [note this question is asked at least 28 days post birth] } \\
\hline \multicolumn{2}{|c|}{$\begin{array}{l}\text { 28-Day Neonatal } \\
\text { Mortality } \\
\text { Identification Rule }\end{array}$} & $\begin{array}{l}\text { Baby cried immediately after delivery and has now passed } \\
\text { away (117a = Yes \& } 119=\text { Passed Away), or } \\
\text { Baby did not cry immediately after delivery, was born alive, and } \\
\text { has now passed away (117a = No \& } 118=\text { Yes } \& 119=\text { Passed } \\
\text { Away), or } \\
\text { Baby did not cry immediately after delivery, and doctor/health } \\
\text { care provided attempted to resuscitate the baby }(117 a=\text { No \& } \\
118=\text { No \& } 118 a=\text { Yes), or } \\
\text { Baby was alive at time of initial survey, but has died within one } \\
\text { month of delivery (119 = alive and healthy or alive and sick \& } \\
\text { MU201 = No \& MU204 < } 1 \text { month) }\end{array}$ \\
\hline \multicolumn{2}{|c|}{$\begin{array}{l}\text { Stillborn Death } \\
\text { Identification Rule }\end{array}$} & $\begin{array}{l}\text { Baby did not cry immediately after delivery, was not born alive, } \\
\text { and doctor did not do anything to attempt to resuscitate the } \\
\text { baby (117a = No \& } 118=\text { No \& } 118 a=\text { No), or } \\
\text { Baby did not cry immediately after delivery, baby was not born } \\
\text { alive, and question about resuscitating the baby was not } \\
\text { applicable (117a = No \& } 118=\text { No \& } 118 a=\text { Not applicable) }\end{array}$ \\
\hline
\end{tabular}

